\title{
The Reactions of Zinc Vapor with ZIRCALOY-4 and Pure Zirconium
}

\section{Maureen Williams}

\author{
U.S. DEPARTMENT OF COMMERCE \\ Technology Administration \\ National Institute of Standards \\ and Technology \\ Division here \\ 100 Bureau Drive, Stop 8555 \\ Gaithersburg, MD 20899-8555
}

$Q C$ 



\section{NISTIR 6447}

\section{The Reactions of Zinc Vapor with Zircaloy-4 and Pure Zirconium}

Maureen Williams

U.S. DEPARTMENT OF COMMERCE Technology Administration National Institute of Standards and Technology Division here 100 Bureau Drive, Stop 8555 Gaithersburg, MD 20899-8555

January 2000

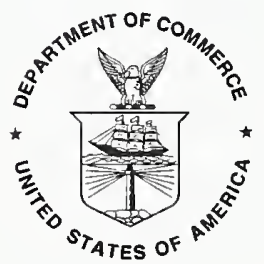

U.S. DEPARTMENT OF COMMERCE William M. Daley, Secretary

TECHNOLOGY ADMINISTRATION Dr. Cheryl L. Shavers, Under Secretary of Commerce for Technology

NATIONAL INSTITUTE OF STANDARDS AND TECHNOLOGY

Raymond G. Kammer, Director 



\begin{abstract}
Title of Thesis: $\quad$ The Reactions of Zinc Vapor with Zircaloy-4 and Pure Zirconium

Degree candidate: Maureen Elizabeth Williams

Degree and year: Master of Science, 1999

Thesis directed by: Dr. Manfred Wuttig

Department of Materials and Nuclear Engineering and Dr. William J. Boettinger

National Institute of Standards and Technology
\end{abstract}

The need for the Nuclear Regulatory Commission to extend the existing licenses on temporary dry storage containers of spent radioactive fuel, coated with zinc paint to prevent corrosion, from 20 years to 100 years initiated this study. The investigation of the reaction of zinc vapor on unirradiated samples of Zircaloy-4 and nuclear grade zirconium at various temperatures between $650{ }^{\circ} \mathrm{C}$ and $800{ }^{\circ} \mathrm{C}$ is presented.

Through various analytical techniques: optical metallography, scanning electron microscopy (SEM), transmission electron microscopy (TEM), and X-ray diffraction, the reaction of zinc vapor with Zircaloy-4 and nuclear grade zirconium was investigated. The temperatures for the diffusion experiments were based on the $\mathrm{Zn}-\mathrm{Zr}$ binary phase diagram. Temperatures below $750{ }^{\circ} \mathrm{C}$ were chosen to remain in the hexagonal closepacked (hcp) $\alpha$ zirconium phase, yet high enough to insure that a reaction would occur in a reasonably short period of time. Extrapolation to $350{ }^{\circ} \mathrm{C}$ would then be used to estimate the effect during dry storage. However, experiments at $725^{\circ} \mathrm{C}$ indicated the presence of $\beta$ zirconium, so additional experiments with nuclear grade zirconium at temperatures above $725^{\circ} \mathrm{C}$ were performed to confirm the eutectoid reaction temperature in the binary phase diagram and to investigate the solubility of zinc in zirconium. 


\section{DISCLAIMER}

Commercial equipment and materials are identified in order to adequately specify certain procedures. In no case does such identification imply recommendation or endorsement by the National Institute of Standards and Technology, nor does it imply that the materials or equipment identified are necessarily the best available for the purpose. 


\section{Acknowledgements}

I would like to express my wholehearted thanks to my friends and colleagues at NIST for all their help, guidance and patience through all the study sessions and work crisis, especially Carrie Campbell, Julia Chan, Sandy Claggett, Frank Gayle, Dan Josell, Candy Lang, Kil-Won Moon, Mark Stoudt, David van Heerden, Marie Weber and Janet Williams. Also special thanks are in order to Leonid Bendersky for the TEM work, Ursula Kattner for the thermodynamic assessment, and John Manning, my former NIST supervisor, (now happily retired) for involving me in this NRC project. And finally my deep thanks go to Bill Boettinger, for encouraging my professional development, shaping me into a scientist, and being my thesis advisor at NIST. I would also like to acknowledge two very skilled artisans at NIST, the glassblower Jeff Anderson, and the metallographer Leonard Smith, who made the success of my project possible.

Last but not least I have to thank my husband Alan for his patience, love and support through years of school and my cats Symmetry and Andromeda. 
LIST OF TABLES vi vi

LIST OF FIGURES vii

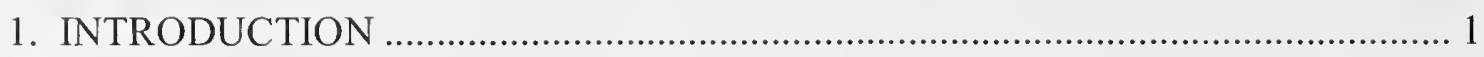

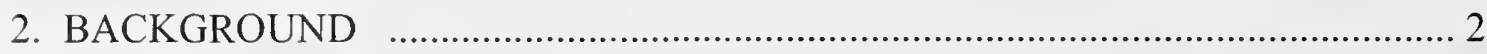

2.1 Zinc - Zirconium Phase Diagram....................................................... 3

2.2 Intermetallics and Crystallography …………....................................... 4

2.3 Invariant Points .............................................................................. 4

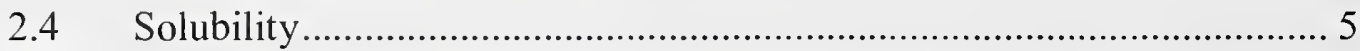

2.5 Material Properties of Zirconium and Zircaloy-4 .................................. 5

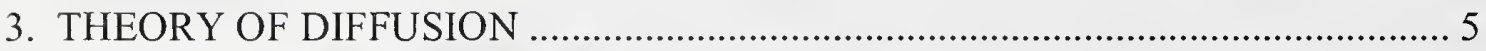

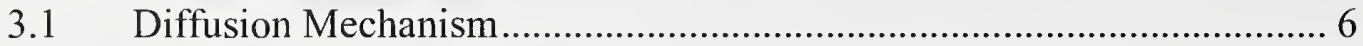

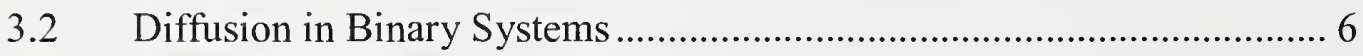

3.3 Phase Equilibrium ....................................................................... 7

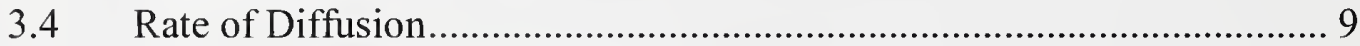

3.5 Diffusion in Multicomponent / Multiphase .......................................... 11

3.6 Growth Mechanism / Parabolic............................................................... 11

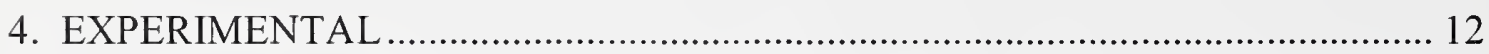

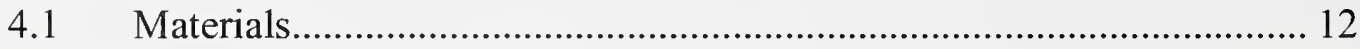

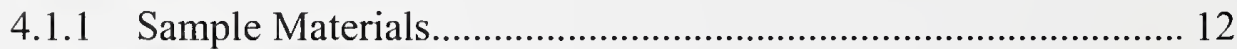

4.1.2 Zinc Vapor Source ................................................................ 13

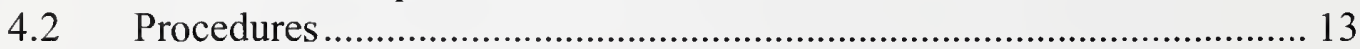

4.2.1 Sample Preparation .............................................................. 13

4.2.2 Heat Treatment....................................................................... 14

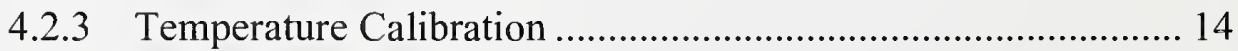

4.2.4 Sample Quenching ............................................................ 14

4.2.5 Choice of Heat Treatment Temperatures .................................. 15

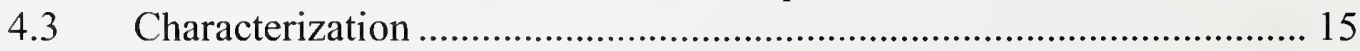

4.3.1 Metallography ..................................................................... 15

4.3.2 Energy Dispersive Spectroscopy................................................. 15

4.3.3 Complications in the Interpretation of Composition

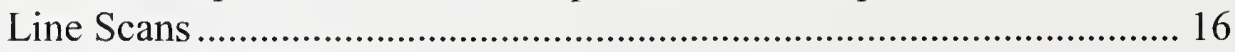

4.3.4 X-Ray Diffraction ............................................................... 20

5. RESULTS 20

5.1 Phase Sequences ............................................................................. 20

5.2 Individual Intermetallic and Total Reaction Zone Thickness ................. 23 


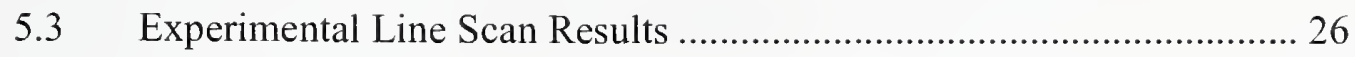

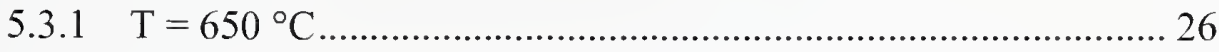

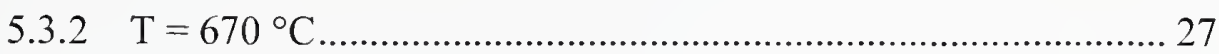

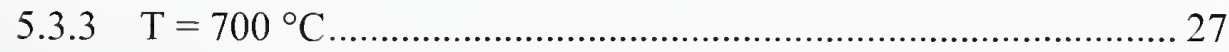

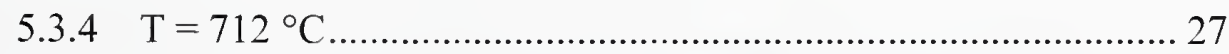

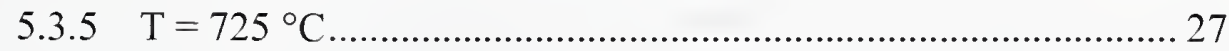

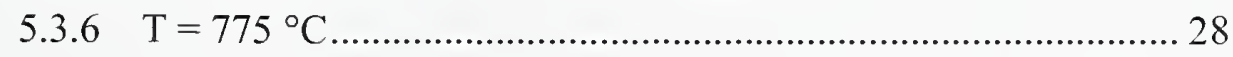

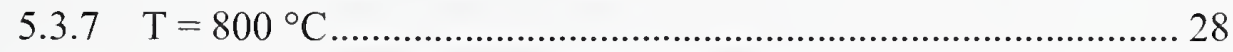

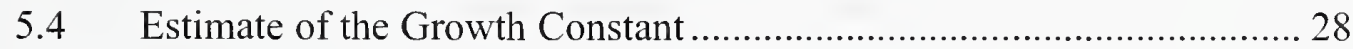

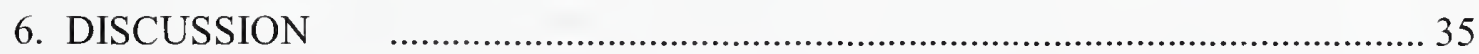

6.1 Correlation of Observed Phases to the Phase Diagram............................ 35

6.1.1 Phases Present Below $725^{\circ} \mathrm{C}$.................................................. 35

6.1.2 Phases Present Above $725^{\circ} \mathrm{C}$.................................................. 35

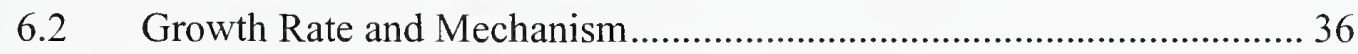

6.3 TEM of Nuclear Grade Zirconium at $800^{\circ} \mathrm{C}$....................................... 38

6.4 Correction of Eutectoid Temperature .................................................... 40

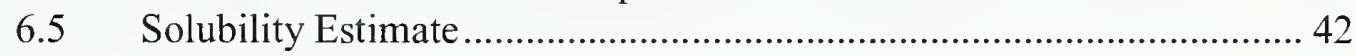

6.6 Experimental Phase Diagram ..............................................................42

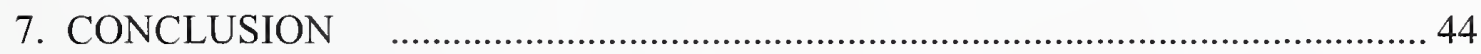

APPENDIX

REFERENCES 


\section{LIST OF TABLES}

Table 1 Phases in the Zn-Zr Binary Phase Diagram ................................................... 4

Table 2 Invariant Points of Zn-Zr Binary Phase Diagram .......................................... 5

Table 3 Activity and Chemical Potential of Zinc in $\alpha$-Brass........................................ 9

Table 4 Trace Element Composition of Nuclear Grade Zirconium .............................. 12

Table 5 Composition of Phases in the Two Phase Region .......................................... 18

Table 6 Phase Sequence of Zircaloy-4 and Nuclear Grade Zirconium.....................21-22

Table 7 Zircaloy-4 Phase Thicknesses and Total Reaction Zone Thickness................. 24

Table 8 Nuclear Grade Zirconium Phase Thicknesses and Total Reaction Zone

Thickness

Table 9 Reaction Zone Thickness and Growth Constant for Zircaloy-4 ....................... 29

Table 10 Reaction Zone Thickness and Growth Constant for Nuclear Grade

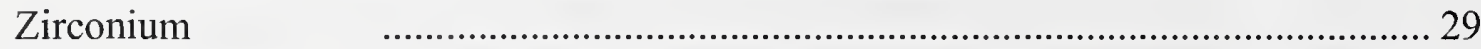

Table 11 Solubility Data for Zinc in Nuclear Grade Alpha Zirconium ....................... 42 


\section{LIST OF FIGURES}

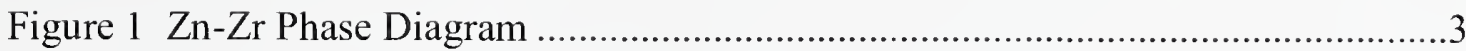

Figure 2 Schematic of Free Energy as a Function of Composition ................................. 7

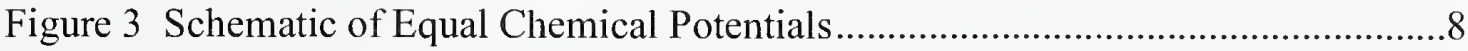

Figure 4 Typical Concentration Profiles with Increasing Time.....................................10

Figure 5 A Schematic of a Composition Profile ..............................................................11

Figure 6 Line Scan of Nuclear Grade Zirconium Exposed to Zinc Vapor at $775{ }^{\circ} \mathrm{C}$

for $12 \mathrm{~d}$

Figure 7 Line Scan of Zircaloy-4 exposed to Zinc Vapor at $650{ }^{\circ} \mathrm{C}$ for $126 \mathrm{~d}$................19

Figure 8 Microstructure of Zircaloy-4 Exposed to Zinc Vapor at $650{ }^{\circ} \mathrm{C}$

for $126 \mathrm{~d}$

Figure 9 Three Phase Sequences of Zircaloy-4 Exposed to Zinc Vapor at $725^{\circ} \mathrm{C}$ for

$11.8 \mathrm{~d}$

Figure 10 Zircaloy-4 Total Intermetallic Reaction Zone Thickness at $650{ }^{\circ} \mathrm{C}$...............30

Figure 11 Arrhenius Plot of the Growth Constant $K$ for Zircaloy-4 Exposed to Zinc

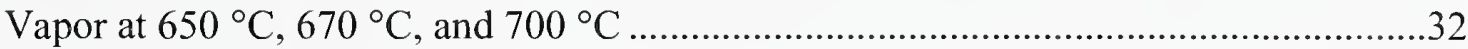

Figure 12 Arrhenius Plot of the Growth Constant $K$ for Nuclear Grade Zirconium

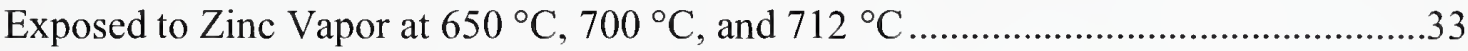

Figure 13 Arrhenius Plot of the Growth Constant $K$ for Nuclear Grade Zirconium

Exposed to Zinc Vapor at $725^{\circ} \mathrm{C}, 775^{\circ} \mathrm{C}$, and $800{ }^{\circ} \mathrm{C}$................................................34

Figure 14 Surface Morphology Sequence of Nuclear Grade Zirconium Exposed to Zinc

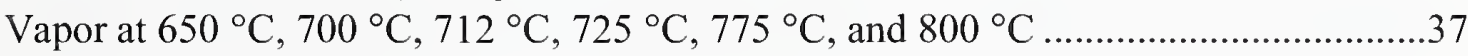

Figure 15 Surface Morphology Sequence of Zircaloy-4 Exposed to Zinc Vapor at 650

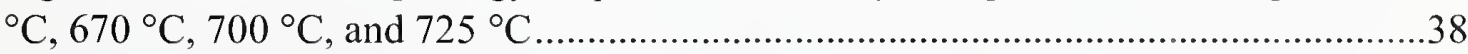

Figure 16 SEM and TEM of the Martensitic Structure of Quenched $\beta$ in Nuclear Grade

Zirconium Exposed to Zinc Vapor at $800^{\circ} \mathrm{C}$ for $12 \mathrm{~d}$....................................................39

Figure 17 TEM Diffraction Patterns of the Martensitic Structure of Quenched $\beta$ phase

in Nuclear Grade Zirconium Exposed to Zinc Vapor at $800^{\circ} \mathrm{C}$ for $12 \mathrm{~d}$........................39

Figure 18 Experimental Eutectoid Reaction Temperature and Solubility Data from this

Study Plotted with the Currently Published Phase Diagram ................................ 41

Figure 19 Experimental Zn-Zr Phase Diagram from this Study ....................................43

Figure Al Nuclear Grade Zirconium Heat Treated with Zinc Vapor at $650^{\circ} \mathrm{C}$,

$16 \mathrm{~d}$

Figure A2 Nuclear Grade Zirconium Heat Treated with Zinc Vapor at $650^{\circ} \mathrm{C}$,

$64 \mathrm{~d}$

Figure A3 Zircaloy-4 TREX Heat Treated with Zinc Vapor at $650^{\circ} \mathrm{C}, 16 \mathrm{~d}$.................49

Figure A4 Zircaloy-4 TREX Heat Treated with Zinc Vapor at $650^{\circ} \mathrm{C}, 64 \mathrm{~d}$..................50

Figure A5 Zircaloy-4 TREX Heat Treated with Zinc Vapor at $650^{\circ} \mathrm{C}, 126 \mathrm{~d}$................51

Figure A6 Zircaloy-4 TREX Heat Treated with Zinc Vapor at $650^{\circ} \mathrm{C}, 126 \mathrm{~d}$................52

Figure A7 Zircaloy-4 TREX Heat Treated with Zinc Vapor at $670^{\circ} \mathrm{C}, 20.75 \mathrm{~d}$............53 
Figure A8 Nuclear Grade Zirconium Heat Treated with Zinc Vapor at $700{ }^{\circ} \mathrm{C}$, $12 \mathrm{~d}$

Figure A9 Nuclear Grade Zirconium Heat Treated with Zinc Vapor at $700^{\circ} \mathrm{C}$, $32 \mathrm{~d}$ .55

Figure A10 Zircaloy-4 TREX Heat Treated with Zinc Vapor at $700^{\circ} \mathrm{C}, 4 \mathrm{~d}$................56

Figure Al1 Zircaloy-4 TREX Heat Treated with Zinc Vapor at $700{ }^{\circ} \mathrm{C}, 10 \mathrm{~d}$.................57

Figure A12 Zircaloy-4 TREX Heat Treated with Zinc Vapor at $700{ }^{\circ} \mathrm{C}, 32 \mathrm{~d}$................58

Figure A13 Nuclear Grade Zirconium Heat Treated with Zinc Vapor at $712{ }^{\circ} \mathrm{C}$, $11.8 \mathrm{~d}$ .59

Figure A14 Nuclear grade zirconium heat treated with zinc vapor at $725^{\circ} \mathrm{C}$ for $11.8 \mathrm{~d}$ .60

Figure A15 Nuclear Grade Zirconium Heat Treated with Zinc Vapor at $725^{\circ} \mathrm{C}$, $12 \mathrm{~d}$

Figure A16 Nuclear Grade Zirconium Heat Treated with Zinc Vapor at $725^{\circ} \mathrm{C}$, $64 \mathrm{~d}$ .62

Figure A17 Zircaloy-4 TREX Heat Treated with Zinc Vapor at $725^{\circ} \mathrm{C}, 2 \mathrm{~d}$...............63

Figure A18 Zircaloy-4 TREX Heat Treated with Zinc Vapor at $725^{\circ} \mathrm{C}, 11.8 \mathrm{~d}$............64

Figure A19 Zircaloy-4 Tubing Heat Treated with Zinc Vapor at $725^{\circ} \mathrm{C}, 39 \mathrm{~d}$..............65

Figure A20 Nuclear Grade Zirconium Heat Treated with Zinc Vapor at $775^{\circ} \mathrm{C}$, $12 \mathrm{~d}$ .66

Figure A21 Nuclear grade zirconium heat treated with zinc vapor at $800^{\circ} \mathrm{C}$, $12 \mathrm{~d}$ .67 
Spent nuclear fuel storage in the United States is a major concern for both the power utilities that operate nuclear power plants and the government regulating authority, the Nuclear Regulatory Commission (NRC). The NRC needs to extend the existing licenses on temporary dry storage containers from 20 years to 100 years, because of the delay in the completion of the Yucca Mountain permanent storage facility in Nevada. The Department of Energy (DOE) is currently doing a viability assessment study of the Yucca Mountain repository. According to the department estimates, if the facility is licensed in 2002, the site could begin to receive radioactive material by 2010 [1].

When a spent fuel bundle containing as many as 300 individual fuel rods is removed from a reactor core, it is placed in a pool of water for approximately five years to radioactively "cool". The "cooled" fuel bundle is then loaded underwater (to limit radioactive exposure) into a steel storage container called a cask. The loading of the spent fuel may take up to a week. When the loading is completed the cask is removed from the water, vacuum dried, and the top sealed by welding. The internal temperature of the dry cask storage system (DCSS) is expected to equilibrate at approximately 350 ${ }^{\circ} \mathrm{C}$ during normal dry storage. However, the maximum internal temperature may reach $570{ }^{\circ} \mathrm{C}$ during vacuum drying [2]. The DCSS containing this spent fuel then remains on site at the power plant. This is the current method of temporary storage until the highlevel radioactive waste site at Yucca Mountain is ready [3].

During the underwater spent fuel loading, corrosion of the steel cask produced radioactive iron particles that contaminated the storage pool filters. In recent years, the practice of coating the inside of the DCSS with zinc paint was implemented to prevent this corrosion. However, the introduction of zinc in the sealed storage system may possibly cause problems with the fuel rod material Zircaloy-4 (a zirconium alloy containing 1.5 wt. $\%$ tin, 0.2 wt. $\%$ iron, and 0.1 wt. \% chromium) [4]. The Zircaloy- 4 tubes that contain the fuel are referred to as fuel cladding. If the reaction layer between the Zircaloy- 4 and zinc vapor given off by the paint at $350{ }^{\circ} \mathrm{C}$ is large enough to degrade the fuel cladding and cause cracks or gross ruptures during the dry storage, then the transfer of the spent fuel in the casks to the permanent repository may be in jeopardy. For example, if the cladding failed and spent uranium oxide $\left(\mathrm{UO}_{2}\right)$ fuel piled up in the bottom of the container, then fuel retrieval would become a major problem and a water leak in such a case could possibly cause the fuel to become critical causing a nuclear reaction of thermal neutrons [5].

This study does not take into consideration the effects of radiation or the approximately $100 \mu \mathrm{m}$ zirconium oxide layer that forms on the fuel cladding while it is in the reactor core. All of the samples are unirradiated and have not been preoxidized. Parallel experiments using both Zircaloy-4 and nuclear grade zirconium exposed to zinc vapor from $\alpha$-brass $\left(\mathrm{Cu}-30\right.$ wt. $\% \mathrm{Zn}$ ) were conducted below $800^{\circ} \mathrm{C}$. The temperatures for the diffusion experiments were based on the $\mathrm{Zn}-\mathrm{Zr}$ binary phase diagram.

Temperatures below $750{ }^{\circ} \mathrm{C}$ were chosen to remain in the $\alpha$ hcp zirconium phase, yet high enough to insure that a reaction would occur in an experimentally accessible time 
frame. Extrapolation of these high temperature results to $350^{\circ} \mathrm{C}$ would then be used to estimate the effect during dry storage. However, experiments at $725^{\circ} \mathrm{C}$ indicated the presence of $\beta$ zirconium, so additional experiments with nuclear grade zirconium at temperatures above $725^{\circ} \mathrm{C}$ were performed to confirm the eutectoid reaction temperature in the binary phase diagram and to investigate the solubility of zinc in zirconium. The main questions to be addressed in this study are : a) will the zinc vapor react with the Zircaloy-4 alloy and pure nuclear grade zirconium, b) how deep will the reaction go, and c) what phases are in the reaction. This thesis will show that a reaction does occur, the depth of penetration is measured and the phases formed are identified.

The $\mathrm{Zn}-\mathrm{Zr}$ phase diagram, shown in Figure 1 [6], is an important starting point to understanding the possible zinc reactions with nuclear grade zirconium as well as the zirconium alloy Zircaloy-4. However, the $\mathrm{Zn}-\mathrm{Zr}$ binary system is not well defined in the $\mathrm{Zr}$-rich side as indicated by the dashed lines on phase diagram. Experiments performed on nuclear grade zirconium exposed to zinc vapor will clear up some of the uncertainty in this region of the phase diagram, specifically the eutectoid temperature and the solubility of $\mathrm{Zn}$ in $\alpha-\mathrm{Zr}$. 


\subsection{Zinc - Zirconium Phase Diagram}

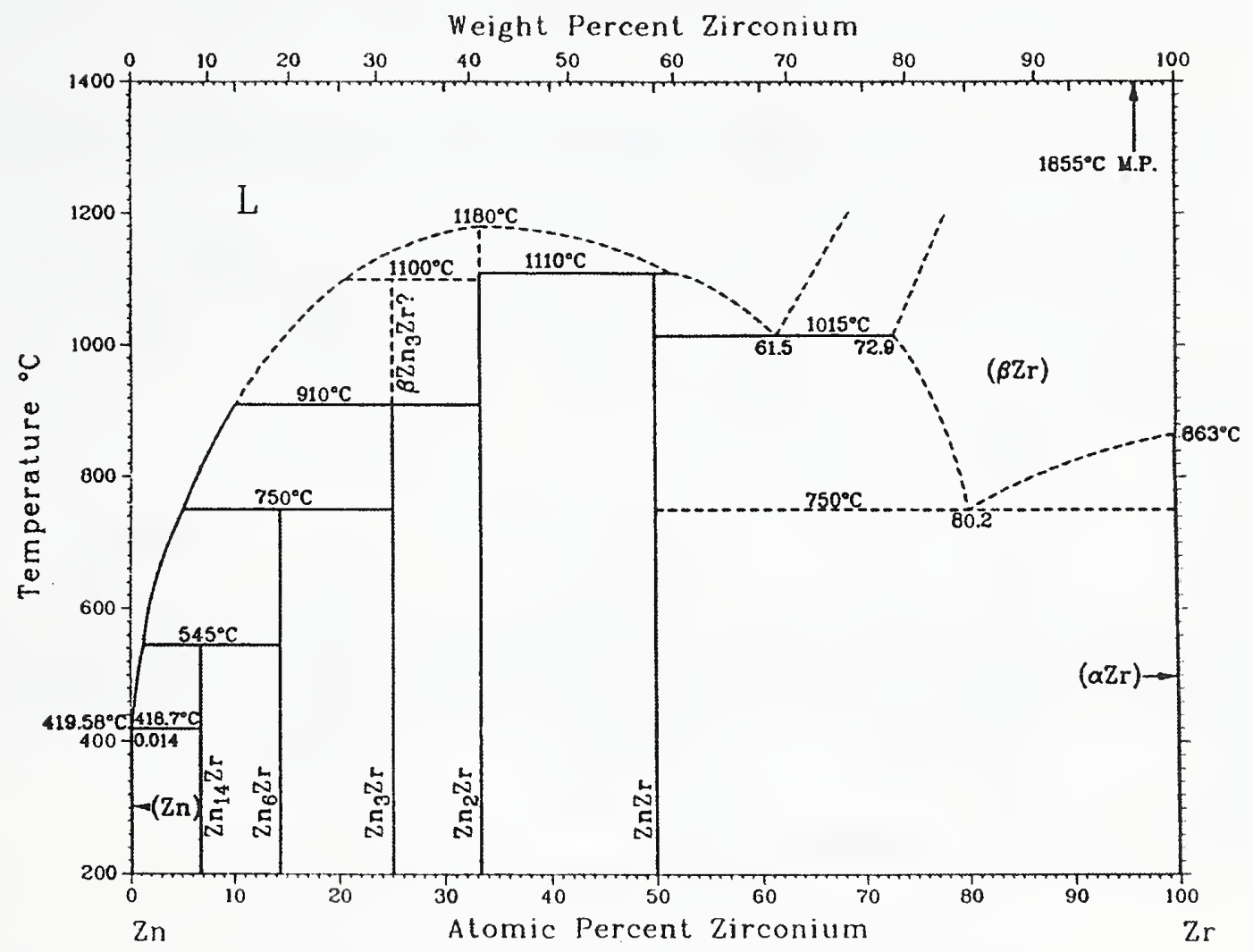

Figure 1. Zn-Zr phase diagram (from Binary Alloy Phase Diagrams, Vol.3, 3542, 1990 ASM International, Materials Park, Ohio) 


\subsection{Intermetallics and Crystallography}

In the $\mathrm{Zn}-\mathrm{Zr}$ phase diagram there are eight intermetallics [6,7] reported and listed in Table 1. Note that three of the intermetallics, $\mathrm{Zn}_{22} \mathrm{Zr}, \mathrm{Zn}_{2} \mathrm{Zr}_{3}$, and $\mathrm{ZnZr}_{2}$ are not shown in the currently assessed $\mathrm{Zn}-\mathrm{Zr}$ phase diagram in Figure 1. The lattice parameters, space groups and atomic structure prototypes are also listed in Table 1.

Table 1 Composition, Lattice Parameters, Space Group and Prototype of Phases in the $\mathrm{Zn}-\mathrm{Zr}$ Binary Phase Diagram from the Literature

Phase Composition at. \% $\mathrm{Zr}$

Lattice parameter $(\AA)$ Space group Prototype

\begin{tabular}{|c|c|c|c|c|}
\hline$(\mathrm{Zn})$ & 0 & $a=2.664 c=4.946$ & $\mathrm{P}_{3} / \mathrm{mmc}$ & $\mathrm{Mg}$ \\
\hline $\mathrm{Zn}_{22} \mathrm{Zr}(\mathrm{e})$ & $?$ & $a=14.103$ & $\mathrm{Fd} \overline{3} \mathrm{~m}$ & $\cdots$ \\
\hline $\mathrm{Zn}_{14} \mathrm{Zr}$ & 6.67 & $\ldots$ & $\mathrm{Fd} \overline{3} \mathrm{~m}$ & $\ldots$ \\
\hline $\mathrm{Zn}_{6} \mathrm{Zr}$ & 14.3 & $\ldots$ & $\ldots$ & $\ldots$ \\
\hline $\mathrm{Zn}_{3} \mathrm{Zr}$ & 25 & $a=8.16 c=16.23$ & $\ldots$ & $\ldots$ \\
\hline $\mathrm{Zn}_{2} \mathrm{Zr}$ & 33.3 & $a=7.394$ & $\mathrm{Fd} \overline{3} \mathrm{~m}$ & $\mathrm{Cu}_{2} \mathrm{Mg}$ \\
\hline $\mathrm{ZnZr}$ & 50 & $a=3.336$ & $\operatorname{Pm} \overline{3} \mathrm{~m}$ & $\mathrm{CsCl}$ \\
\hline $\mathrm{Zn}_{2} \mathrm{Zr}_{3}(\mathrm{e})$ & 60.5 & $a=7.633 c=6.965$ & $\mathrm{P} 4_{2} \mathrm{~nm}$ & $\mathrm{Al}_{2} \mathrm{Gd}_{3}$ \\
\hline $\mathrm{ZnZr}_{2}(\mathrm{e})$ & 66.7 & $a=3.303 c=11.26$ & $\mathrm{I} / \mathrm{mmm}$ & $\mathrm{MoSi}_{2}$ \\
\hline$(\beta \mathrm{Zr})$ & 72.9 to 100 & $a=3.546$ & $\mathrm{P} 6_{3} / \mathrm{mmc}$ & $\mathrm{Mg}$ \\
\hline$(\alpha \mathrm{Zr})$ & 100 & $a=3.232 c=5.147$ & $\operatorname{Im} \overline{3} \mathrm{~m}$ & W \\
\hline
\end{tabular}

Note: (e) Not shown in the phase diagram.

\subsection{Invariant points}

Table 2 [6] lists the invariant points for the $\mathrm{Zn}-\mathrm{Zr}$ system. The two reactions of greatest interest in this study are the allotropic transformation and the eutectoid reaction. Elemental zirconium under goes an allotropic phase transformation at $863{ }^{\circ} \mathrm{C}$ from a high temperature $\beta$ body-centered cubic (bcc) structure to a low temperature $\alpha$ hexagonal close-packed (hcp) structure. At the eutectoid temperature of $750{ }^{\circ} \mathrm{C}$, on the zirconium rich side of the phase diagram, high temperature $\beta$ transforms into $\alpha-\mathrm{Zr}$ and the intermetallic $\mathrm{ZnZr}(\beta \rightarrow \alpha-\mathrm{Zr}+\mathrm{ZnZr})$. However, one author suggests [8] that an additional metastable intermetallic phase $\mathrm{ZnZr}_{2}$ can sometimes form producing two two phase fields of $\alpha-\mathrm{Zr}+\mathrm{ZnZr}_{2}$ and $\mathrm{ZnZr}_{2}+\mathrm{ZnZr}$. In this case the eutectoid reaction would be $\beta \rightarrow \alpha-Z r+Z_{n} r_{2}$. 
Table 2 Invariant Points of Zn-Zr Binary Phase Diagram

$\underline{\text { Reaction }}$ composition at $\% \mathrm{Zr} \quad$ Temperature ${ }^{\circ} \mathrm{C}$ Reaction Type

$\begin{array}{llllll}\mathrm{L} \leftrightarrow \mathrm{Zn} \ldots \ldots \ldots \ldots \ldots & & 0 & & 419.58 & \text { Melting } \\ \mathrm{L} \leftrightarrow(\mathrm{Zn})+\mathrm{Zn}_{14} \mathrm{Zr} \ldots . . & 0.014 & 0.01 & 6.67 & 418.7 & \text { Eutectic } \\ \mathrm{L}+\mathrm{Zn} \mathrm{n}_{6} \mathrm{Zr} \leftrightarrow \mathrm{Zn}_{14} \mathrm{Zr} . . & 1.1 & 14.3 & 6.67 & 545 & \text { Peritectic } \\ \mathrm{L}+\mathrm{Zn} \mathrm{n}_{3} \mathrm{Zr} \leftrightarrow \mathrm{Zn}_{6} \mathrm{Zr} \ldots & 4.4 & 25.0 & 14.3 & 750 & \text { Peritectic } \\ \mathrm{L}+\mathrm{Zn} \mathrm{n}_{2} \mathrm{Zr} \leftrightarrow \mathrm{Zn}_{3} \mathrm{Zr} \ldots & 10.0 & 33.3 & 25.0 & 910 & \text { Peritectic } \\ \mathrm{L} \leftrightarrow \mathrm{Zn}_{2} \mathrm{Zr} \ldots \ldots \ldots \ldots \ldots & 33.3 & & 1180 & \text { Congruent } \\ \mathrm{L}+\mathrm{Zn} \mathrm{n}_{2} \mathrm{Zr} \leftrightarrow \mathrm{ZnZr} \ldots & 51.8 & 33.3 & 50 & 1110 & \text { Peritectic } \\ \mathrm{L} \leftrightarrow \mathrm{Zn} \mathrm{n}_{3} \mathrm{Zr}+(\beta-\mathrm{Zr}) & 61.5 & 50 & 73 & 1015 & \text { Eutectic } \\ (\beta-\mathrm{Zr}) \leftrightarrow \mathrm{ZnZr}+(\alpha \mathrm{Zr}) & 80.2 & 50 & 100 & 750 & \text { Eutectoid } \\ \mathrm{L} \leftrightarrow \beta-\mathrm{Zr} \ldots \ldots \ldots \ldots \ldots & 100 & & 1855 & \text { Melting } \\ \beta-\mathrm{Zr} \leftrightarrow \alpha-\mathrm{Zr} \ldots \ldots \ldots \ldots . & 100 & & 863 & \text { Allotropic }\end{array}$

\section{$2.4 \quad$ Solubility}

There are no data reported on the solubility of $\mathrm{Zn}$ in $\mathrm{Zr}$ [6]. However, in this study, composition profiles of nuclear grade zirconium exposed to zinc vapor revealed a small solubility of approximately 2 at. \% zinc. These findings will be discussed in Section 6.5 .

\subsection{Material Properties of Zirconium and Zircaloy-4}

Two properties of zirconium that make it useful for nuclear applications are low thermal-neutron capture cross section (i.e. transparency to thermal neutrons) and high corrosion resistance [9]. The Zircaloy-4 cladding provides the structural support for the uranium oxide $\left(\mathrm{UO}_{2}\right)$ fuel and the alloy's transparency to thermal neutrons allows the neutrons produced by fission of this fuel to pass through the cladding. Zirconium is a highly reactive metal and a stable protective oxide layer naturally forms resulting in a corrosion resistant surface [10]. The corrosion resistance of the Zircaloy-4 cladding protects the fuel in the reactor environment from the high temperature water and steam, typically $350^{\circ} \mathrm{C}$ in a pressure water reactor [11].

\section{THEORY OF DIFFUSION REACTIONS}

Sub-sections one through six will provide a summary of diffusion theory in the following order: 1) mechanisms of atomic movement, 2) the number of phases that can form in a two component system based on the Gibbs phase rule, 3) thermodynamics to explain local equilibrium at different times in the non-equilibrium diffusion process, 4) the rate of diffusion, 5) multicomponent effect on diffusion and 6) growth mechanism. 


\subsection{Diffusion Mechanisms}

Diffusion is defined as the movement of atoms in a material [12]. The two main types of atomic movement in a solid solution are interstitial and vacancy. Interstitial diffusion occurs when atoms move into the spaces of the atomic lattice not normally occupied. Vacancy diffusion occurs when atoms substitute on vacant lattice sites. In this study the main type of atomic movement is by vacancy diffusion. As the temperature of a material increases, the number of vacancies increases as well as the jump frequency allowing more opportunity for atomic movement. The atomic movement through the crystal can occur either in the bulk lattice structure or along the grain boundaries.

\subsection{Diffusion in Binary Systems}

The number of phases that are present in an equilibrium system can be found based on degrees of freedom. The Gibbs phase rule states that a system in equilibrium with $\mathrm{C}$ number of components and $\mathrm{P}$ number of phases will have $\mathrm{F}$ number degrees of freedom, as expressed in equation 1.

$$
\mathrm{F}=\mathrm{C}-\mathrm{P}+2
$$

The degrees of freedom are the number of intensive variables, such as temperature, pressure, and chemical potential that can be independently varied without necessarily changing the phase present in the equilibrium system [13]. Therefore the degrees of freedom must be zero in order to completely describe the system [12]. With the pressure fixed equation 1 , becomes equation 2

$$
\mathrm{F}=\mathrm{C}-\mathrm{P}+1
$$

and in binary two component system with $\mathrm{C}=2$, reduces to equation 3 .

$$
\mathrm{F}=3-\mathrm{P}
$$

Thus, the degrees of freedom for a single phase field is two, requiring both temperature and composition to be specified to completely describe the system. In a two phase field of the phase diagram, only one degree of freedom remains. Either the composition of the phases or the temperature must be specified to completely describe the system. So, once the temperature is fixed, then the composition of the two phases are fixed and vice versa if the compositions of the phases are fixed then the temperature is fixed. This means in a binary isothermal diffusion couple a two phase reaction zone, i.e. "containing precipitates or wavy interfaces" [14] can not exist. However, in multicomponent systems (three components or more) a two phase region can exist in the diffusion couple since the degrees of freedom would be greater than one and allow for composition variation of the phases at a fixed temperature. 


\subsection{Phase Equilibrium}

Knowing the activity of a surrounding vapor, allows the local equilibrium at the surface to be estimated.

The equilibrium between the metal surface and the vapor [15] occurs when the chemical potential, $\mu$, of each component is equal in the two phases, as expressed in equation 4

$$
\mu_{A}^{\alpha}=\mu_{A}^{\beta}, \mu_{B}^{\alpha}=\mu_{B}^{\beta} .
$$

Often the activity, $\mathrm{a}$, is defined by equation 5

$$
\mu=\mu^{o}+R T \ln a
$$

where $\mu^{o}$ is the chemical potential at a reference state, $\mathrm{R}$ is the gas constant equal to $8.314 \mathrm{~J} /$ mole Kelvin, and $\mathrm{T}$ is the temperature in degrees Kelvin. So from equation 5 when the two phases are in equilibrium the activities are also equal, as expressed in equation 6

$$
a_{A}^{\alpha}=a_{A}^{\beta}, a_{B}^{\alpha}=a_{B}^{\beta} .
$$

The common tangent to the Gibbs free energy curves $G^{\alpha}$ and $G^{\beta}$ gives the phase compositions, where the two phases have equal chemical potentials. This is shown schematically in Figure 2 where the free energy is plotted as a function of composition and the chemical potentials are at the endpoints of the tangent line.

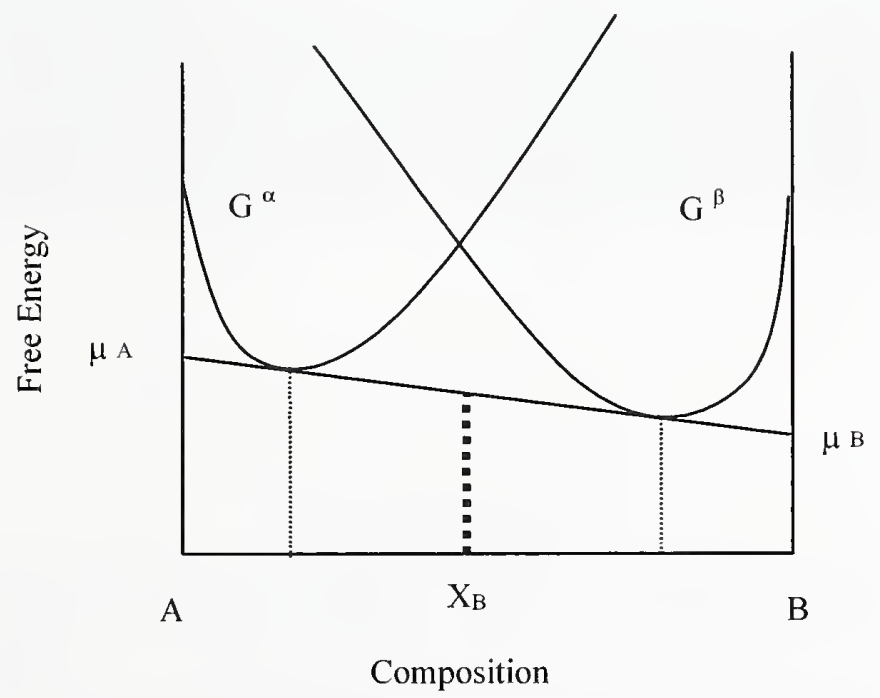

Figure 2. Schematic of free energy as a function of composition at constant pressure and temperature. $\mathrm{X}_{\mathrm{B}}$ represents the alloy composition. 
In this study, the activity of the zinc leaving the $\alpha$-brass is equal to the activity of the zinc arriving at the surface of the zirconium and the local equilibrium can be defined. This situation is illustrated in Figure 3.

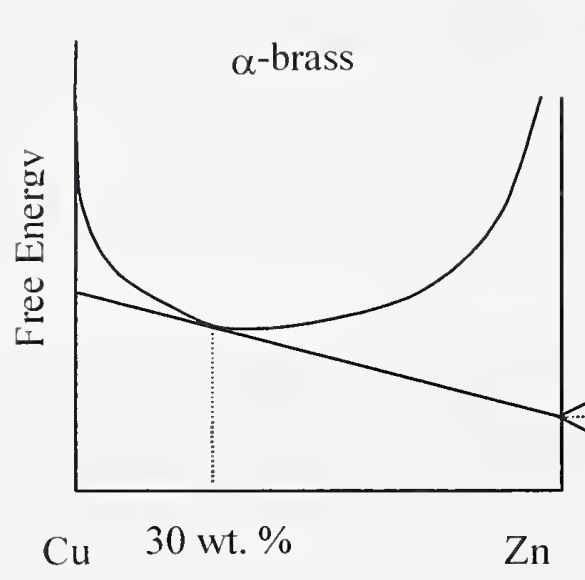

a

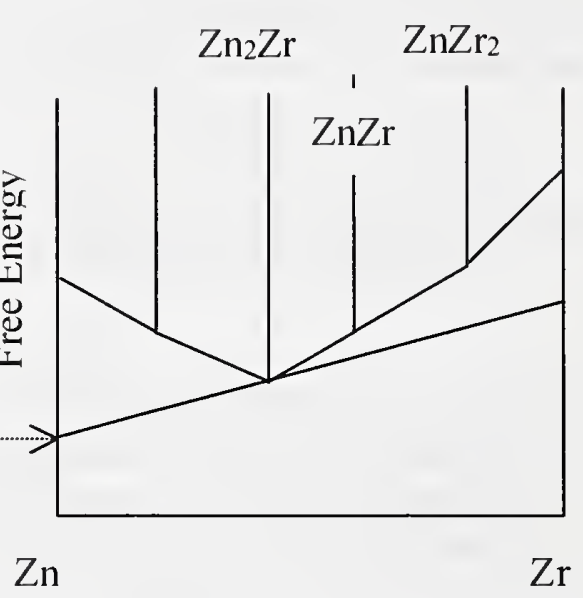

b

Figure 3. Schematic of equal chemical potentials a) from the surface of the $\alpha$-brass and b) of the single phase layer that forms on the surface of the zirconium. In this case $\mathrm{Zn}_{2} \mathrm{Zr}$ would be the surface phase formed on the $\mathrm{Zr}$ surface.

A thermodynamic assessment of zinc in $\alpha$-brass ( $\mathrm{Cu}-30 \mathrm{wt}$. \% $\mathrm{Zn}$ ) [16] was used to find the activity and chemical potential of zinc at the surface of the bulk zirconium or Zircaloy- 4 at the seven different heat treatment temperatures and the results are listed in Table 3 (the reference state for these calculations was based on the melting point of zinc, $419.5^{\circ} \mathrm{C}$ ). See Section 4.2.1, equation 12, for a discussion of the vapor pressure of pure zinc. 
Table 3 Activity and Chemical Potential of Zinc in $\alpha$-Brass (Cu-30 wt. \% Zn)

\begin{tabular}{|c|c|c|c|c|}
\hline $\begin{array}{c}\text { Temperature } \\
\left({ }^{\circ} \mathrm{C}\right)\end{array}$ & $\begin{array}{c}\text { Activity of Zinc } \\
\text { in } \alpha \text {-Brass }\end{array}$ & $\begin{array}{c}\text { Chemical } \\
\text { Potential of } \\
\text { Zinc in } \alpha \text {-Brass } \\
(\text { Joules } / \text { mole })\end{array}$ & $\begin{array}{c}\text { Vapor } \\
\text { Pressure of } \\
\text { Pure Zinc } \\
(\mathrm{kPa})\end{array}$ & $\begin{array}{c}\text { Partial } \\
\text { Pressure of } \\
\text { Zinc in } \alpha- \\
\text { Brass } \\
(\mathrm{kPa})\end{array}$ \\
\hline 650 & $5.1404 \times 10^{-2}$ & $-2.2781 \times 10^{4}$ & 3.59 & 0.185 \\
\hline 670 & $5.5459 \times 10^{-2}$ & $-2.2679 \times 10^{4}$ & 4.98 & 0.276 \\
\hline 700 & $6.1786 \times 10^{-2}$ & $-2.2527 \times 10^{4}$ & 7.85 & 0.485 \\
\hline 712 & $6.4396 \times 10^{-2}$ & $-2.2466 \times 10^{4}$ & 9.44 & 0.608 \\
\hline 725 & $6.7272 \times 10^{-2}$ & $-2.2399 \times 10^{4}$ & 11.4 & 0.767 \\
\hline 775 & $7.8786 \times 10^{-2}$ & $-2.2145 \times 10^{4}$ & 22.48 & 1.771 \\
\hline 800 & $8.4792 \times 10^{-2}$ & $-2.2017 \times 10^{4}$ & 30.83 & 2.614 \\
\hline
\end{tabular}

\subsection{Rate of Diffusion}

Diffusion is the movement of atoms and this movement can be described by measuring the flux, J, through a cross sectional unit area of material, the units for flux are mass $/ \mathrm{cm}^{2} \mathrm{~s}$. Fick's first law, equation 7 equates the flux, with the product of the diffusion coefficient, $\mathrm{D}$, and the concentration gradient where $\mathrm{c}$ is concentration and $\mathrm{x}$ is the distance,

$$
J=-D \frac{\partial c}{\partial x}
$$

The diffusion coefficient is defined in equation 8 as

$$
\mathrm{D}=\mathrm{D}_{0} \exp (-\mathrm{Q} / \mathrm{RT}),
$$

where $\mathrm{D}_{0}$ is the diffusion constant $\left(\mathrm{cm}^{2} / \mathrm{s}\right)$ for a specific material, $\mathrm{Q}$ is the activation energy $(\mathrm{J} / \mathrm{mole}), \mathrm{R}$ is the gas constant $=8.314 \mathrm{~J} /$ mole Kelvin and $\mathrm{T}$ is the temperature in degrees Kelvin.

To express the change in concentration as a function of time and assuming the diffusion coefficient does not change with concentration then Fick's second law can be expressed as equation 9 ,

$$
\frac{\partial c}{\partial t}=\frac{\partial}{\partial x}\left[D \frac{\partial c}{\partial x}\right]=D \frac{\partial^{2} c}{\partial x^{2}}
$$


Assuming the sample length of the bulk material is infinite compared to the length of the diffusion region, then Fick's second law can be solved by using the error function, $\operatorname{erf}(z)$. Where $\operatorname{erf}(z)$ is defined by equation 10

$$
\operatorname{erf}(z)=\frac{2}{\sqrt{\pi}} \int_{0}^{c} e^{-z^{2}} d z .
$$

The error function is available in any computer spread sheet. Assuming an infinite source of zinc vapor at the surface of nuclear grade zirconium, which is initially free of any solute, the surface concentration will remain constant over time. For the boundary conditions $x=0, t \geq 0, c=c^{\prime}$ and at $x=\infty, t \geq 0, c=0$. The concentration of the zinc diffusing into the bulk zirconium is given by equation 11 , where $c^{\prime}$ is the fixed surface concentration,

$$
c(x, t)=c^{\prime}\left[1-\operatorname{erf}\left(\frac{x}{2 \sqrt{D t}}\right)\right] .
$$

Figure 4 illustrates two concentration profiles increasing with time, both have fixed surface concentrations: a) profile of a single phase solid solution and b) profile of a solid solution with an intermetallic phase at the surface.

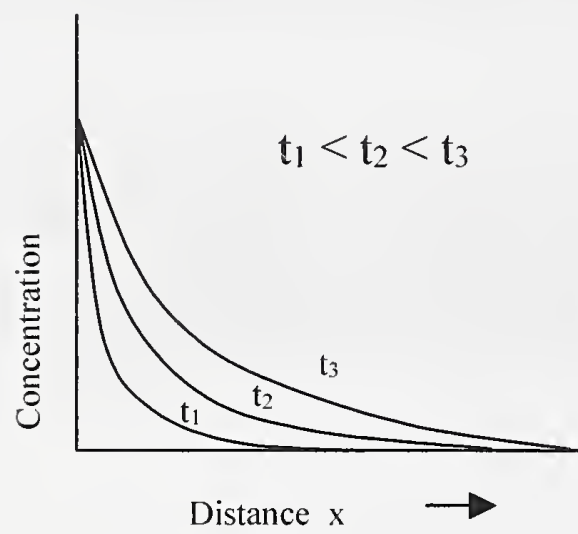

a

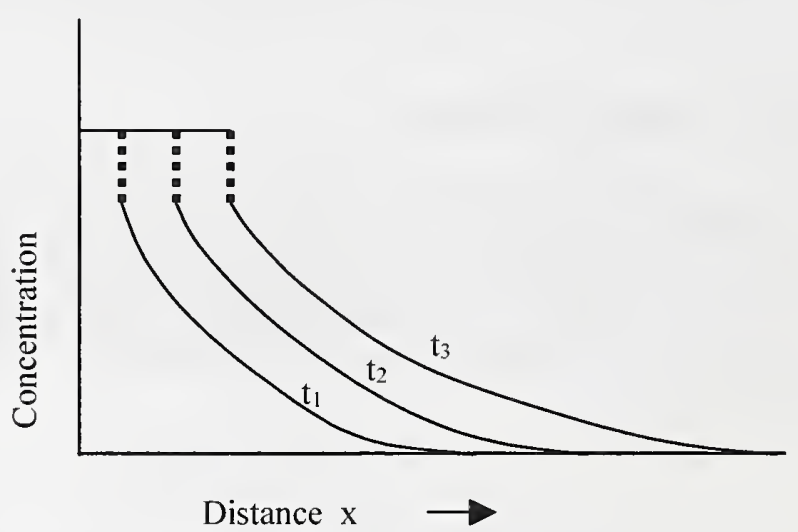

b

Figure 4. Typical concentration profiles for fixed surface concentration increasing with time. a) single phase in a solid solution b) solid solution containing a surface intermetallic phase.

The reaction of zinc vapor with the Zircaloy- 4 and nuclear grade zirconium produced intermetallic layers growing parallel to the surface. As illustrated in Figure 5, the presence of plateaus on the composition profile indicates a stoichiometric intermetallic 
compound, and a line that slightly slopes indicates a phase with some range of homogeneity. The vertical jump in concentration indicate an interphase interface.
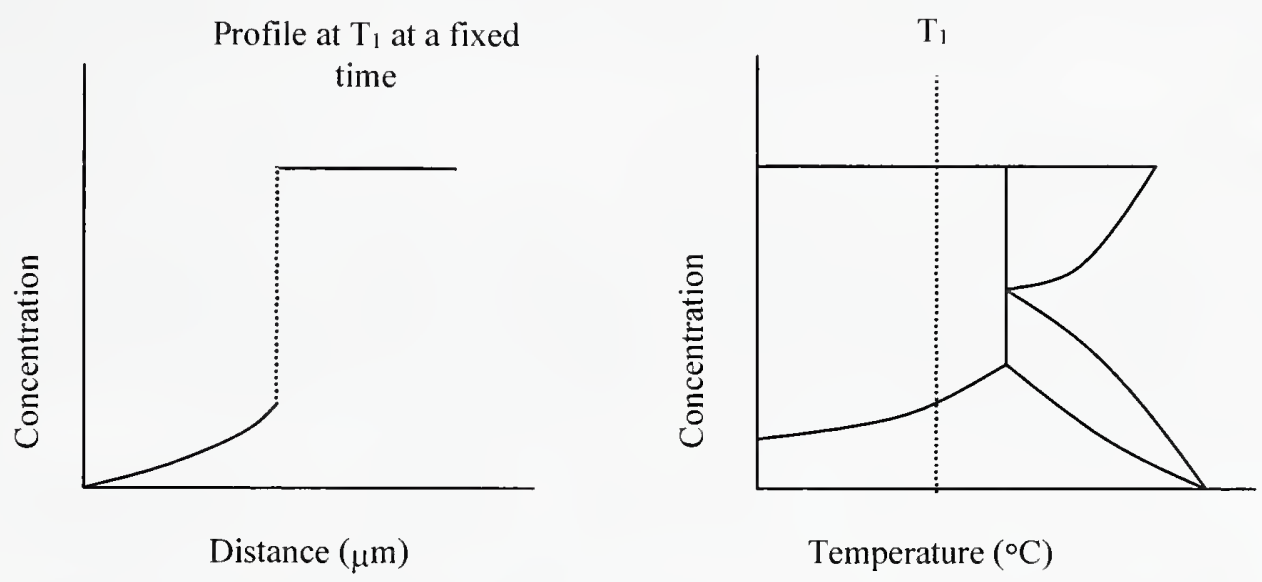

Figure 5. A schematic of a composition profile at $T_{1}$ and how it relates to a binary phase diagram.

\subsection{Diffusion in Multicomponent / Multiphase Systems}

In the Zircaloy-4 samples the alloying elements, $\mathrm{Sn}, \mathrm{Fe}$, and $\mathrm{Cr}$ can change phase boundaries, cause additional phases to form, and produce two phase regions. Experimental problems associated with multiphase regions will be discussed in Section 4.3.3.

\subsection{Growth mechanisms - Parabolic}

To determine of the type of growth, the depth of the reaction zone is measured at different times at the same temperature. Based on the depth of the reaction zone, $\mathrm{x}$, the time exponent, $\mathrm{n}$, can be determined by plotting the experimental data as $x=(K t)^{n}$. If $\mathrm{n}$ equals one, the growth is linear, if $n$ equals $1 / 2$ the growth is parabolic and will form a straight line when the data is plotted in the form $\frac{x}{\sqrt{t}}=\sqrt{K}$ where $\sqrt{K}$ is the slope of the line. The value of the growth constant $K$ is then found by squaring the slope. The growth constant should follow the expression for a diffusion process as $K=K_{0} \exp \left(\frac{-Q}{R T}\right)$. Where $K_{0}$ is the growth constant coefficient in $\mathrm{cm}^{2} / \mathrm{s}, \mathrm{Q}$ is the activation energy in $\mathrm{J} /$ mole, $\mathrm{R}$ is the gas constant equal to $8.314 \mathrm{~J} /$ mole Kelvin and $\mathrm{T}$ is the temperature in Kelvins. In general, the growth constant $K$ is a function of the diffusion constants, $\mathrm{D}$, of all the layers and the concentration at all the interfaces from the phase diagram. 


\subsection{Materials}

\subsubsection{Sample Materials}

Diffusion experiments were performed on three types of non-radioactive samples: nuclear grade zirconium, Zircaloy-4 tube reduced extrusion (TREX), and Zircaloy-4 tubing. Nuclear grade zirconium is produced by refining commercial grade zirconium which contains approximately 1.5 to $4.5 \mathrm{wt}$ \% hafnium [12]. Since hafnium is a neutron absorbing element (hafnium's thermal neutron capture cross section is $133 \times 10^{-24} \mathrm{~cm}^{2}$ compared to Zircaloy-4 with $0.22 \times 10^{-24} \mathrm{~cm}^{2}$ [12]), it is not desirable for nuclear fuel cladding and is removed by a liquid chemical process [13]. The nuclear grade zirconium for this study was cut from ingot \# 340667-Zr provided by OremetWah Chang*, and it contains 58 parts per million by weight ( $\mathrm{ppm}$ ) of hafnium (ASTM limit for hafnium in nuclear grade material is $100 \mathrm{ppm}$ [4]). Table 4 lists the range of trace element composition in this ingot.

Table 4 Trace Element Composition of Nuclear Grade Zirconium Ingot \# 340667-Zr as given by Oremet-Wah Chang, an Allegheny Teledyne Company*

$\begin{array}{llll}\text { Element } & \text { ppm } & \text { Element } & \text { ppm } \\ \mathrm{Al} & 20 & \mathrm{Na} & 5 \\ \mathrm{~B} & 0.025 \rightarrow 0.25 & \mathrm{Nb} & 50 \\ \mathrm{C} & 34 & \mathrm{Ni} & 35 \\ \mathrm{Ca} & 10 & \mathrm{O} & 60 \rightarrow 300 \\ \mathrm{Cd} & 0.25 & \mathrm{P} & 4 \rightarrow 5 \\ \mathrm{Cl} & 5 & \mathrm{~Pb} & 4 \rightarrow 5 \\ \mathrm{Co} & 10 & \mathrm{Si} & 25 \\ \mathrm{Cr} & 50 & \mathrm{Sn} & 10 \\ \mathrm{Cu} & 10 & \mathrm{Ta} & 50 \\ \mathrm{Fe} & 50 \rightarrow 90 & \mathrm{Ti} & 25 \\ \mathrm{H} & 3 & \mathrm{U} & 1 \\ \mathbf{H f} & \mathbf{5 7 \rightarrow 5 8} & \mathrm{V} & 25 \\ \mathrm{Mg} & 10 & \mathrm{~W} & 25 \\ \mathrm{Mn} & 25 & & \\ \mathrm{Mo} & 10 & & \\ \mathrm{~N} & 12 \rightarrow 19 & & \\ \text { Values are in parts per million by weight (ppm) }\end{array}$


Zircaloy-4 is a dilute $\alpha$ zirconium alloy containing $1.5 \mathrm{wt}$. \% tin, $0.2 \mathrm{wt}$. \% iron, and 0.1 wt. \% chromium. This alloy is used as nuclear fuel cladding in pressure water reactors. The exact dimensions of the fuel cladding vary according to the reactor design but typical dimensions are $4 \mathrm{~m}$ in length, $11 \mathrm{~mm}$ in outside diameter with a wall thickness of $0.75 \mathrm{~mm}$ [17]. Both the TREX and tubing (lot \# 3ME13-8) were provided by McDermott Technology, Inc* (formerly Babcock \& Wilcox R\&D) in Lynchburg, Virginia.

The Zircaloy-4 TREX has a $6.35 \mathrm{~cm}$ outside diameter and a wall thickness of $1.27 \mathrm{~cm}$ and is the first step in tube production [18]. The Zircaloy-4 tubing as-received was already stress relieved through annealing at $500{ }^{\circ} \mathrm{C}$ by the supplier. This tubing has dimensions of $11 \mathrm{~mm}$ outside diameter and a wall thickness of $0.75 \mathrm{~mm}$. It is the final step in cladding production before the tube surface is pre-oxidized and ready to receive fuel.

\subsubsection{Zinc Vapor Source}

The zinc vapor source used for this study was $\alpha$-brass $(\mathrm{Cu}-30 \mathrm{wt} . \% \mathrm{Zn})$ that contains less than $0.01 \mathrm{wt} \% \mathrm{Fe}$. A $1.27 \mathrm{~cm}$ diameter rod was cleaned with ethyl alcohol and the rod was turned on a lathe to remove the surface layer. After the surface layer was removed, addition machining was done to produce thin brass filings. The brass filings were then cleaned in an ultrasonic bath with acetone and then ethyl alcohol and stored in a desiccator.

\subsection{Procedures}

\subsubsection{Sample Preparation}

The Zircaloy-4 TREX and the nuclear grade zirconium samples were sliced from bulk material with a diamond saw. All samples were cut to approximately the same dimensions, $12 \mathrm{~mm}$ long, $3 \mathrm{~mm}$ wide and $1.5 \mathrm{~mm}$ thick. The surfaces were ground, finishing with wet 600 grit $\mathrm{SiC}$ paper, and then polished with a $6 \mu \mathrm{m}$ diamond suspension. The samples were then cleaned with acetone and ethanol and air-dried. Samples were encapsulated in a quartz tube under a vacuum of $1.33 \times 10^{-5} \mathrm{~Pa}$. The samples were annealed at approximately $700{ }^{\circ} \mathrm{C}$ for six $\mathrm{d}$ in order to relieve any stresses introduced by the extrusion process and sample preparation. After air cooling the tube containing the annealed samples was broken and each sample was polished to $1 / 4 \mu \mathrm{m}$ finish, cleaned and then individually encapsulated with high purity $\alpha$-brass filings under a vacuum of $1.33 \times 10^{-5} \mathrm{~Pa}$. A single Zircaloy-4 tubing sample (pre-annealed at $500{ }^{\circ} \mathrm{C}$ ) and was cut into a $25 \mathrm{~mm}$ length, cleaned and encapsulated with brass. At the highest experimental temperature of $800{ }^{\circ} \mathrm{C}$, the zinc vapor pressure over brass is $30.83 \mathrm{kPa}$ as given in Table 3. The vapor pressure of copper at $800{ }^{\circ} \mathrm{C}$ is insignificant. This was calculated using equation 12 , where $\mathrm{P}$ is in $\mathrm{mm} \mathrm{Hg}$ and the temperature $\mathrm{T}$ is in Kelvins [19]. 


$$
\log _{10} P=\frac{-0.05223(a)}{T}+b
$$

For liquid zinc in the temperature range between $600{ }^{\circ} \mathrm{C}$ and $985{ }^{\circ} \mathrm{C}$ the values of the constants are $\mathrm{a}=118,000$ and $\mathrm{b}=8.108$. The constant values for copper $(\mathrm{a}=468,000$ and $\mathrm{b}=12.344$ ) are only valid in the temperature range between $2100{ }^{\circ} \mathrm{C}$ and $2310^{\circ} \mathrm{C}$ so during the heat treatments the brass filings are only a source of zinc vapor. Table 3 in section 3.3 lists the zinc vapor pressure at other heat treatment temperatures.

\subsubsection{Heat Treatment}

A $5 \mathrm{~cm}$ inside diameter vertical Marshall tube furnace was used for the heat treatments. A Nichrome cylindrical container, $8.25 \mathrm{~cm}$ tall with a $3.75 \mathrm{~cm}$ inside diameter, with lid was placed in the middle of the furnace hot zone and allowed to equilibrate at the furnace temperature. This produced an isothermal hot zone within the container. The furnace tube above and below the container was packed with firebrick to prevent convection currents in the tube. The encapsulated sample was then placed inside the Nichrome container. The sample was monitored by a type K (chromel-alumel) sheathed thermocouple placed through the lid to within $5 \mathrm{~mm}$ of the sample. This thermocouple was connected to a large external aluminum isothermal plate that serves as the cold junction reference. This external panel was then connected to a temperature data acquisition board in a computer. The furnace temperature was maintained with a separate type $\mathrm{K}$ thermocouple connected to a temperature controller.

\subsubsection{Temperature Calibration}

The furnace was calibrated using a pure element encapsulated in quartz. The furnace temperature is set approximately $10{ }^{\circ} \mathrm{C}$ below the element's melting point. Once the furnace is equilibrated, the encapsulated standard is placed in the Nichrome container. The furnace temperature is raised by one degree and the standard is removed and visually inspected for melting and then placed back in the Nichrome container and the furnace is then allowed to re-equilibrate. This process is repeated until the standard melts. The temperature of the thermocouple monitoring the standard is recorded and then all other thermocouples are placed in that furnace one at a time and their temperatures are recorded. The thermocouples were Inconel sheathed type K with the thermocouple junction tip grounded to the sheath. Using three different furnaces set at the melting points of lead, zinc, and aluminum $\left(327{ }^{\circ} \mathrm{C}, 419{ }^{\circ} \mathrm{C}\right.$, and $660{ }^{\circ} \mathrm{C}$ respectively), each thermocouple had a three point calibration. All thermocouples were corrected using these results.

\subsubsection{Sample Quenching}

At the end of the diffusion anneal the samples were quenched in water at room temperature. The sample was immersed in the water and then the quartz tube was 
broken using a hammer. The time from removal of the sample from the furnace until the quartz tube is broken underwater was approximately $5 \mathrm{~s}$ to $10 \mathrm{~s}$.

\subsubsection{Choice of Heat Treatment Temperatures}

The experiments were performed with Zircaloy-4 TREX, Zircaloy-4 tubing, and nuclear grade zirconium encapsulated with brass filings in vacuum at $650^{\circ} \mathrm{C}, 670^{\circ} \mathrm{C}, 700^{\circ} \mathrm{C}$, $712{ }^{\circ} \mathrm{C}, 725^{\circ} \mathrm{C}, 775^{\circ} \mathrm{C}$, and $800^{\circ} \mathrm{C}$. The initial choice of temperatures for the diffusion experiments were based on the $\mathrm{Zn}-\mathrm{Zr}$ binary phase diagram, shown in Figure 1. Temperatures just below $750{ }^{\circ} \mathrm{C}$ were chosen to remain in the hcp $\alpha$ zirconium phase, yet high enough to insure that reaction would occur in the shortest period of time possible. However experiments at $725^{\circ} \mathrm{C}$ indicated the presence of $\beta$ zirconium, so additional experiments with nuclear grade zirconium at temperatures above $725^{\circ} \mathrm{C}$ were performed to confirm the eutectoid reaction temperature in the binary phase diagram.

\subsection{Characterization}

\subsubsection{Metallography}

All of the samples were cut in cross section and mounted in epoxy resin for optical metallography. The samples were then ground with 400 and 600 grit wet SiC papers and then polished starting with $15 \mu \mathrm{m}$ diamond suspension and finishing with $1 / 4 \mu \mathrm{m}$ diamond suspension. The grain size measurement of the Zircaloy-4 tubing, Zircaloy-4 TREX, and nuclear grade zirconium as-received materials was performed using the circular intercept method, ASTM standard test method E112-96 [20], on a $1 / 4 \mu \mathrm{m}$ diamond polished sample, etched with a solution of hydrofluoric acid, nitric acid and water [21]. The measured grain sizes of the three as received materials, Zircaloy-4 tubing, Zircaloy-4 TREX and nuclear grade zirconium was found to be approximately 2 $\mu \mathrm{m}, 10 \mathrm{um}$ and $140 \mu \mathrm{m}$, respectively. After grain size measurements, all of the samples were repolished to a $1 / 4 \mu \mathrm{m}$ surface finish to remove the chemical etch.

\subsubsection{Energy Dispersive Spectrometry}

Each sample was examined with a JEOL model 840A* Scanning Electron Microscope (SEM). Using Energy Dispersive Spectrometry (EDS) with elemental standards for zinc, zirconium, tin, iron, and chromium, a compositional line scan was done on each sample. All line scans were preformed with the an accelerating voltage of $20 \mathrm{kV}$, a probe current of $535 \mathrm{pA}$, and a $100 \mathrm{~s}$ acquisition time. The EDS composition profiles started at the edge of the sample and the electron beam was scanned towards the middle. The SEM electron beam resolution for EDS analysis is $\sim 1 \mu \mathrm{m}$ and the line scan steps were varied from $0.5 \mu \mathrm{m}$ to $1.5 \mu \mathrm{m}$. The results gave a composition profile and the penetration depth of the zinc diffusion reaction zone. 


\subsubsection{Complications in the Interpretation of Composition Line Scans}

The line scans results of all the samples are shown in Appendix A, Figures Al through A21. The edge of the sample is always on the left and is highlighted by a white outline produced by the electron beam. The arrow indicates the path of the electron beam. An explanation of interpreting these line scans is in order.

In the profiles of samples exposed to zinc vapor for short diffusion times, the single phase layers were very narrow, on the order of $1 \mu \mathrm{m}$ or $2 \mu \mathrm{m}$ thick, so the shelves and steps of the line scans are not well defined because the phase width is approximately the same as the $1 \mu \mathrm{m}$ resolution of the SEM probe beam. Combined with the beam resolution problem is the number of points measured in this narrow reaction layer zone. Using too many points causes an overlapping and the data appears smeared and taking too few points makes the line scan data appear choppy. So in the short heat treatment profiles the lines representing the separation of two different phase layers is not truly vertical and the plateaus are not truly horizontal. However, the different phases were distinguishable by the change in contrast in the SEM micrographs taken in the compositional backscattered mode. Figure 6 shows an example of a line scan of nuclear grade zirconium exposed to zinc vapor for at $775^{\circ} \mathrm{C}$ for $12 \mathrm{~d}$. This scan shows very clearly the plateau of the single phase intermetallic at 50 at. $\% \mathrm{Zr}$, the vertical line representing the interface separating the $\mathrm{ZnZr}$ intermetallic and the $\beta$ phase, and the sloping line of the $\beta$ phase that indicates a range of composition in that phase. 


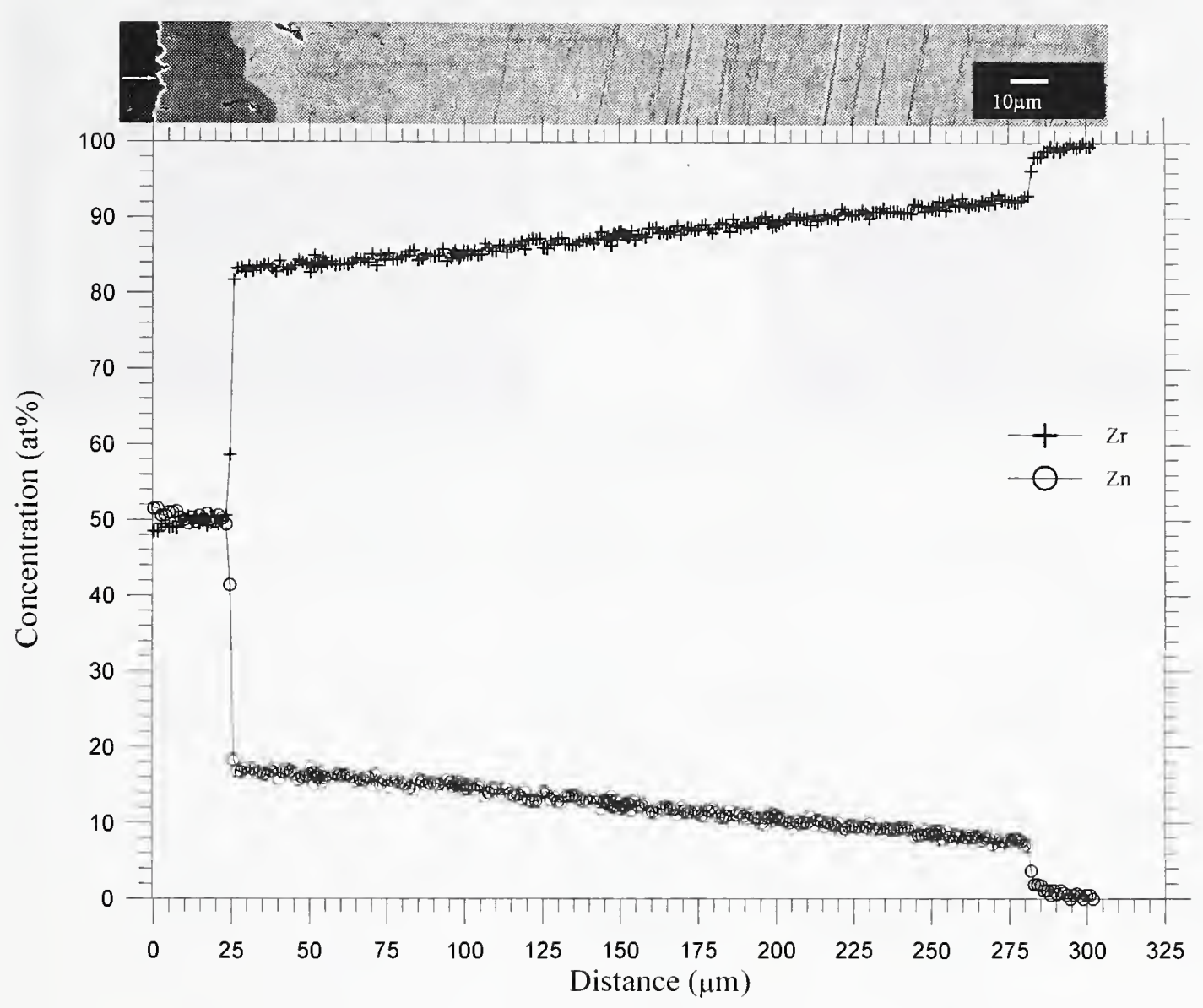

Figure 6. Nuclear grade zirconium exposed to zinc vapor at $775^{\circ} \mathrm{C}$ for $12 \mathrm{~d}$. Note the interface between the $\beta$ phase and $\alpha-\mathrm{Zr}$ is not visible.

An example of a line scan with questionable and non-existent plateaus is shown in appendix A Figure A1. This scan of nuclear grade zirconium exposed to zinc vapor at $650{ }^{\circ} \mathrm{C}$ for $16 \mathrm{~d}$ illustrates the problems of narrow width phases and also too few data points.

For the Zircaloy-4 samples exposed to zinc vapor, two new complications arise due to the multicomponent nature of Zircaloy-4. First, the Fe and Sn atoms appear to substitute on the same lattice sites as the $\mathrm{Zn}$ atoms in the intermetallic compounds. So in order to identify the different phases from the line scans only the $\mathrm{Zr}$ concentration was typical of the intermetallic stochiometry. The second complication is the formation of a 2 phase layer of light colored precipitates in a dark colored matrix between two layers of single phases. As the line scan crossed this layer, the beam was either overlapping the two phases, measuring an average composition of the precipitates and the matrix, or the beam hit only one the phases and measured the precipitate or the 
matrix individually. Therefore the line scans across this 2 phase layer do not give accurate compositions, so individual point measurements were done on each of the phases making up the 2 phase layer separately. The average composition of the individual phases in this two phase region, the matrix and precipitate, were determined by measuring four different points in each phase. The correct compositions of the matrix and precipitates and those results are shown Table 5. The phases were identified as $(\mathrm{Zn}, \mathrm{Fe}, \mathrm{Sn}) \mathrm{Zr}$ dark matrix and $(\mathrm{Zn}, \mathrm{Fe}, \mathrm{Sn}) \mathrm{Zr}_{2}$ as the light precipitate. For simplicity these phases will be abbreviated as $(\mathrm{Zn}, \mathrm{x}) \mathrm{Zr}$ and $(\mathrm{Zn}, \mathrm{x}) \mathrm{Zr}_{2}$, respectively, where $\mathrm{x}$ represents the $\mathrm{Fe}$ and $\mathrm{Sn}$ on the $\mathrm{Zn}$ sublattice.

Table 5 Composition of Phases in the Two Phase Region

\begin{tabular}{|c|c|c|c|c|c|}
\hline & at $\% \mathrm{Zr}$ & at $\% \mathrm{Zn}$ & at $\% \mathrm{Sn}$ & at $\% \mathrm{Fe}$ & at $\% \mathrm{Cr}$ \\
\hline \multicolumn{6}{|c|}{ Light region } \\
\hline Average & 63.78 & 22.70 & 2.78 & 10.41 & 0.36 \\
\hline Std. Dev. & 4.20 & 4.63 & 0.51 & 0.19 & 0.15 \\
\hline \multicolumn{6}{|c|}{ Dark region } \\
\hline Average & 52.78 & 36.35 & 0.58 & 9.55 & 0.70 \\
\hline Std. Dev. & 0.51 & 0.90 & 0.18 & 0.50 & 0.10 \\
\hline
\end{tabular}

In Figure 7 two line scan profiles of Zircaloy- 4 exposed to zinc vapor at $650{ }^{\circ} \mathrm{C}$ for 126 d shows: a) the profile when the beam only passes through the matrix phase of the 2 phase layer and b) the profile when the beam passes through the precipitate phase of the 2 phase layer. In order to correctly interpret the line scans both the micrograph and the graph must be carefully evaluated. 

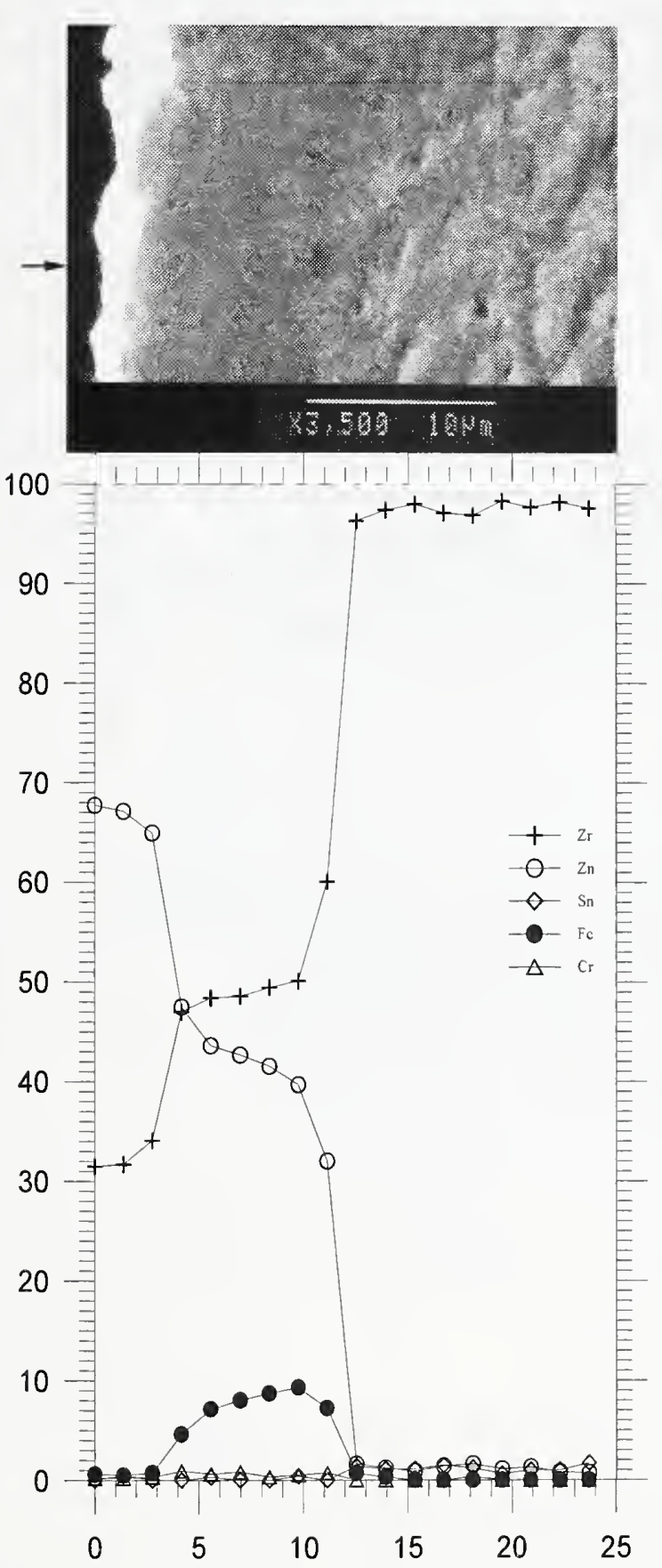

Distance $(\mu \mathrm{m})$

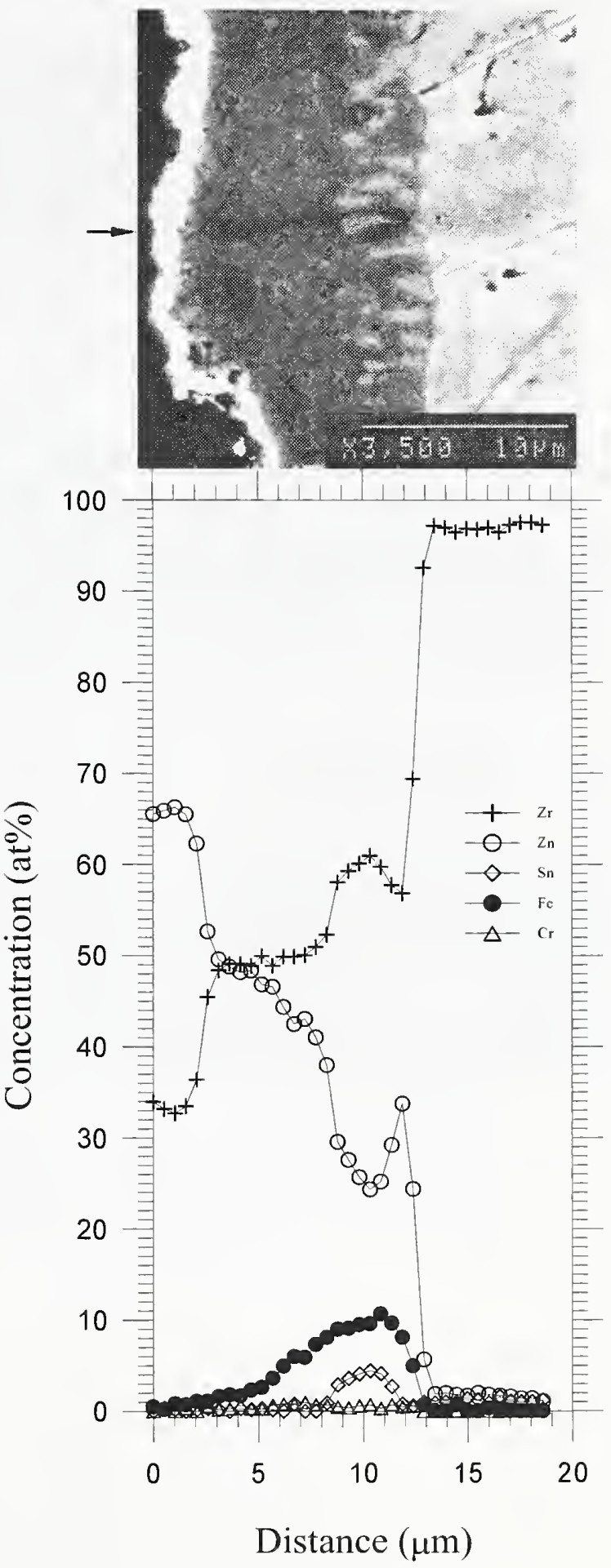

Figure 7. Zircaloy-4 exposed to zinc vapor at $650^{\circ} \mathrm{C}$ for $126 \mathrm{~d}$ a) the profile when the beam only passes through the matrix phase of the 2 phase layer and $b$ ) the profile when the beam passes through the precipitate phase of the 2 phase layer. 


\subsubsection{X-Ray Diffraction}

The X-ray diffraction scans were performed on three samples; Zircaloy-4 TREX, Zircaloy-4 tubing as-received, nuclear grade zirconium as-received, using a theta-two theta Scintag* diffractometer with a copper target at power setting of $45 \mathrm{kV}$ and $40 \mathrm{~mA}$. All scans were done over a two theta range from $20^{\circ}$ to $125^{\circ}$ at a step size of $0.02^{\circ}$ and a count time of $10 \mathrm{~s}$ per step. The $\mathrm{x}$-ray diffraction patterns of all three samples correspond to the hep $\alpha-\mathrm{Zr}$ phase.

\section{$5 \quad$ RESULTS}

In Section 5.1 a brief summary of the phase sequences within the reaction zone will be given. In Section 5.2 the thickness of the individual phases and the overall thickness of the total reaction zone will be summarized. In section 5.3 the details of the microstructure, composition profiles and phase analysis will be discussed. Section 5.4 will follow with an estimate of the growth constant based on the total reaction zone thickness.

\subsection{Phase sequences}

A two phase layer of $(\mathrm{Zn}, \mathrm{x}) \mathrm{Zr}+(\mathrm{Zn}, \mathrm{x}) \mathrm{Zr}_{2}$ was only found in the Zircaloy-4 samples. Six distinct phase sequences were observed from the sample surface to the interior in nuclear grade zirconium and Zircaloy-4 exposed to zinc vapor depending on temperature. Table 6 provides a summary the phase sequence of each individual Zircaloy 4 and nuclear grade zirconium sample. To easily distinguish identical phase sequences, each sequence listed in Table 6 is numbered. 


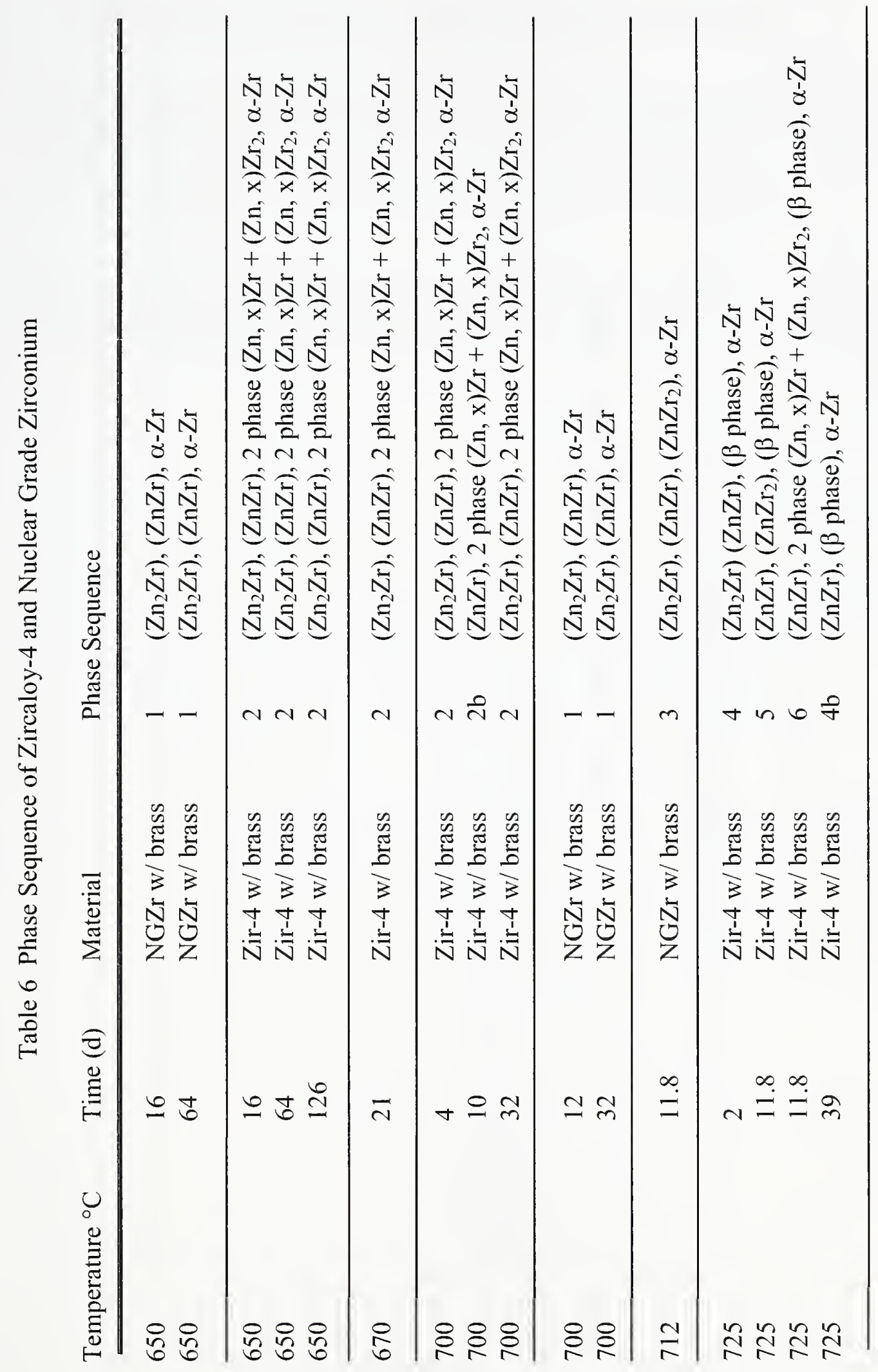




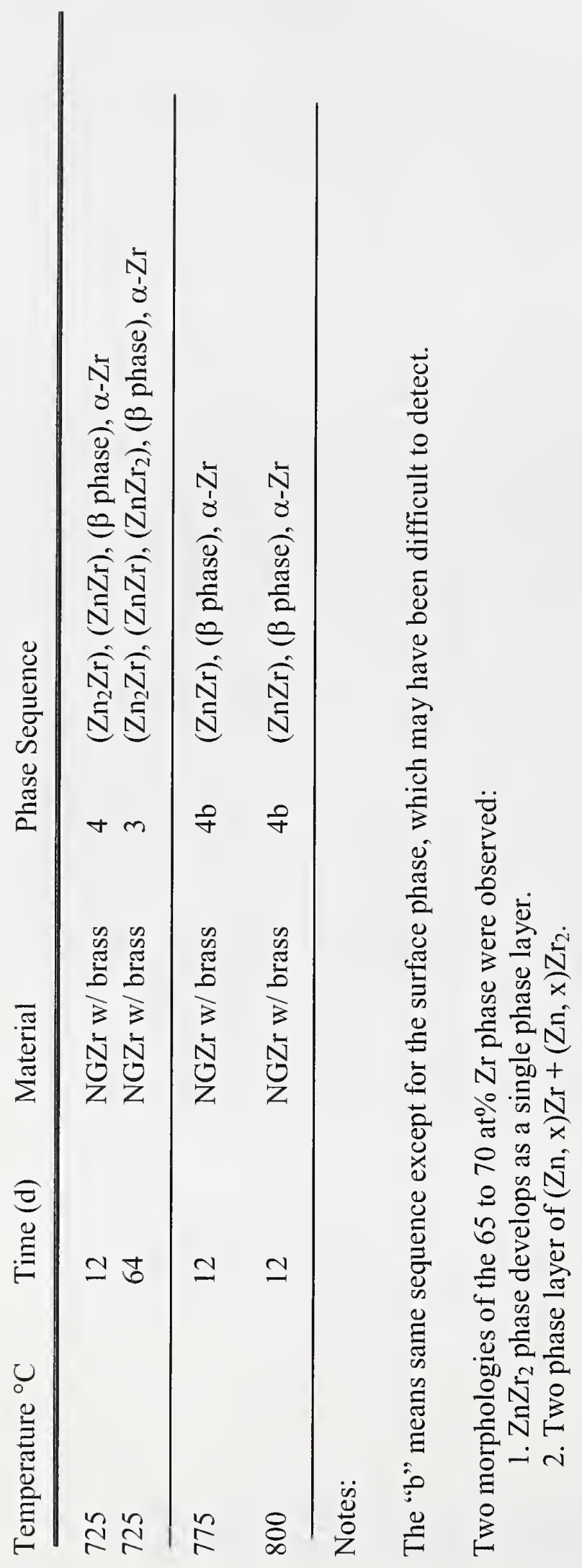




\subsection{Individual Intermetallic and Total Reaction Zone Thickness}

The region of interest in this study begins with the $\mathrm{Zn}_{2} \mathrm{Zr}$ phase at 33 at. \% zirconium, the first intermetallic observed on the surface during $\mathrm{Zn}$ exposure from brass. Moving in from the surface the next observed intermetallics are the $\mathrm{ZnZr}, 50$ at. \% zirconium, and the $\mathrm{ZnZr}_{2}$ containing 67 at. \% zirconium. The metastable $\mathrm{Zn}_{3} \mathrm{Zr}_{2}$ phase containing 60 at. $\%$ zirconium was not observed. The phase sequence ends with the $\alpha-Z$ r.

Tables 7 and 8 summarize the thickness of individual phases and the total reaction zone thickness for both the Zircaloy-4 and nuclear grade zirconium samples. The reported uncertainly of the total thickness of the reaction zone measurement is an absolute bounds error. The last column in both Tables is the maximum reaction zone thickness. 


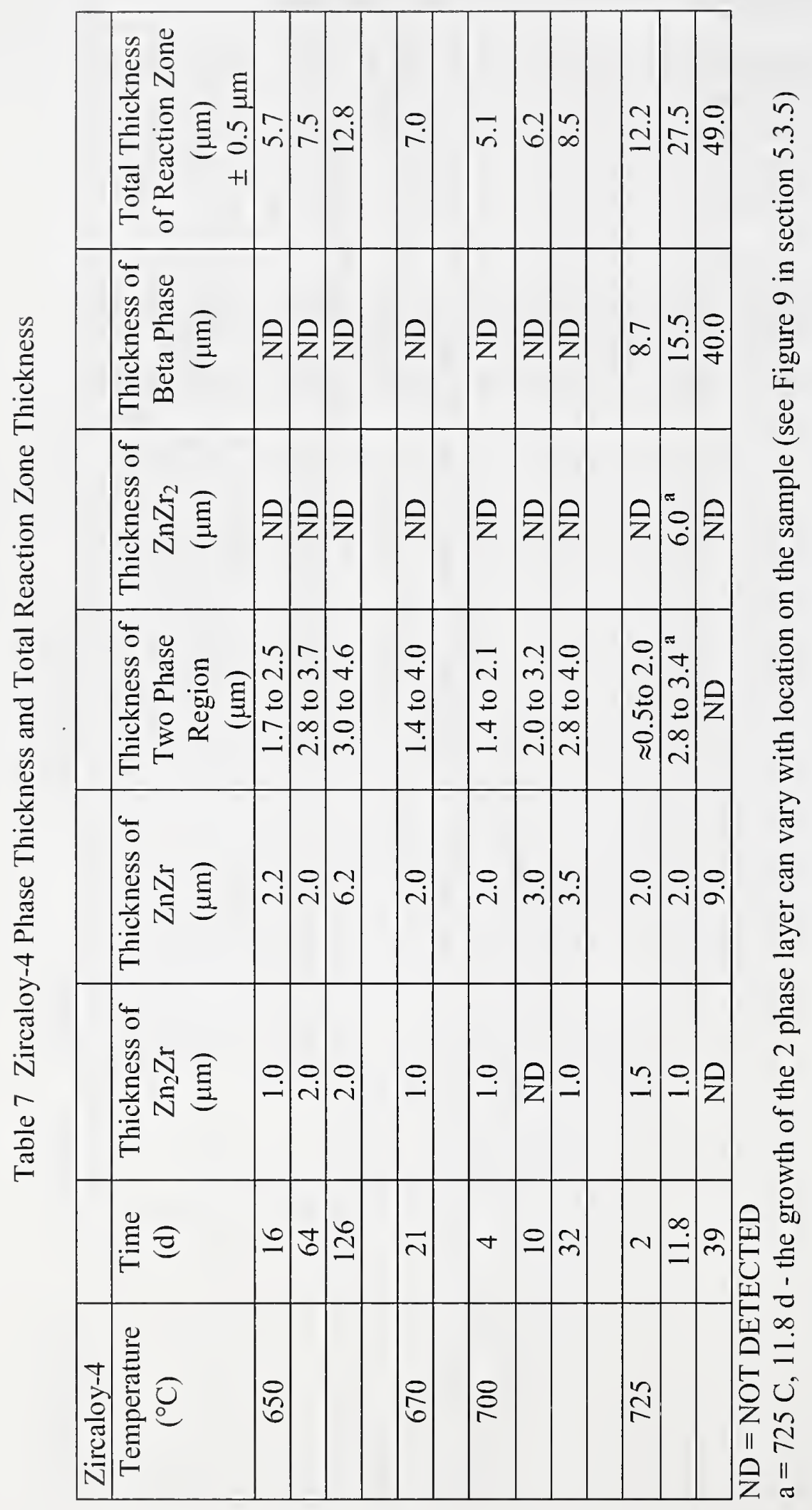




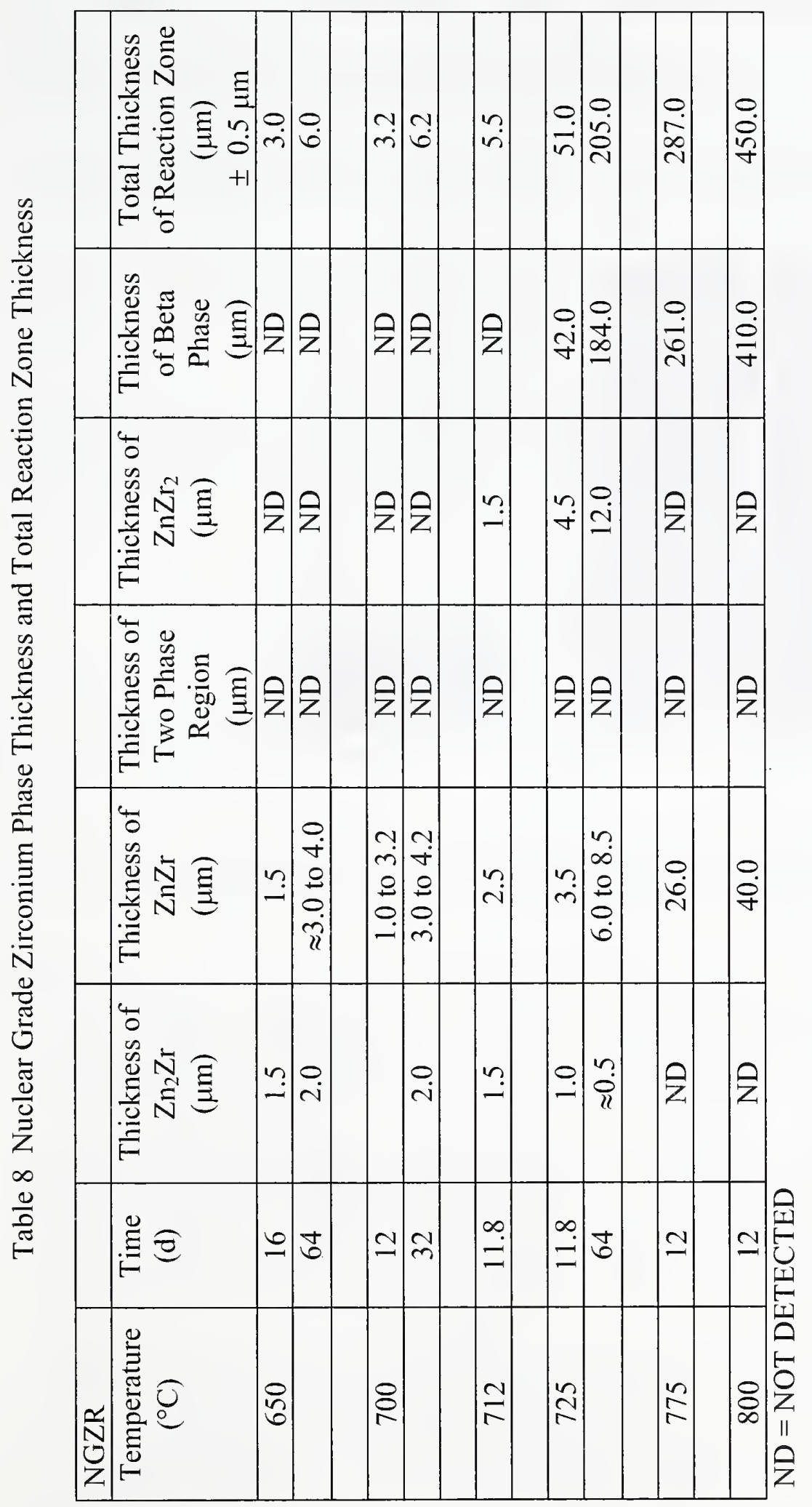




\subsection{Experimental Line Scan Results}

\subsubsection{Temperature $650^{\circ} \mathrm{C}$ microstructure/composition profiles /phase analysis}

The microstructure of the Zircaloy-4 sample exposed to zinc vapor at $650{ }^{\circ} \mathrm{C}$ for $126 \mathrm{~d}$ in Figure 8 shows three planar layers: the $\mathrm{ZnZr}$ single phase layer at the edge, the 2 phase layer, and the single phase $\alpha-Z r$. The edge of the sample on the left has a white outline, this is an edge effect from the electron microscope, and the dashed white line indicates the interface between the $\mathrm{ZnZr}$ and the 2 phase layer.

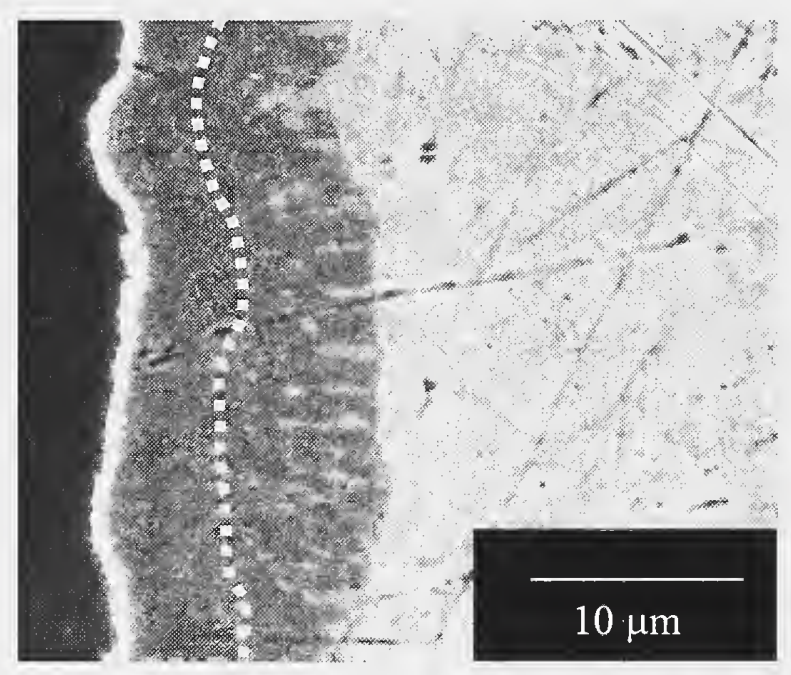

Figure 8. Microstructure of Zircaloy-4 heat treated with zinc vapor at $650{ }^{\circ} \mathrm{C}$ for $126 \mathrm{~d}$. The dashed line is the interface between the two visible phases closest to the edge, $\mathrm{ZnZr}$ and the 2 phase layer.

However, the line scan profiles of the Zircaloy- 4 at $16 \mathrm{~d}, 64 \mathrm{~d}$ and $126 \mathrm{~d}$ (Figures A3, $\mathrm{A} 4$, and $\mathrm{A} 5$ ) all show that a fourth phase $\mathrm{Zn}_{2} \mathrm{Zr}$ (33 at. \% zirconium), approximately 1 $\mu \mathrm{m}$ thick at the edge, is also present. The next layer to form is the $\mathrm{ZnZr}$ phase (50 at. \% zirconium), and then a two phase layer containing a light colored precipitate phase ( $\mathrm{Zn}$, $\mathrm{x}) \mathrm{Zr}_{2}$ and dark colored matrix phase $(\mathrm{Zn}, \mathrm{x}) \mathrm{Zr}$ previously identified in Table 5. After the two phase region the composition of zirconium varies from approximately 98 to 100 at. $\%$ in the bulk $\alpha-Z r$. In summary the phase sequence for Zircaloy- 4 from surface to interior at this temperature is $\mathrm{Zn}_{2} \mathrm{Zr}, \mathrm{ZnZr}, 2$ phase $(\mathrm{Zn}, \mathrm{x}) \mathrm{Zr}_{2}+(\mathrm{Zn}, \mathrm{x}) \mathrm{Zr}$, and $\alpha-\mathrm{Zr}$.

Nuclear grade zirconium was also heat treated at $650{ }^{\circ} \mathrm{C}$ for $16 \mathrm{~d}$ and $64 \mathrm{~d}$, and as expected, does not contain a 2 phase layer. Both samples have the $\mathrm{Zn}_{2} \mathrm{Zr}$ phase at the edge followed by the $\mathrm{ZnZr}$ phase. In the $64 \mathrm{~d}$ sample the EDS analysis and micrographs indicate the $\mathrm{ZnZr}_{2}$ phase may be present, but with a thickness less than 1 $\mu \mathrm{m}$. The phase sequence for the nuclear grade zirconium is $\mathrm{Zn}_{2} \mathrm{Zr}, \mathrm{ZnZr}$, and $\alpha-\mathrm{Zr}$. 


\subsubsection{Temperature $670{ }^{\circ} \mathrm{C}$ microstructure/composition profiles /phase analysis}

At $670{ }^{\circ} \mathrm{C}$ the composition profile of the Zircaloy- 4 for $21 \mathrm{~d}$ shows that this sample has the same sequence of phases as the $650^{\circ} \mathrm{C}$ samples. The $\mathrm{Zn}_{2} \mathrm{Zr}$ and $\mathrm{ZnZr}$ intermetallic layers and the 2 phase layer all form parallel to the edge.

\subsubsection{Temperature $700{ }^{\circ} \mathrm{C}$ microstructure/composition profiles /phase analysis}

At $700{ }^{\circ} \mathrm{C}$ the Zircaloy-4 samples at $4 \mathrm{~d}$ and $32 \mathrm{~d}$ show the same phase sequence as the $650{ }^{\circ} \mathrm{C}$ and $670{ }^{\circ} \mathrm{C}$ samples. However, the $\mathrm{Zn}_{2} \mathrm{Zr}$ phase was not detected on the edge of the $10 \mathrm{~d}$ Zircaloy-4 sample.

The nuclear grade zirconium specimen heat treated at $700{ }^{\circ} \mathrm{C}$ for $12 \mathrm{~d}$ does not contain a 2 phase layer and goes directly from the $\mathrm{Zn}_{2} \mathrm{Zr}$ and $\mathrm{ZnZr}$ layers at the surface to the $\alpha-\mathrm{Zr}$. However, the line scan of the $32 \mathrm{~d}$ sample indicates the $\mathrm{ZnZr}_{2}$ phase may be present, but with a thickness less than $1 \mu \mathrm{m}$.

\subsubsection{Temperature $712^{\circ} \mathrm{C}$ microstructure/composition profiles /phase analysis}

Nuclear grade zirconium at $712{ }^{\circ} \mathrm{C}$ for $11.8 \mathrm{~d}$ does not contain a 2 phase layer, but a narrow layer of the $\mathrm{ZnZr}_{2}$ phase is present. It has a different phase sequence then the lower temperature heat treatments. In summary the phase sequence is $\mathrm{Zn}_{2} \mathrm{Zr}, \mathrm{ZnZr}$, $\mathrm{ZnZr}_{2}$, and $\alpha-\mathrm{Zr}$.

\subsubsection{Temperature $725^{\circ} \mathrm{C}$ microstructure/composition profiles /phase analysis}

The results of the $725{ }^{\circ} \mathrm{C}$ heat treatments of Zircaloy- 4 revealed an unexpected zirconium phase with approximately 85 at. \% zirconium in the reported $\alpha-\mathrm{Zr}+\mathrm{ZnZr}$ region of the $\mathrm{Zn}-\mathrm{Zr}$ phase diagram below $750{ }^{\circ} \mathrm{C}$. This 85 at. $\%$ zirconium phase was later found to be a $\beta$ phase and will be discussed in Section 6.3 .

Three Zircaloy-4 samples were heat treated with brass at $725^{\circ} \mathrm{C}$. Two of the samples were TREX heat treated for $2 \mathrm{~d}$ and $11.8 \mathrm{~d}$ and the third sample was tubing heat treated for $39 \mathrm{~d}$. In the $2 \mathrm{~d}$ sample the phase sequence was $\mathrm{Zn}_{2} \mathrm{Zr}$ at the surface followed by $\mathrm{ZnZr}$, the 2 phase layer, the $\beta$ phase and then bulk $\alpha$-Zr. The 2 phase layer is less than 1 $\mu \mathrm{m}$ wide and is barely visible in micrographs of the two d sample. In the $11.8 \mathrm{~d}$ sample the growth of the 2 phase layer varied with location on the sample. In some places the 2 phase layer was absent, in others the precipitate and matrix are both clearly present, and still in other places only a distinct region of the $\mathrm{ZnZr}_{2}$ forms as a non-planar layer between the planar $Z n Z r$ and $\beta$ phase. These three phase sequences are shown in Figure 9, 1) $\mathrm{ZnZr}, \beta$ phase, $\alpha-\mathrm{Zr}$ 2) $\mathrm{ZnZr}, 2$ phase layer, $\beta$ phase, $\alpha-\mathrm{Zr}$ and 3) $\mathrm{ZnZr}, \mathrm{ZnZr}_{2}, \beta$ phase, $\alpha-Z r$. 


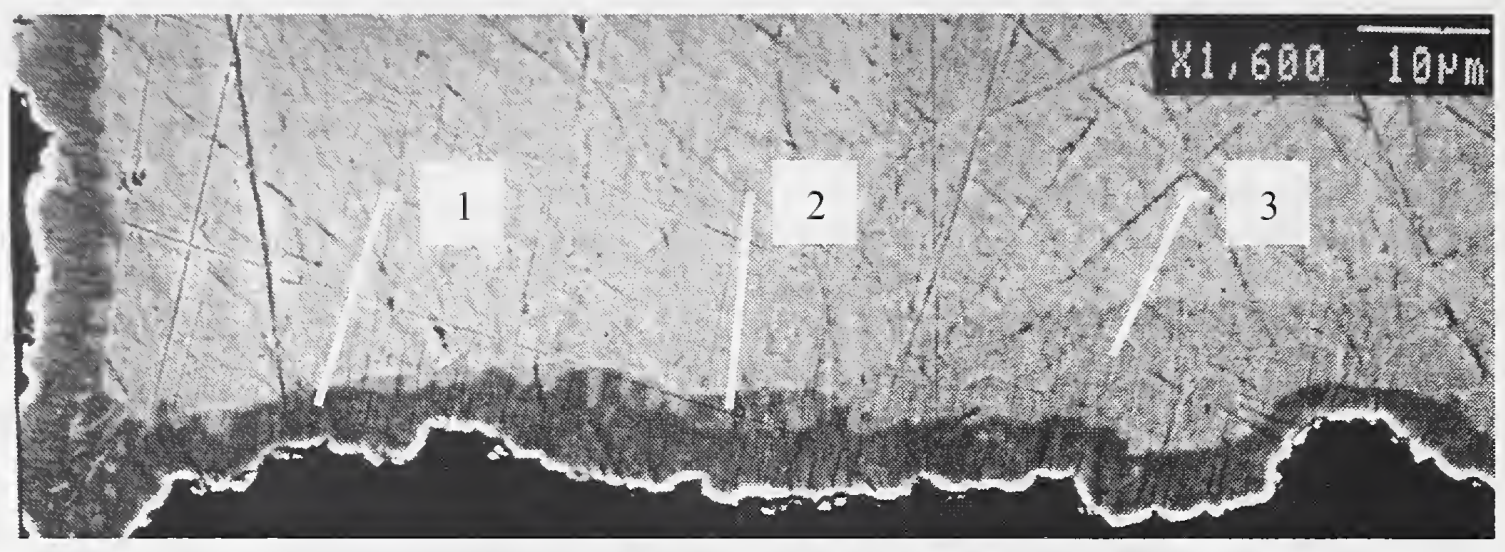

Figure 9. Zircaloy-4 TREX exposed to zinc vapor at $725^{\circ} \mathrm{C}$ for $11.8 \mathrm{~d}$. Three phase sequences are shown 1) $\mathrm{ZnZr}, \beta$ phase, $\alpha-\mathrm{Zr}$ 2) $\mathrm{ZnZr}, 2$ phase layer, $\beta$ phase, $\alpha-\mathrm{Zr}$ and 3) $\mathrm{ZnZr}, \mathrm{ZnZr}_{2}, \beta$ phase, $\alpha-\mathrm{Zr}$.

The $39 \mathrm{~d} Z$ ircaloy-4 tubing sample does not contain the 2 phase layer or the $\mathrm{ZnZr}_{2}$ and has a phase sequence of $\mathrm{ZnZr}, \beta$ phase, $\alpha-\mathrm{Zr}$.

Nuclear grade zirconium was heat treated at $725^{\circ} \mathrm{C}$ for $12 \mathrm{~d}$ and $64 \mathrm{~d}$ and as expected did not contain the 2 phase layer. Both of these samples had similar phase sequences with $\mathrm{Zn}_{2} \mathrm{Zr}, \mathrm{ZnZr}, \beta$ phase and $\alpha-\mathrm{Zr}$, but the $64 \mathrm{~d}$ also contained the $\mathrm{ZnZr}_{2}$ phase.

\subsubsection{Temperature $775^{\circ} \mathrm{C}$ microstructure / composition profiles / phase analysis}

At $775^{\circ} \mathrm{C}$ for nuclear grade zirconium, the $\mathrm{ZnZr}$ phase forms at the edge but has a nonplanar irregular shape. The thickness of this phase varies from approximately $10 \mu \mathrm{m}$ to $90 \mu \mathrm{m}$. In summary the phase sequence is $\mathrm{ZnZr}, \beta$ phase, $\alpha-\mathrm{Zr}$.

\subsubsection{Temperature $800^{\circ} \mathrm{C}$ microstructure/composition profiles /phase analysis}

At $800{ }^{\circ} \mathrm{C}$ the nuclear grade zirconium has the identical phase sequence as the $775^{\circ} \mathrm{C}$ sample. The non-planar growth of the $\mathrm{ZnZr}$ phase varied in thickness from $40 \mu \mathrm{m}$ to $300 \mu \mathrm{m}$.

\subsection{Estimate of the Growth Constant}

The Zircaloy-4 samples were heat treated at $650^{\circ} \mathrm{C}, 700^{\circ} \mathrm{C}$, and $725^{\circ} \mathrm{C}$ at three different times and the nuclear grade zirconium samples were heat treated at $650{ }^{\circ} \mathrm{C}$, 
$700{ }^{\circ} \mathrm{C}$, and $725^{\circ} \mathrm{C}$ at two different times. The depths of the total reaction zone are reported from the surface to bulk $\alpha-\mathrm{Zr}$, see Tables 9 and 10 .

Table 9

Reaction Zone Thickness and Growth Constant for Zircaloy-4

\begin{tabular}{|c|c|c|c|}
\hline $\begin{array}{c}\text { Zircaloy-4 } \\
\left({ }^{\circ} \mathrm{C}\right)\end{array}$ & $\begin{array}{c}\text { Time } \\
(\mathrm{d})\end{array}$ & $\begin{array}{c}\text { Total Reaction Zone } \\
\text { Thickness }(\mu \mathrm{m}) \\
\pm 0.5 \mu \mathrm{m}\end{array}$ & $\begin{array}{c}\text { Estimate of Growth } \\
\text { Constant } \mathrm{K} \\
\left(\mathrm{cm}^{2} / \mathrm{sec}\right)\end{array}$ \\
\hline 650 & 16 & 5.7 & \\
\hline & 64 & 8.6 & $1.3305 \times 10^{-13}$ \\
\hline & 126 & 13.5 & \\
\hline 700 & 4 & 5.2 & $3.2291 \times 10^{-13}$ \\
\hline & 10 & 6.3 & \\
\hline & 32 & 8.6 & $7.1038 \times 10^{-12}$ \\
\hline 725 & 2 & 10.0 & \\
\hline & 11.8 & 27.5 & \\
\hline & 39 & 49.0 & \\
\hline
\end{tabular}

Table 10

Reaction Zone Thickness and Growth Constant for Nuclear Grade Zirconium

\begin{tabular}{|c|c|c|c|}
\hline NGZR & & & \\
\hline $\begin{array}{c}\text { Temperature } \\
\left({ }^{\circ} \mathrm{C}\right)\end{array}$ & $\begin{array}{c}\text { Time } \\
(\mathrm{d})\end{array}$ & $\begin{array}{c}\text { Total Reaction Zone } \\
\text { Thickness }(\mu \mathrm{m}) \\
\pm 0.5 \mu \mathrm{m}\end{array}$ & $\begin{array}{c}\text { Estimate of Growth } \\
\text { Constant K } \\
\left(\mathrm{cm}^{2} / \mathrm{sec}\right)\end{array}$ \\
\hline 650 & 16 & 3.0 & $7.4076 \times 10^{-14}$ \\
\hline & 64 & 6.5 & $1.2893 \times 10^{-13}$ \\
\hline 700 & 12 & 3.2 & $6.6484 \times 10^{-13}$ \\
\hline & 32 & 6.3 & 51.0 \\
\hline 725 & 12 & 205.0 & \\
\hline & 64 & &
\end{tabular}

The diffusion distance can be expressed by equation 13

$$
x=\sqrt{K t}
$$

Where $\mathrm{x}$ is the total reaction zone thickness, $K$ is the growth constant of the reaction zone, and $t$ is the diffusion time. This equation can also be expressed as equation 14

$$
\frac{x}{\sqrt{t}}=\sqrt{K} \quad \text {. }
$$


As shown in Figure 10, three Zircaloy-4 samples heat treated at $650{ }^{\circ} \mathrm{C}$ for $16 \mathrm{~d}, 64 \mathrm{~d}$ and $126 \mathrm{~d}$ (with total reaction thicknesses of $5.14 \mu \mathrm{m}, 8.57 \mu \mathrm{m}$, and $13.5 \mu \mathrm{m}$, respectively) are plotted using equation 14 . The linearity of the data point fit represents parabolic growth behavior. The slope of this graph which is the $\sqrt{K}$ was found using the slope intercept method. And the growth constant $K$ is obtained by squaring the value of the slope.

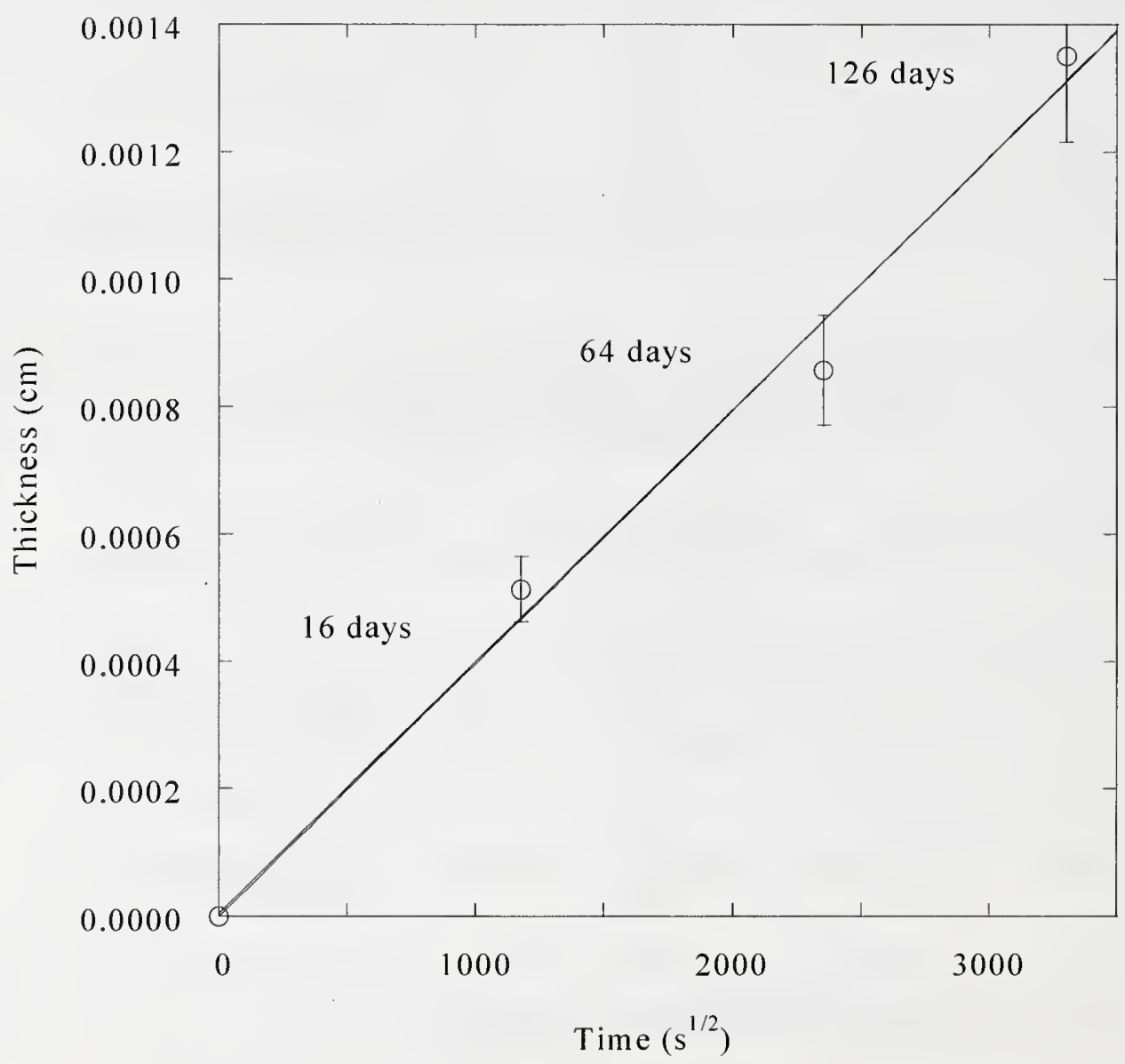

Figure 10. Total reaction zone thickness of Zircaloy- 4 heat treated at $650{ }^{\circ} \mathrm{C}$. (The reaction zone thickness measurements have a $\pm 10 \%$ absolute bounds uncertainty). 
The growth constant value, $K$ for all of the Zircaloy- 4 and the nuclear grade zirconium samples heat treated at $650^{\circ} \mathrm{C}, 700{ }^{\circ} \mathrm{C}$, and $725^{\circ} \mathrm{C}$ at various times was found using the same method. However, at $670{ }^{\circ} \mathrm{C}, 712^{\circ} \mathrm{C}, 775^{\circ} \mathrm{C}$ and $800{ }^{\circ} \mathrm{C}$ only one sample was heat treated at these temperatures and the parabolic growth constant $\mathrm{K}$ was obtained simply by dividing the measured penetration distance squared, divided by the diffusion time.

From the growth constant $K$ found at the various individual temperatures, the activation energy, $\mathrm{Q}$ and growth constant coefficient $\mathrm{K}_{0}$ can then be calculated using the expression in equation 15

$$
K=K_{0} \exp \left(\frac{-Q}{R T}\right) .
$$

By taking the $\log$ of both sides of equation 15 an Arrhenius plot of $\ln K$ as a function of inverse temperature in Kelvins, gives an estimate the activation energy $Q$ from the slope and the growth constant coefficient $\mathrm{K}_{0}$ from the $\mathrm{y}$ intercept. The slope of the line is equal to $\mathrm{Q} / \mathrm{R}$, where $\mathrm{R}$ is the gas constant equal to $8.314 \mathrm{~J} / \mathrm{mole} \mathrm{K}$. In Figure 11, from the Arrhenius plot of Zircaloy- 4 below $725^{\circ} \mathrm{C}$ an activation energy $\mathrm{Q}$ of 128.56 $\mathrm{kJ} /$ mole was calculated and the y intercept gave a growth constant coefficient $K_{0}$ equal to $3.741 \times 10^{-6} \mathrm{~cm}^{2} / \mathrm{s}$. The Arrhenius plot of nuclear grade zirconium exposed to zinc vapor at $650^{\circ} \mathrm{C}, 700^{\circ} \mathrm{C}$ and $712{ }^{\circ} \mathrm{C}$, shown in Figure 12, the activation energy 126.65 $\mathrm{kJ} /$ mole was measured and the y intercept gave a growth constant coefficient $K_{0}$ equal to $1.04 \times 10^{-6} \mathrm{~cm}^{2} / \mathrm{s}$. In Figure 13, the Arrhenius plot of the nuclear grade zirconium at $725^{\circ} \mathrm{C}, 775{ }^{\circ} \mathrm{C}$ and $800{ }^{\circ} \mathrm{C}$ containing the $\beta$ phase gave an activation energy of 554.69 $\mathrm{kJ} /$ mole and a growth constant coefficient $K_{0}$ equal to $2.03 \times 10^{+14} \mathrm{~cm}^{2} / \mathrm{s}$. 


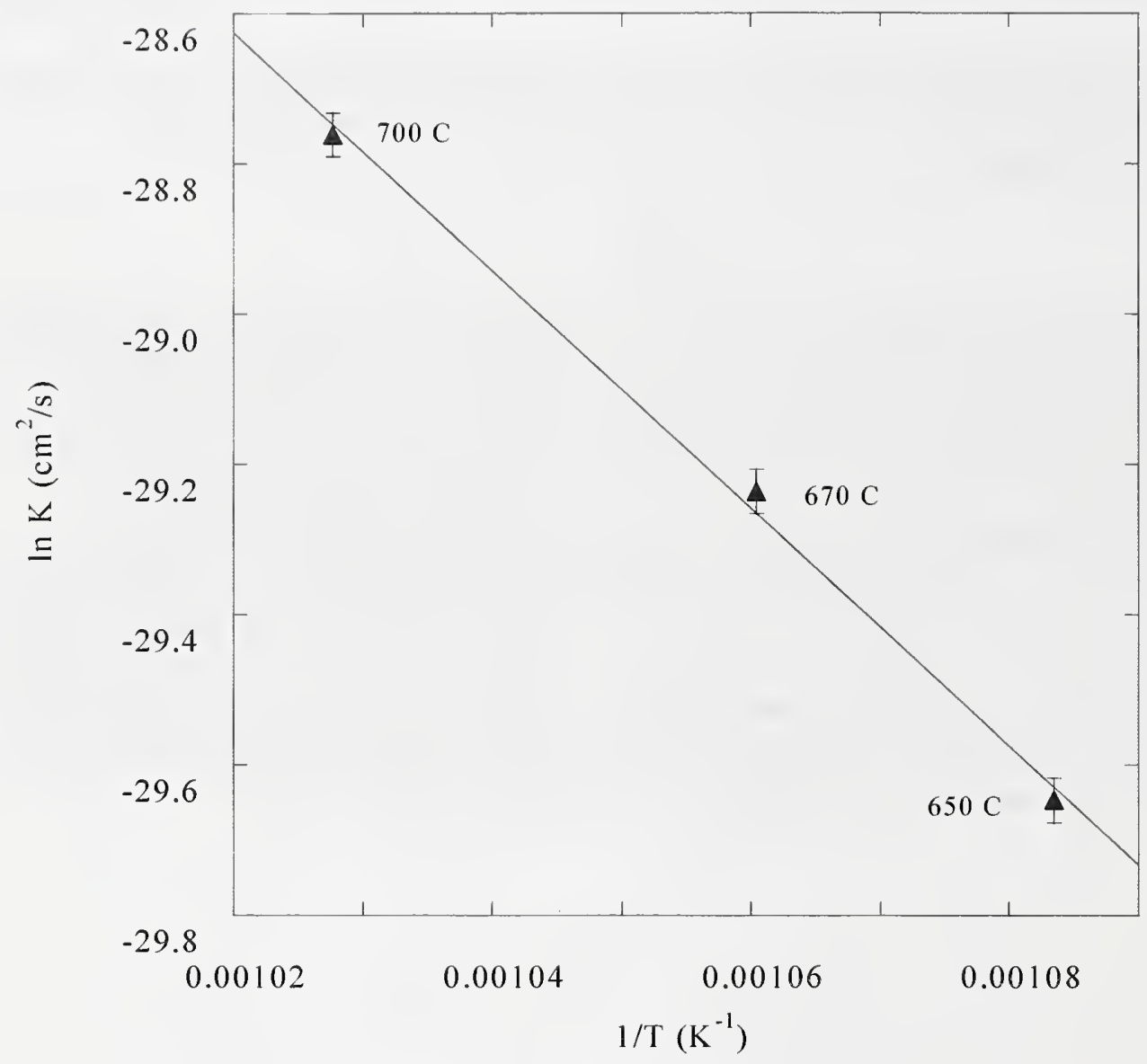

Figure 11. Arrhenius plot of the growth constant $K$ for Zircaloy-4 exposed to zinc vapor at $650{ }^{\circ} \mathrm{C}, 670{ }^{\circ} \mathrm{C}$ and $700{ }^{\circ} \mathrm{C}$. (The data reflects a $\pm 0.1 \%$ absolute bounds error of $\ln K$ value). The measured activation energy is $128.56 \mathrm{~kJ} / \mathrm{mole}$. 


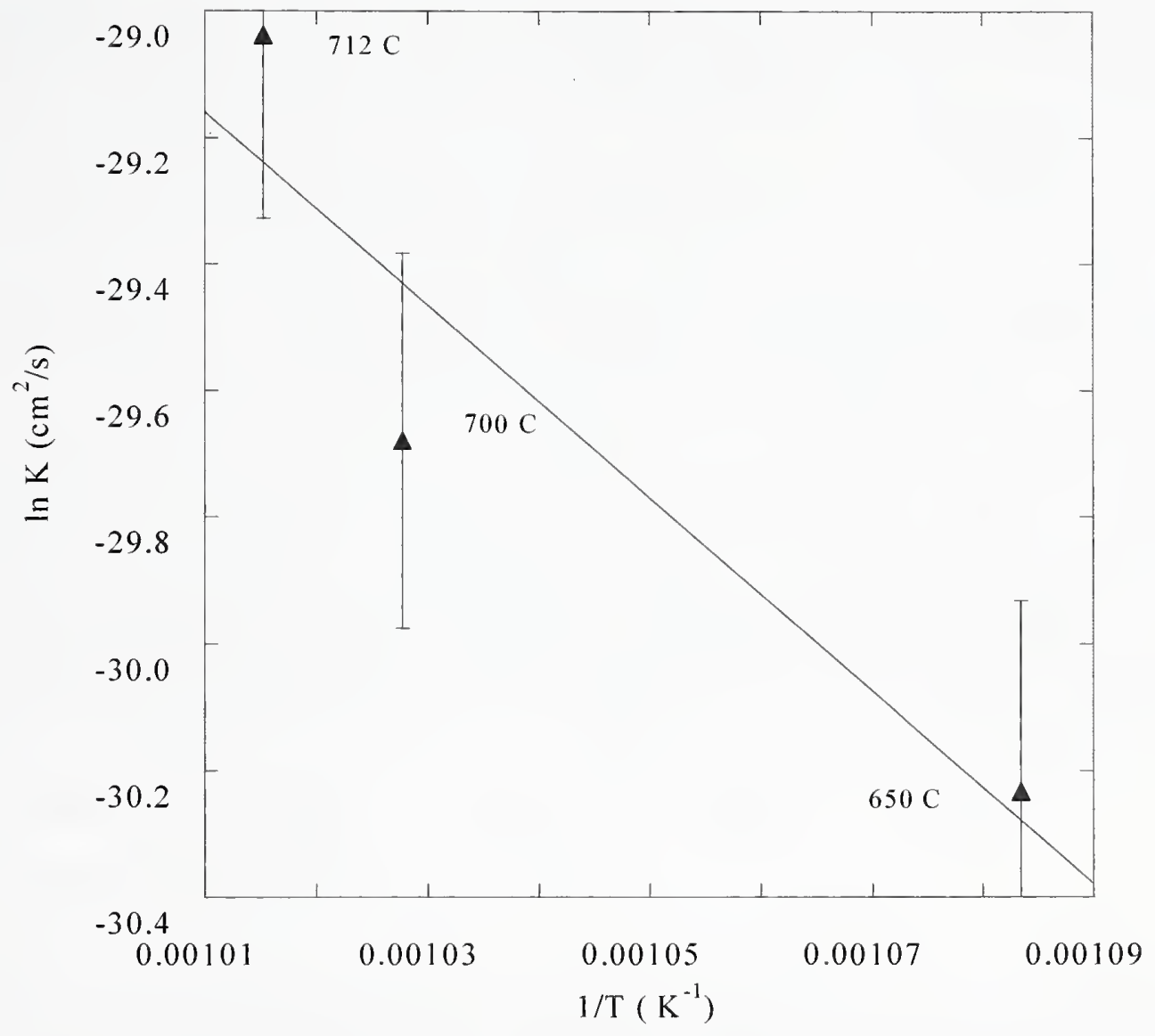

Figure 12. Arrhenius plot of the growth constant $K$ for nuclear grade zirconium exposed to zinc vapor at $650{ }^{\circ} \mathrm{C}, 700{ }^{\circ} \mathrm{C}$ and $712{ }^{\circ} \mathrm{C}$. (The data reflects a $\pm 1 \%$ absolute bounds error of $\ln K$ value). The measured activation energy is 126.65 $\mathrm{kJ} / \mathrm{mole}$. 


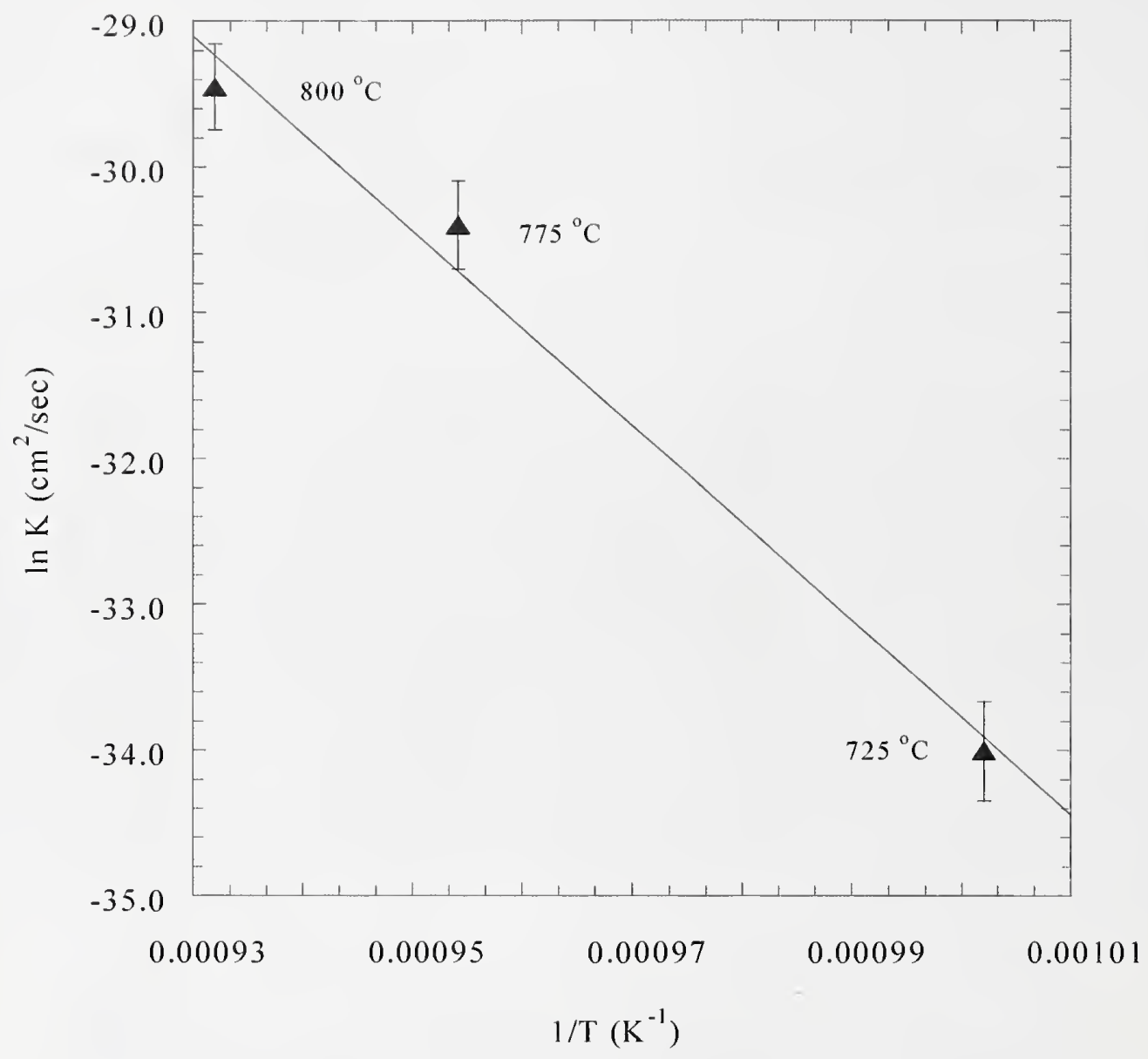

Figure 13. Arrhenius plot of the growth constant $K$ for nuclear grade zirconium exposed to zinc vapor at $725^{\circ} \mathrm{C}, 775^{\circ} \mathrm{C}$ and $800{ }^{\circ} \mathrm{C}$. (The data reflects a $\pm 1 \%$ absolute bounds error of $\ln K$ value). The measured activation energy is 554.69 $\mathrm{kJ} / \mathrm{mole}$. 


\subsection{Correlation of observed phases to the phase diagram}

The observed intermetallic phase growth of the zinc vapor reaction with the Zircaloy-4 and nuclear grade zirconium agrees with the phase sequence of the binary Zn-Zr phase diagram. $\mathrm{Zn}_{2} \mathrm{Zr}$, the 33 at. \% $\mathrm{Zr}$ phase is the first intermetallic to form on the surface of most of the samples. The $\mathrm{ZnZr} 50$ at $\%$ phase is present in all samples. The metastable $\mathrm{Zn}_{2} \mathrm{Zr}_{3}, 60$ at. \% phase was not observed in any of the samples. The $\mathrm{ZnZr}_{2}, 67$ at. \% $\mathrm{Zr}$, was only found in the nuclear grade zirconium heat treated at $712{ }^{\circ} \mathrm{C}$ for $11.8 \mathrm{~d}$ and at $725^{\circ} \mathrm{C}$ for $64 \mathrm{~d}$ and in the Zircaloy- 4 at $725^{\circ} \mathrm{C}$ for $12 \mathrm{~d}$. The two phase $(\mathrm{Zn}, \mathrm{x}) \mathrm{Zr}_{2}$ and $(\mathrm{Zn}, \mathrm{x}) \mathrm{Zr}$ region is only present in the multicomponent Zircaloy -4 samples. The precipitates in this two phase region are $\mathrm{Sn}$ and Fe rich surrounded by a $\mathrm{ZnZr}$ matrix rich in Fe. The dark matrix ( $\mathrm{Zn}, \mathrm{x}$ ) $\mathrm{Zr}$ phase composition is approximately 50 at. \% $\mathrm{Zr}$, 38.7 at. $\% \mathrm{Zn}, 10$ at. $\% \mathrm{Fe}, 0.6$ at. $\% \mathrm{Sn}$ and 0.7 at. \% Cr. The precipitate phase is ( $\mathrm{Zn}$, x) $\mathrm{Zr}_{2}$ with 64 at. $\% \mathrm{Zr}, 22.6$ at. \%, 10 at. \% Fe, 3.0 at. \% $\mathrm{Sn}$ and 0.4 at. \% Cr. Also the growth of the 2 phase region can vary with location on the sample as shown in figure 9 in section 5.3.5. Three different possibilities exist; 1) the absence of $\mathrm{ZnZr}_{2}$ in any form 2) the two phase region with a light precipitate phase composed of $(\mathrm{Zn}, \mathrm{x}) \mathrm{Zr}_{2}$ and the dark matrix phase of $(\mathrm{Zn}, \mathrm{x}) \mathrm{Zr}$, or 3 ) only a distinct region of $\mathrm{ZnZr}_{2}$ is present. In the binary diffusion couple of nuclear grade zirconium exposed to zinc vapor this two phase region does not form in accordance with the Gibbs phase rule, as explained in section 3.2 .

\subsubsection{Phases below $725^{\circ} \mathrm{C}$}

All Zircaloy-4 samples heat treated at $650^{\circ} \mathrm{C}, 670^{\circ} \mathrm{C}$ and $700^{\circ} \mathrm{C}$ have the 2 phase $(\mathrm{Zn}, \mathrm{x}) \mathrm{Zr}_{2}+(\mathrm{Zn}, \mathrm{x}) \mathrm{Zr}$ region, and except for the $10 \mathrm{~d} 700{ }^{\circ} \mathrm{C}$ sample, they all have the $\mathrm{Zn}_{2} \mathrm{Zr}$ phase on the surface. All the nuclear grade samples heat treated at $650{ }^{\circ} \mathrm{C}, 700$ ${ }^{\circ} \mathrm{C}$ and $712{ }^{\circ} \mathrm{C}$ have the same phase sequence of $\mathrm{Zn}_{2} \mathrm{Zr}, \mathrm{ZnZr}$ and $\alpha-\mathrm{Zr}$, except the 712 ${ }^{\circ} \mathrm{C}$ sample which also contains the $\mathrm{ZnZr}_{2}$ phase.

\subsubsection{Phases Present above $725^{\circ} \mathrm{C}$}

At $725^{\circ} \mathrm{C}$ and above the $\beta$ phase is present in all the Zircaloy- 4 and nuclear grade zirconium samples. The Zircaloy-4 TREX samples heat treated at $725^{\circ} \mathrm{C}$ for $2 \mathrm{~d}$, and $11.8 \mathrm{~d}$ contain either the $\mathrm{ZnZr}_{2}$ phase or the 2 phase region, (refer to Figure 9 In section 5.3.5), but these phases are not observed in the Zircaloy-4 tubing sample heat treated for $39 \mathrm{~d}$. In the nuclear grade zirconium samples only the $64 \mathrm{~d} 725^{\circ} \mathrm{C}$ nuclear grade zirconium sample has the $\mathrm{ZnZr}_{2}$ phase. All of the other nuclear grade zirconium samples heat treated at $725^{\circ} \mathrm{C}, 775^{\circ} \mathrm{C}$, and $800^{\circ} \mathrm{C}$ for $12 \mathrm{~d}$ do not contain the $\mathrm{ZnZr}_{2}$ phase. 


\subsection{Growth Rate and Mechanism}

The sequence of the reaction layer growth of the nuclear grade zirconium samples at $650{ }^{\circ} \mathrm{C}, 700{ }^{\circ} \mathrm{C}, 712{ }^{\circ} \mathrm{C}, 725^{\circ} \mathrm{C}, 775^{\circ} \mathrm{C}$, and $800^{\circ} \mathrm{C}$ are shown in Figure 14. The black edge along the extreme left side of the micrographs is not part of the sample. The sample edge is just to the right of the black background. The morphology of the surface phases changes from planar layer growth at temperatures $650^{\circ} \mathrm{C}, 700{ }^{\circ} \mathrm{C}$ and $712{ }^{\circ} \mathrm{C}$ to non-planar layer growth at temperatures of $725^{\circ} \mathrm{C}$ and above. This may be due to the presence of the $\beta$ phase in the samples at $725^{\circ} \mathrm{C}, 775^{\circ} \mathrm{C}$ and $800^{\circ} \mathrm{C}$. 


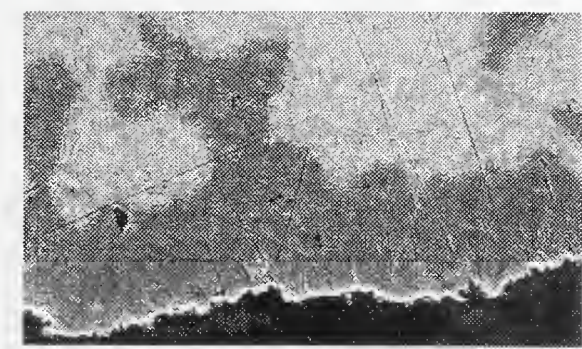

$\begin{array}{ll}0 \\ 0 \\ \infty & \pi\end{array}$

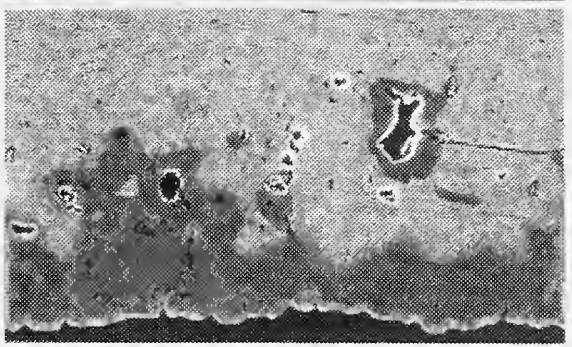

$0 \sum_{0}^{\infty} \quad 00$

ก च

$N$ 등

ลี.

奂带

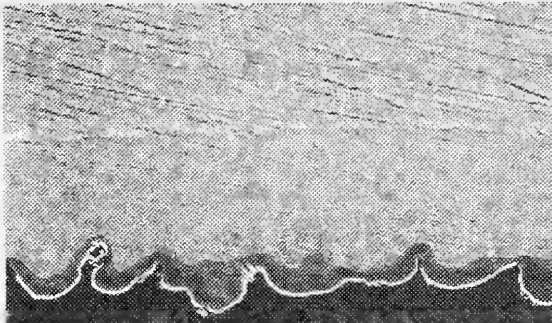

$0 \sum_{0}^{n}$
$n$

잉

ఫृ.

○

这

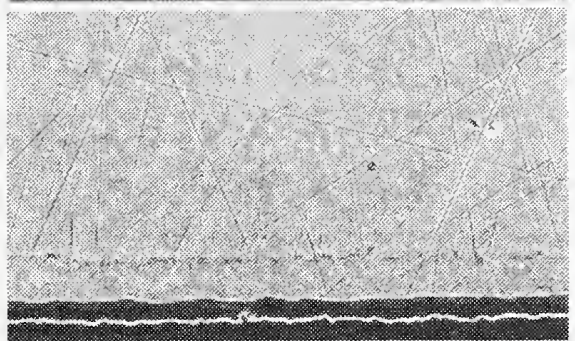

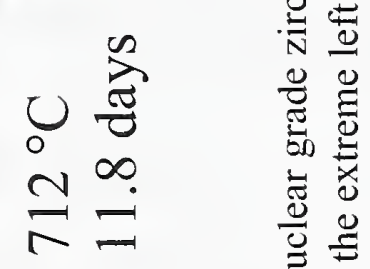

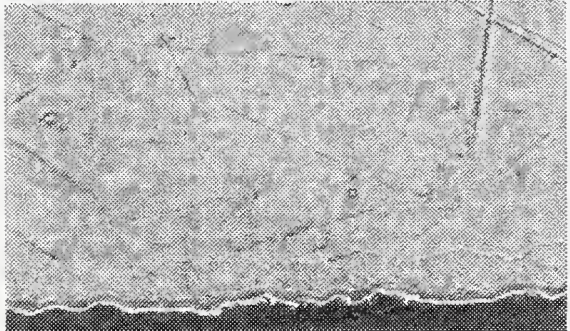

$\int_{0}^{0} \frac{\pi}{\pi}$

$\Xi$
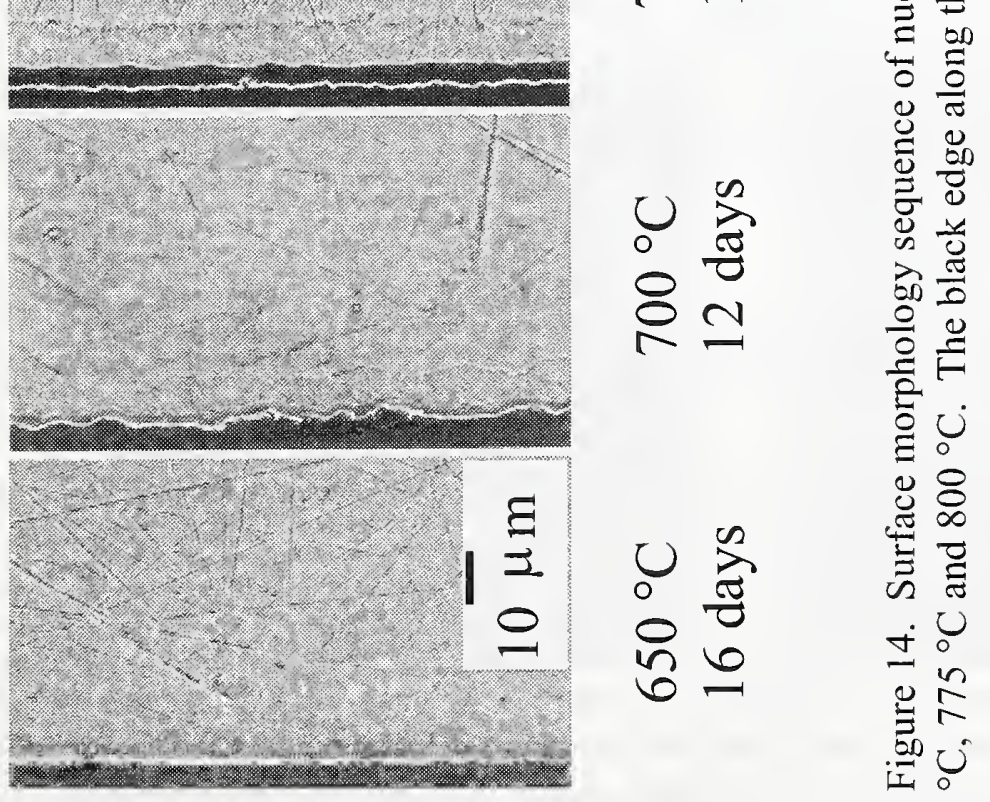
Micrographs of the reaction layer of the Zircaloy- 4 samples heat treated at $650{ }^{\circ} \mathrm{C}, 670$ ${ }^{\circ} \mathrm{C}, 700{ }^{\circ} \mathrm{C}$ and $725^{\circ} \mathrm{C}$ are shown in Figure 15 .

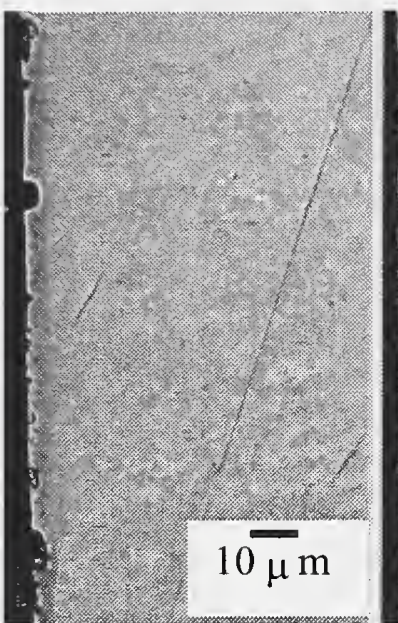

$650^{\circ} \mathrm{C}$

16 days

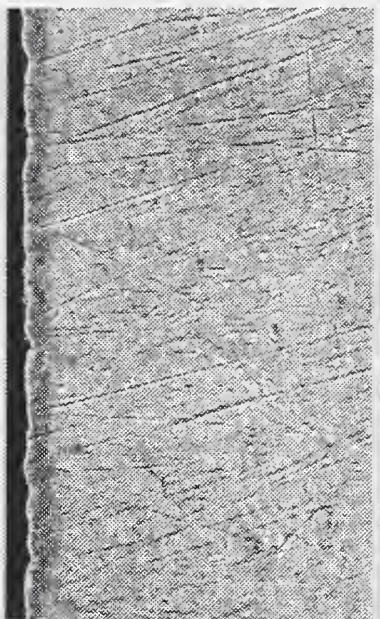

$670{ }^{\circ} \mathrm{C}$

21 days

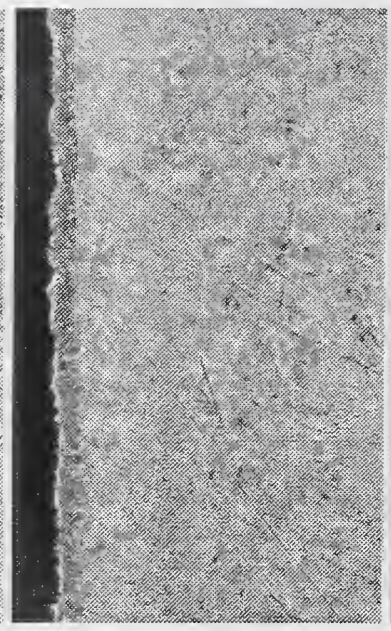

$700{ }^{\circ} \mathrm{C}$

10 days

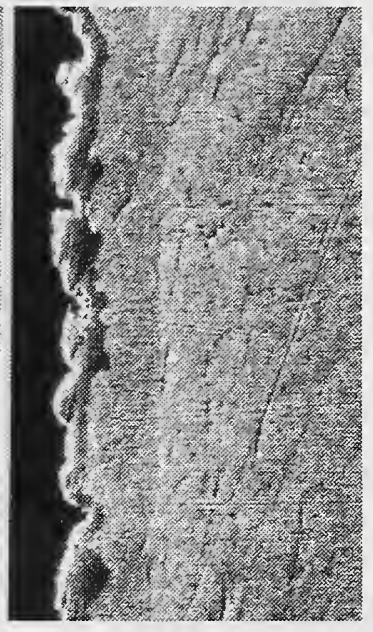

$725^{\circ} \mathrm{C}$

11.8 days

Figure 15. Surface morphology sequence of Zircaloy-4 exposed to zinc vapor at 650 ${ }^{\circ} \mathrm{C}, 670{ }^{\circ} \mathrm{C}, 700{ }^{\circ} \mathrm{C}$ and $725^{\circ} \mathrm{C}$. The black edge along the extreme left side of the micrographs is not part of the sample.

The $725^{\circ} \mathrm{C}$ Zircaloy-4 sample begins to exhibit this wavy surface phase morphology but it is not as pronounced as the nuclear grade zirconium sample at the same temperature. The phase sequence of the $725^{\circ} \mathrm{C}$ sample changes. The dark edge phase is $\mathrm{ZnZr}$ and the next layer is the $\beta$ phase and then the bulk $\alpha-\mathrm{Zr}$. Again one explanation for this change from planar layers at lower temperatures to non-planar may be related to the presence of the $\beta$ phase at $725^{\circ} \mathrm{C}$.

\subsection{TEM of Nuclear Grade Zirconium at $800{ }^{\circ} \mathrm{C}$}

At $725^{\circ} \mathrm{C}$, below the reported eutectoid temperature of $750^{\circ} \mathrm{C}$, a $\beta$ phase containing approximately 85 at. \% zirconium was observed. This same $\beta$ phase was found in nuclear grade zirconium samples heat treated at $775^{\circ} \mathrm{C}$ and $800{ }^{\circ} \mathrm{C}$ for $12 \mathrm{~d}$. The 800 ${ }^{\circ} \mathrm{C}$ sample had the largest $\beta$ phase thickness of approximately $450 \mu \mathrm{m}$, so this sample was chosen for transmission electron microscope (TEM) analysis. First the sample was ground with 600 grit $\mathrm{SiC}$ paper from both sides to remove the $\mathrm{ZnZr}$ and $\alpha-\mathrm{Zr}$ from the surfaces. Then the sample was jet-electropolished with $5 \%$ perchloric and $95 \%$ ethanol with $35 \mathrm{~V}$ at a temperature of minus $5{ }^{\circ} \mathrm{C}$. TEM analysis confirmed a martensitically transformed bcc structure. Figure 16 a) shows SEM backscattered image of the 
martensitic structure on the electropolished surface and b) shows the TEM bright field image of the martensite with different orientations of plate-like variants of $\alpha-\mathrm{Zr}$. None of the samples below $725^{\circ} \mathrm{C}$ contain the $\beta$ phase, see Table 6 . Thus at the temperature of the diffusion experiment the phase was bec.

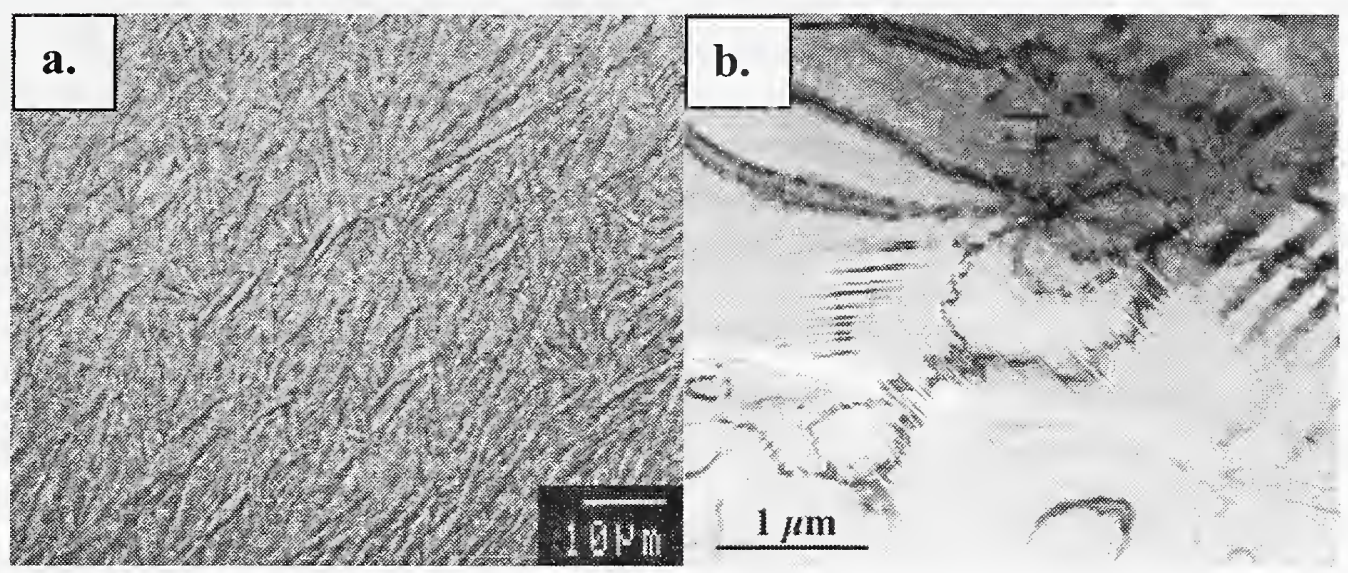

Figure 16. Nuclear grade zirconium heat treated with zinc vapor at $800{ }^{\circ} \mathrm{C}$ a) SEM backscattered image of the martensitic structure, b) TEM bright field image of the martensite with different orientations of the plate-like variants of $\alpha-Z r$.

In Figure 17 two selected TEM diffraction patterns a and $b$ are from the large area of multiple variants from Figure $16 \mathrm{~b}$ showing in a) pseudo 3 -fold symmetry with outlines of hep reciprocal lattices drawn over the pattern and in b) pseudo 4-fold symmetry clearly corresponding to the parent bcc cubic phase.

a.

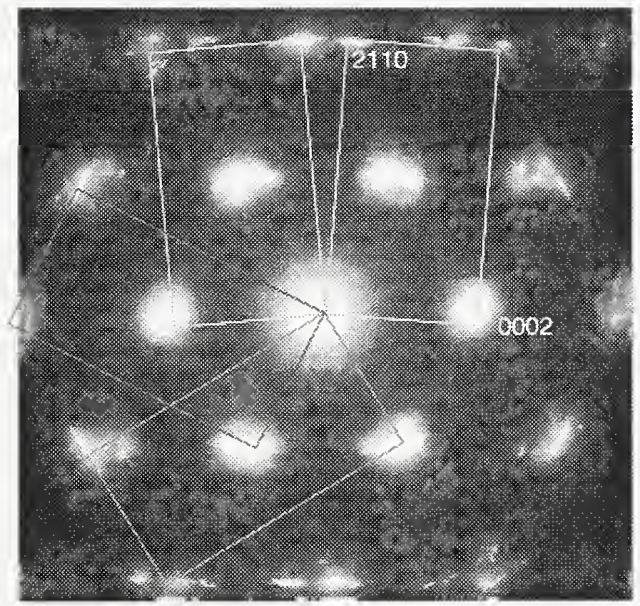

b.

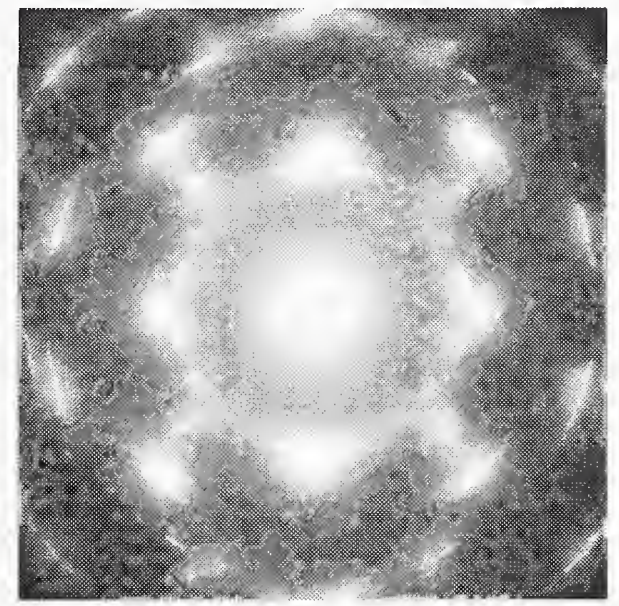

Figure 17. TEM diffraction patterns $\mathrm{a}$ and $\mathrm{b}$ are from the large area of multiple variants in Figure $16 \mathrm{~b}$ of nuclear grade zirconium exposed to zinc vapor at $800{ }^{\circ} \mathrm{C}$ for $12 \mathrm{~d}$ a) 3-fold symmetry and in b) 4-fold symmetry. 


\subsection{Correction of Eutectoid Temperature}

Compositional line scans of nuclear grade zirconium exposed to zinc vapor at $712{ }^{\circ} \mathrm{C}$, $725^{\circ} \mathrm{C}, 775^{\circ} \mathrm{C}$ and $800^{\circ} \mathrm{C}$ are shown in Appendix A, Figures A13, A15, A20 and A21, respectively. The $\beta$ phase was not present at $712{ }^{\circ} \mathrm{C}$, but was present at $725^{\circ} \mathrm{C}, 775{ }^{\circ} \mathrm{C}$ and $800{ }^{\circ} \mathrm{C}$. The $\beta$ phase, represented by a line with constant slope, ranges from 85 to 88 at. $\% \mathrm{Zr}$ at $725^{\circ} \mathrm{C}, 83.5$ to 93 at. $\% \mathrm{Zr}$ at $775^{\circ} \mathrm{C}$, and 82 to 95 at. $\% \mathrm{Zr}$ at $800^{\circ} \mathrm{C}$. The endpoints from each these sloping lines determine the experimentally obtained phase boundaries of the left and right sides of the $\beta$ region above the eutectoid temperature in the $\mathrm{Zn}-\mathrm{Zr}$ phase diagram. Figure 18 shows these experimental data points plotted with the currently reported phase diagram in the region between 70 at.\% $\mathrm{Zr}$ to 100 at. $\% \mathrm{Zr}$ [6]. The experimental results predict the eutectoid reaction temperature should be between $712^{\circ} \mathrm{C}$ and $725^{\circ} \mathrm{C}$, so the temperature $718{ }^{\circ} \mathrm{C}$ was chosen as an estimate. 


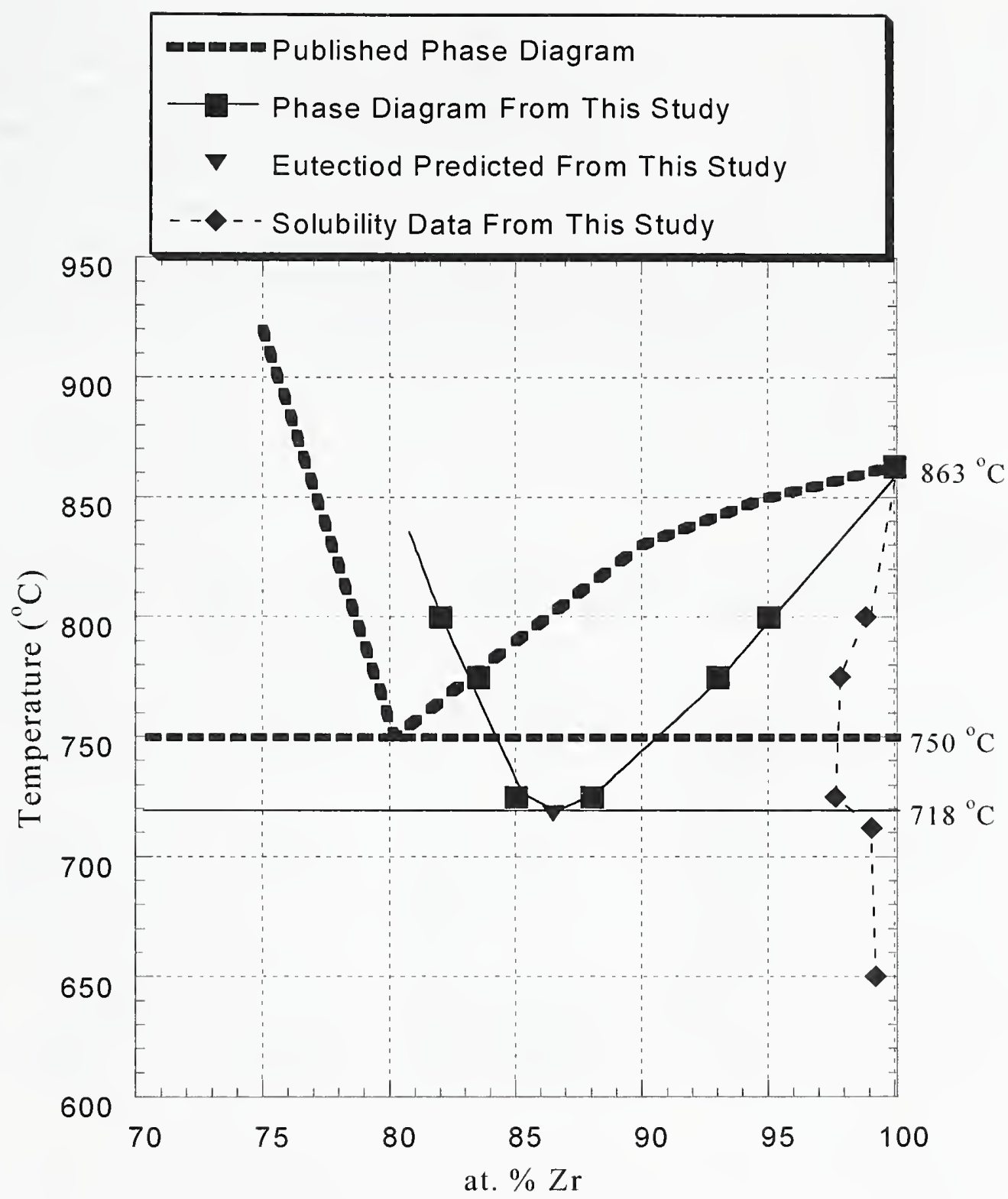

Figure 18. Experimental data from this study is plotted with the currently published phase diagram. The experimental eutectoid reaction temperature (uncertainty is discussed in the text on page 56) is $718{ }^{\circ} \mathrm{C}$ at 86.5 at. $\% \mathrm{Zr}$ and the experimental solubility varies from 0.76 at. $\% \mathrm{Zn}$ at $650{ }^{\circ} \mathrm{C}$ to 1.16 at. $\% \mathrm{Zn}$ at $800{ }^{\circ} \mathrm{C}$. 


\subsection{Solubility Estimate}

Investigation of the nuclear grade zirconium exposed to zinc vapor revealed a solubility of zinc into zirconium. The compositional line scan data of the nuclear grade zirconium samples was acquired until the amount of zinc in the zirconium reached zero and remained zero for approximately $5 \mu \mathrm{m}$. The total depth of zinc penetration into the nuclear grade zirconium is reported in Table 11. The reported uncertainties in Table 11 are absolute bounds errors. The solubility limits were determined by extrapolating the measured values to the interface position. This data is shown in Table 11 and plotted in Figure 18, in the previous section.

Table 11 Solubility Data of Zinc into Nuclear Grade Alpha Zirconium

\begin{tabular}{|c|c|c|c|c|}
\hline $\begin{array}{c}\text { NGZR } \\
\begin{array}{c}\text { Temperature } \\
\left({ }^{\circ} \mathrm{C}\right)\end{array}\end{array}$ & $\begin{array}{c}\text { Time } \\
(\mathrm{d})\end{array}$ & $\begin{array}{c}\text { Total Reaction } \\
\text { Zone Thickness } \\
(\mu \mathrm{m}) \\
\pm 0.5 \mu \mathrm{m}\end{array}$ & $\begin{array}{c}\text { Penetration Depth } \\
\text { of Zinc into the } \\
\text { Alpha Zirconium } \\
(\mu \mathrm{m})\end{array}$ & $\begin{array}{c}\text { Solubility of } \\
\mathrm{Zn} \text { in } \alpha-\mathrm{Zr} \\
(\text { at. \% Zn }) \\
\pm 0.3 \mathrm{at} \%\end{array}$ \\
\hline 650 & 16 & 3.0 & 18.0 & 0.76 \\
\hline & 64 & 6.0 & 34.0 & $\mathrm{NM}$ \\
\hline 700 & 12 & 3.2 & $\approx 30.0$ & $\mathrm{NM}$ \\
\hline & 32 & 6.3 & $\approx 70.0$ & $\mathrm{NM}$ \\
\hline 712 & 11.8 & 3.5 & 35.0 & 0.92 \\
\hline 725 & 11.8 & 51.0 & 82.0 & 2.4 \\
\hline & 64 & 205.0 & 265.0 & $\mathrm{NM}$ \\
\hline 775 & 12 & 287.0 & $\approx 300.0$ & 2.2 \\
\hline & & & & \\
\hline 800 & 12 & 450.0 & 465.0 & 1.2 \\
\hline
\end{tabular}

$\mathrm{NM}=$ NOT MEASURED

\section{6 $\mathrm{ZnZr}_{2}$ Phase}

The $\mathrm{ZnZr}_{2}$ phase was only observed between the temperatures of $712{ }^{\circ} \mathrm{C}$ and $725{ }^{\circ} \mathrm{C}$. Diffusion couples at $775{ }^{\circ} \mathrm{C}$ and $800{ }^{\circ} \mathrm{C}$ did not contain this phase, and in diffusion couples below $712{ }^{\circ} \mathrm{C}$ this phase was not present. Assuming no nucleation barriers this would suggest a phase diagram of the type shown in Figure 19. A peritectoid reaction of $\beta+\mathrm{ZnZr} \rightarrow \mathrm{ZnZr}_{2}$ and a eutectoid reaction of $\mathrm{ZnZr}_{2} \rightarrow \mathrm{ZnZr}+\alpha-\mathrm{Zr}$ would lie somewhere between $712{ }^{\circ} \mathrm{C}$ and $725^{\circ} \mathrm{C}$. However, this temperature range could be larger, possibly from just above $700{ }^{\circ} \mathrm{C}$ to just below $775^{\circ} \mathrm{C}$. Another interpretation is 
that the $\mathrm{ZnZr}_{2}$ fails to nucleate in the low temperature couples and that the $\mathrm{ZnZr}_{2}$ phase does exist at much lower temperatures. Further work needs to be done to confirm the exact temperature range over which the $\mathrm{ZnZr}_{2}$ phase exists.

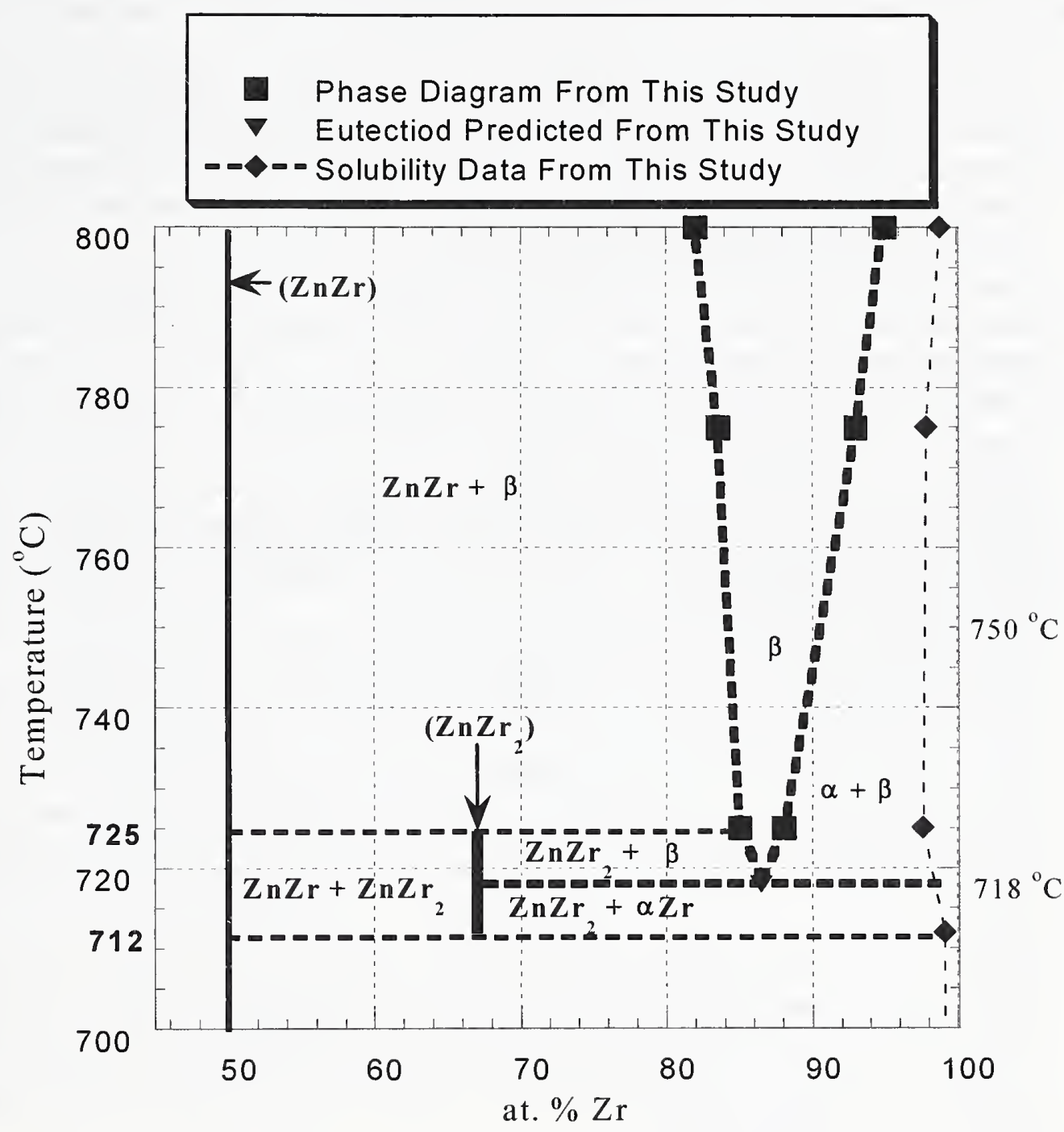

Figure 19. Experimental $\mathrm{Zn}-\mathrm{Zr}$ phase diagram from this study. $718^{\circ} \mathrm{C}$ is the estimated eutectoid temperature (uncertainty is discussed in the text on page 56). 
Zircaloy-4 and nuclear grade zirconium were exposed to zinc vapor in the temperature range of $650^{\circ} \mathrm{C}$ to $800^{\circ} \mathrm{C}$. The spatial sequence of intermetallic phases from the surface into the interior and the total depth of zinc penetration were measured.

- The $\mathrm{Zn}_{2} \mathrm{Zr}$ intermetallic is the surface phase to form in these diffusion experiments with $\alpha$-brass as the zinc vapor source even though four other intermetallics with higher zinc content are listed Table 1 . The likely reason $\mathrm{Zn}_{2} \mathrm{Zr}$ is the surface phase rather than a more zinc rich phase may be due to the activity of the zinc in the $\alpha$ brass being lower than the activity of pure zinc.

- Fe and $S n$ alloying elements in Zircaloy-4 substitute on the $Z n$ sublattice in the $\mathrm{ZnZr}_{2}$ and $\mathrm{ZnZr}$ phases: $(\mathrm{Zn}, \mathrm{Fe}, \mathrm{Sn}) \mathrm{Zr}_{2}$ and $(\mathrm{Zn}, \mathrm{Fe}, \mathrm{Sn}) \mathrm{Zr}$. Fe and $\mathrm{Sn}$ are insoluble in the $\mathrm{Zn}_{2} \mathrm{Zr}$ phase and the $\alpha-\mathrm{Zr}$.

- A two phase layer of $(\mathrm{Zn}, \mathrm{x}) \mathrm{Zr}_{2}+(\mathrm{Zn}, \mathrm{x}) \mathrm{Zr}$ is present in all of the Zircaloy-4 TREX samples in the temperature range of $650^{\circ} \mathrm{C}$ to $725^{\circ} \mathrm{C}$.

- The eutectoid temperature was found to be lower than the currently reported temperature of $750{ }^{\circ} \mathrm{C}$ in the literature. This research puts the eutectoid reaction temperature at approximately $718{ }^{\circ} \mathrm{C}\left( \pm 6{ }^{\circ} \mathrm{C}\right.$ absolute bounds error $)$ with a composition of 86.5 at. \% Zr.

- The solubility of zinc in nuclear grade $\alpha$-zirconium was measured from the composition line scan profiles at five different temperatures. The solubility of zinc increased with temperature from 0.76 at. $\% \mathrm{Zn}$ at $650^{\circ} \mathrm{C}$ to a maximum of 2.36 at. $\% \mathrm{Zn}$ at $725^{\circ} \mathrm{C}$ and decreased with further increases in temperature up to $800^{\circ} \mathrm{C}$.

- The growth constant $K$ for total zinc penetration in both Zircaloy-4 and nuclear grade zirconium samples at $650{ }^{\circ} \mathrm{C}, 700^{\circ} \mathrm{C}$, and $725^{\circ} \mathrm{C}$ for various times confirmed parabolic growth. The activation energy, Q, for Zircaloy-4 below $725{ }^{\circ} \mathrm{C}$ was measured as $128.56 \mathrm{~kJ} / \mathrm{mole}$, and the activation energy of nuclear grade zirconium below $725^{\circ} \mathrm{C}$ was measured as $126.65 \mathrm{~kJ} / \mathrm{mole}$. The close agreement in activation energy between the nuclear grade zirconium and Zircaloy-4 would be expected since Zircaloy-4 is a dilute zirconium alloy. However, for nuclear grade zirconium at $725^{\circ} \mathrm{C}$ and above, containing the $\beta$ phase, the activation energy for the total zinc penetration is $554.69 \mathrm{~kJ} / \mathrm{mole}$.

- The intermetallic $\mathrm{ZnZr}_{2}$ phase was observed between the temperatures of $712{ }^{\circ} \mathrm{C}$ and $725^{\circ} \mathrm{C}$. A peritectoid reaction of $\beta+\mathrm{ZnZr} \rightarrow \mathrm{ZnZr}_{2}$ and a eutectoid reaction of $\mathrm{ZnZr}_{2} \rightarrow \mathrm{ZnZr}+\alpha-\mathrm{Zr}$ lie somewhere between $712^{\circ} \mathrm{C}$ and $725^{\circ} \mathrm{C}$.

- Extrapolating from $650^{\circ} \mathrm{C}$ to the lower temperature of $350^{\circ} \mathrm{C}$, using the experimentally measured activation energy of $128.56 \mathrm{~kJ} / \mathrm{mole}$ and the growth constant coefficient $K_{0}$ equal to $3.741 \times 10^{-6}$ for Zircaloy-4, calculations predict there would not be any significant diffusion reaction in 2000 years. However, experimental results from a Zircaloy-4 TREX sample heat treated with pure zinc at $350{ }^{\circ} \mathrm{C}$ for 6 months indicate that a significant reaction does occur. 


\section{FUTURE DIRECTION OF THIS WORK}

Extrapolating from $650{ }^{\circ} \mathrm{C}$ to the lower temperature of $350{ }^{\circ} \mathrm{C}$, using the experimentally measured activation energy of $128.56 \mathrm{~kJ} / \mathrm{mole}$ and the growth constant coefficient $K_{0}$ equal to $3.741 \times 10^{-6}$ for Zircaloy-4, calculations predict there would not be any significant diffusion reaction in 2000 years. An experiment was performed to check the validity of the extrapolation with a Zircaloy-4 TREX sample heat treated with pure zinc at $350{ }^{\circ} \mathrm{C}$ for 6 months and a significant reaction does occur. This finding implies another mechanism, possibly grain boundary diffusion, may be dominate at the lower temperatures. The results of this high temperature work and the single low temperature experiment has prompted the NRC to request an additional investigation into the reactions caused by zinc vapor.

Further experiments with pure zinc at temperatures $400{ }^{\circ} \mathrm{C}$ and below will be performed with Zircaloy-4 tubing that has been oxidized, Zircaloy-4 tubing with a reduced wall thickness, Zircaloy-4 TREX as-received, and nuclear grade zirconium as-received. The pre-oxidized tubing, with approximately $100 \mu \mathrm{m}$ zirconium oxide layer, simulates the end of life oxidation typically observed on cladding after 5 years service in a reactor core. The tubing with a wall thickness reduced to $1 / 2$ the original wall thickness will be used as mechanical test specimens to investigate the possible grain boundary migration of zinc. The Zircaloy-4 TREX as-received and the nuclear grade zirconium as-received samples will be exposed to zinc vapor to study the phase growth at low temperatures. 
APPENDIX 


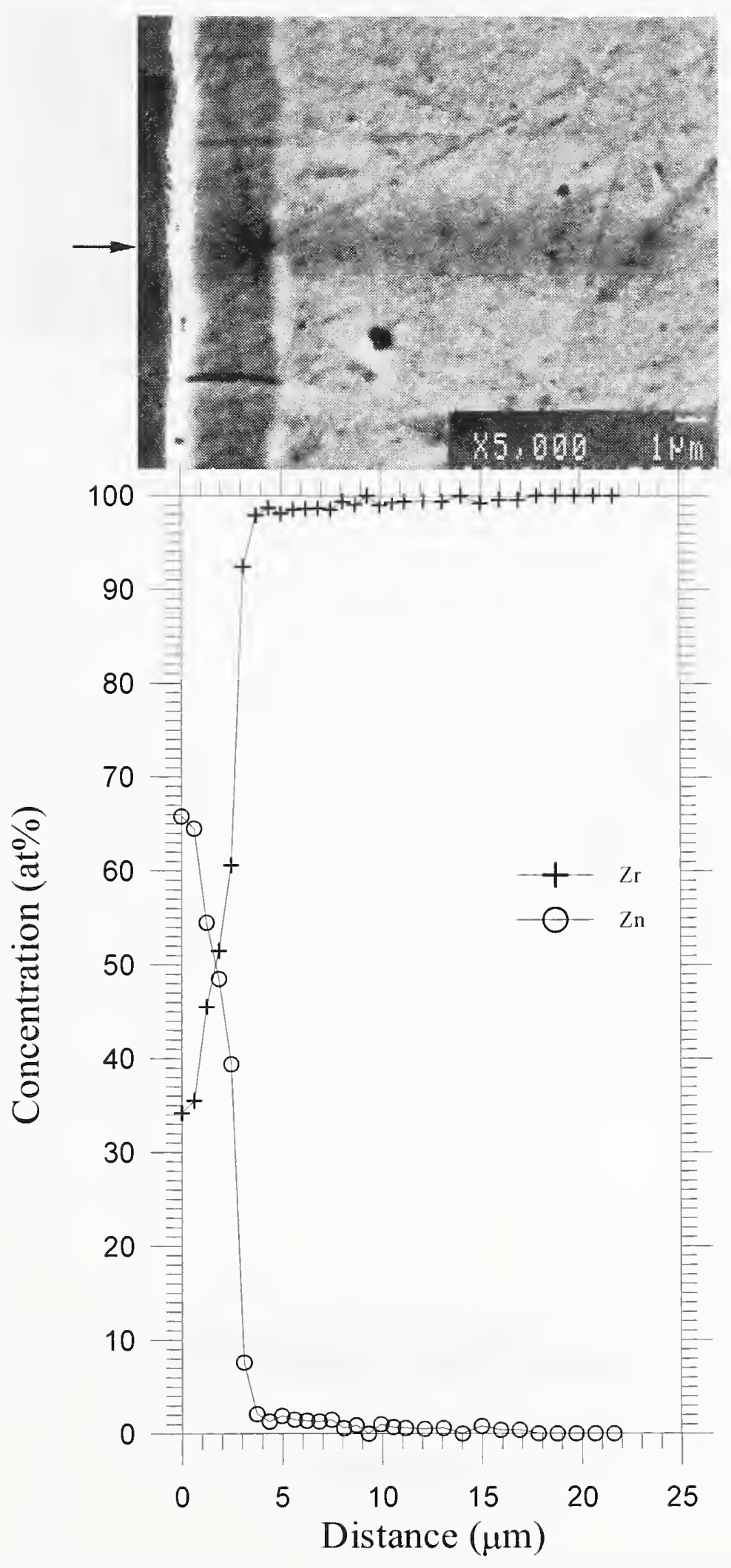

Figure A1. Nuclear grade zirconium heat treated with zinc vapor at $650{ }^{\circ} \mathrm{C}$ for $16 \mathrm{~d}$, water quenched. 


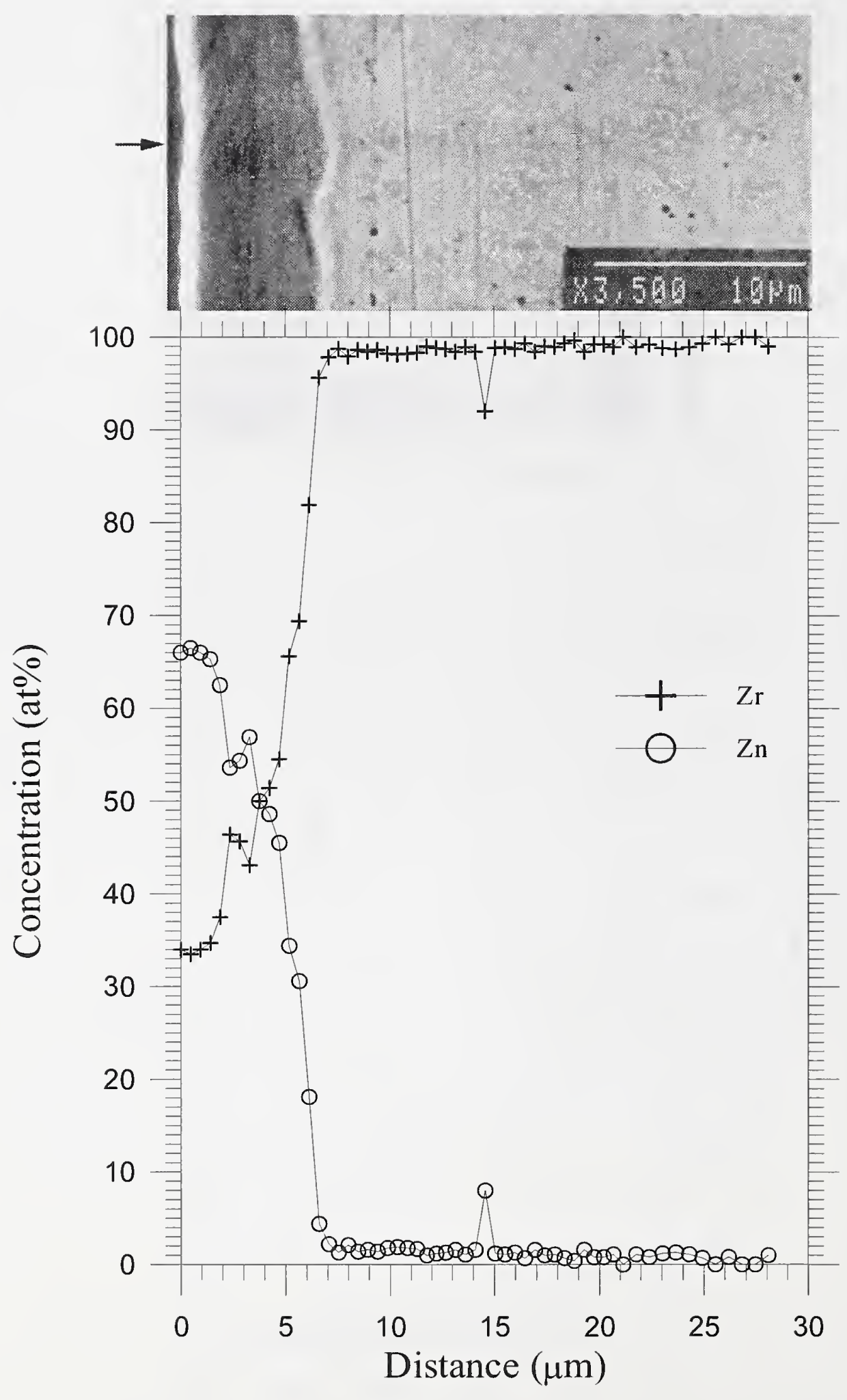

Figure A2. Nuclear grade zirconium heat treated with zinc vapor at $650{ }^{\circ} \mathrm{C}$ for $64 \mathrm{~d}$, water quenched. 


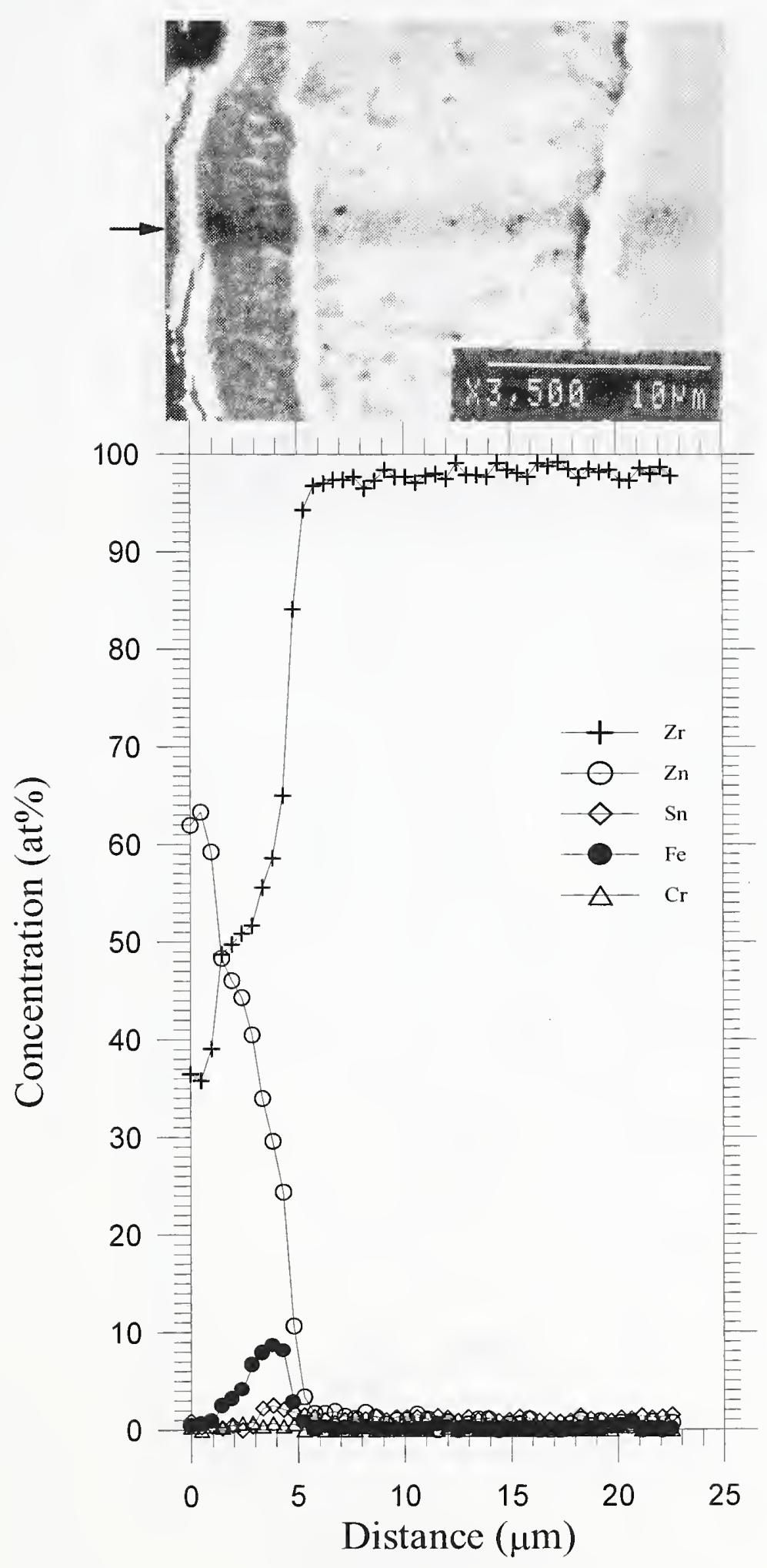

Figure A3. Zircaloy-4 TREX heat treated with zinc vapor at $650{ }^{\circ} \mathrm{C}$ for $16 \mathrm{~d}$, water quenched. 


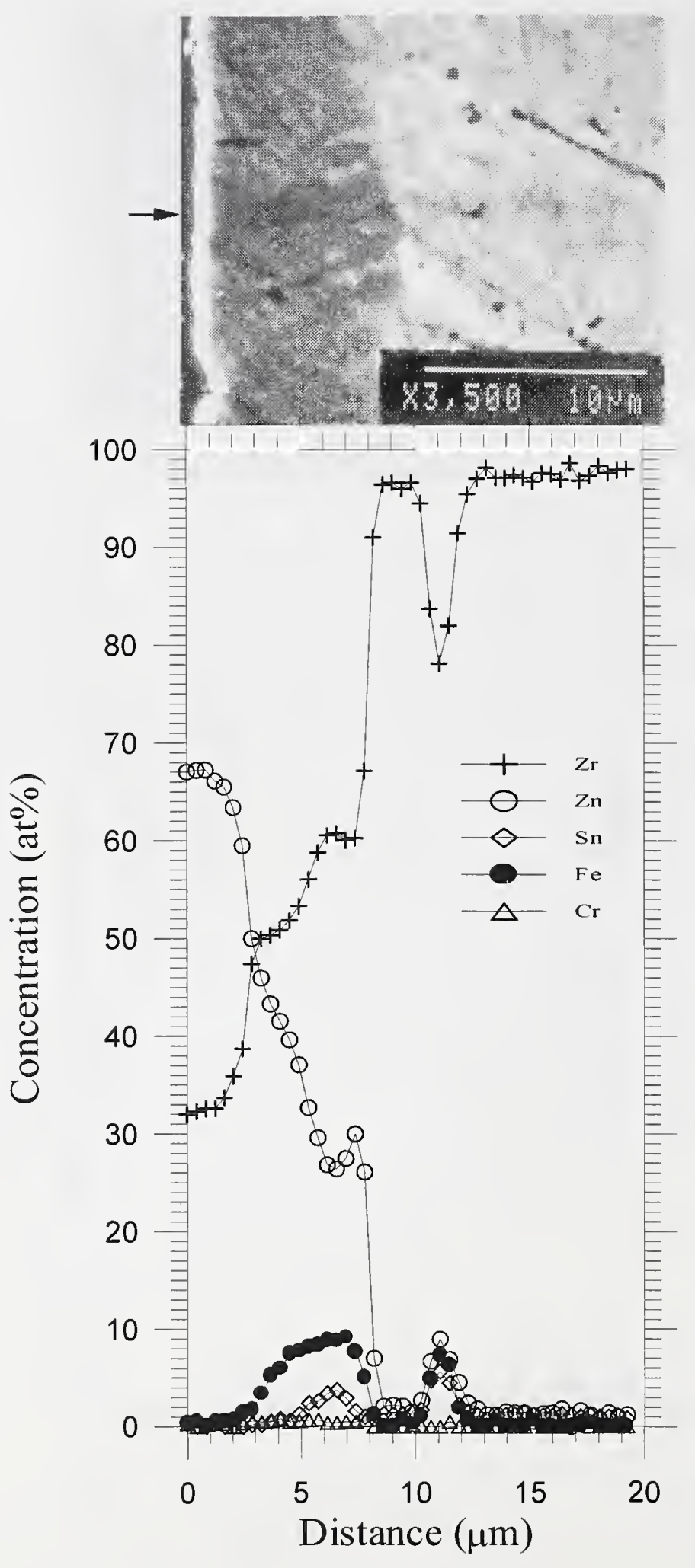

Figure A4. Zircaloy-4 TREX heat treated with zinc vapor at $650^{\circ} \mathrm{C}$ for $64 \mathrm{~d}$, water quenched. 


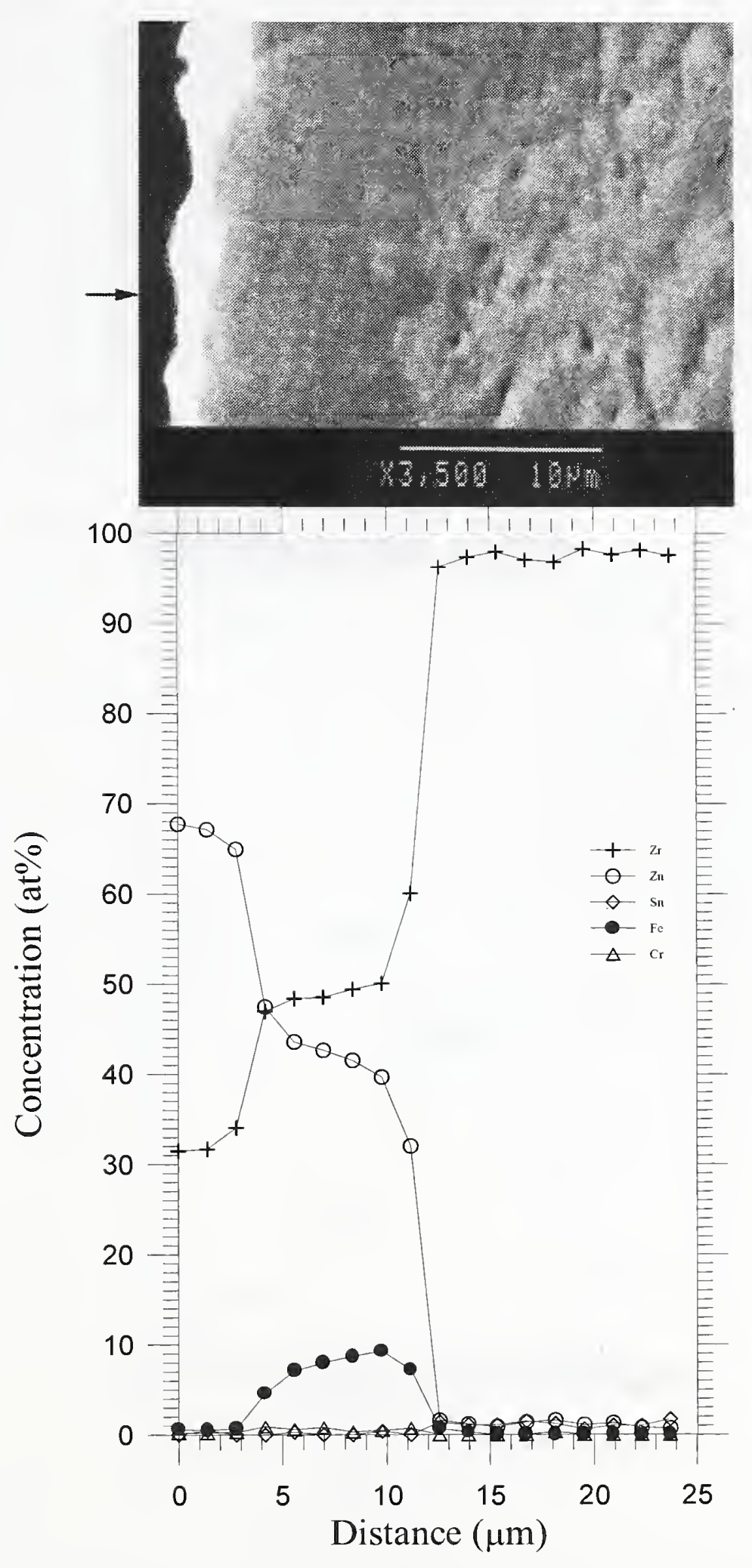

Figure A5. Zircaloy-4 TREX heat treated with zinc vapor at $650{ }^{\circ} \mathrm{C}$ for $126 \mathrm{~d}$, water quenched. 


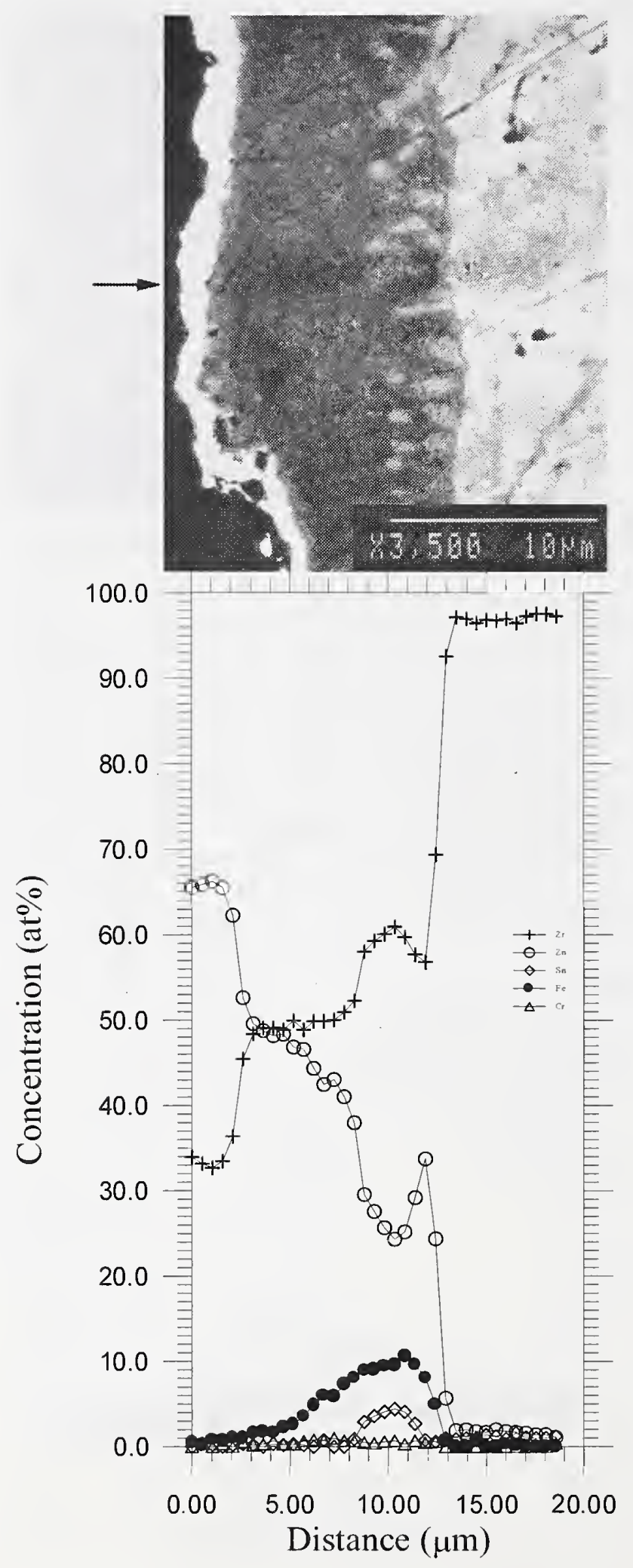

Figure A6. Zircaloy-4 TREX heat treated with zinc vapor at $650^{\circ} \mathrm{C}$ for $126 \mathrm{~d}$, water quenched. 


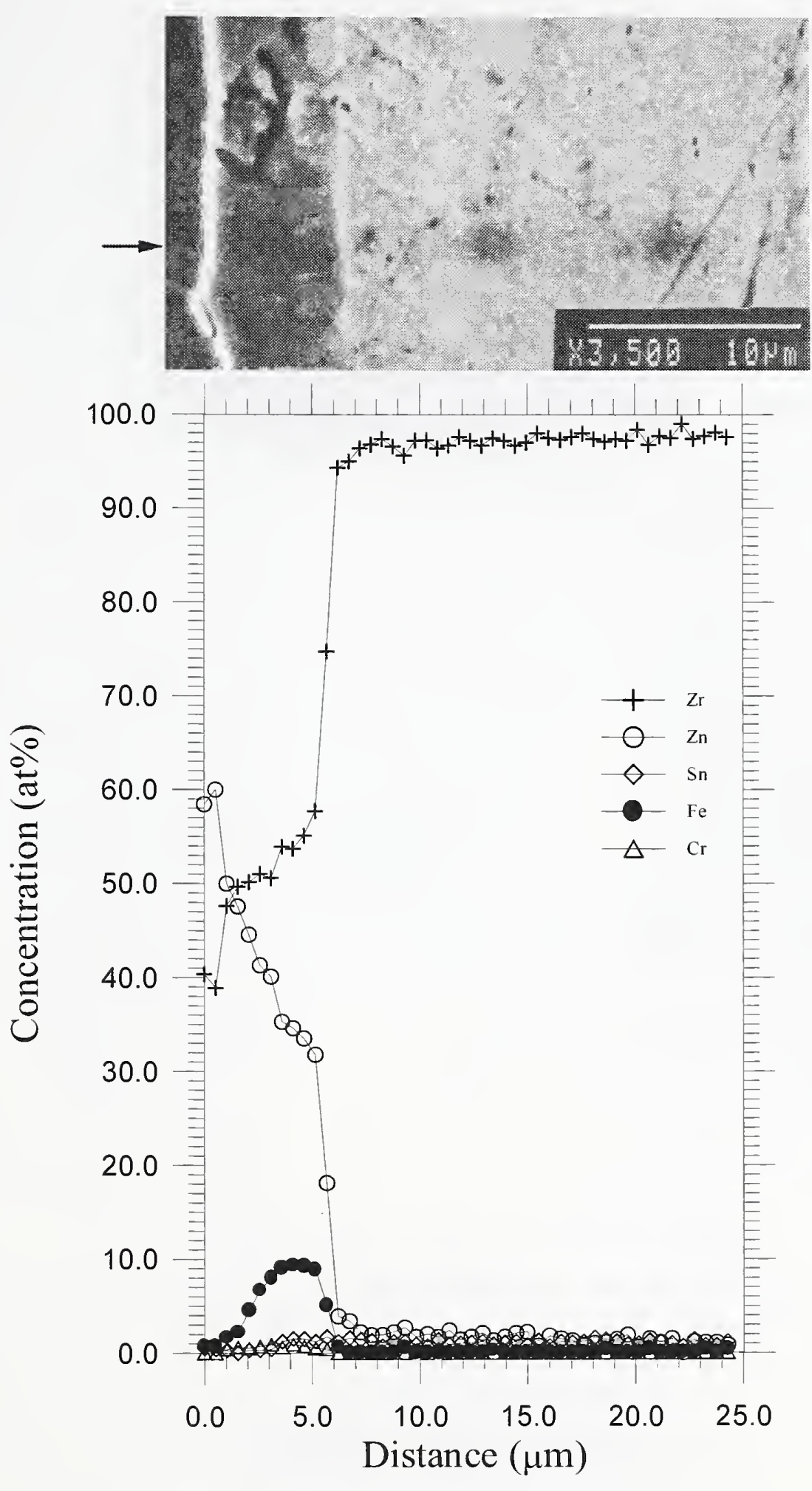

Figure A7. Zircaloy-4 TREX heat treated with zinc vapor at $670{ }^{\circ} \mathrm{C}$ for $20.75 \mathrm{~d}$, water quenched. 


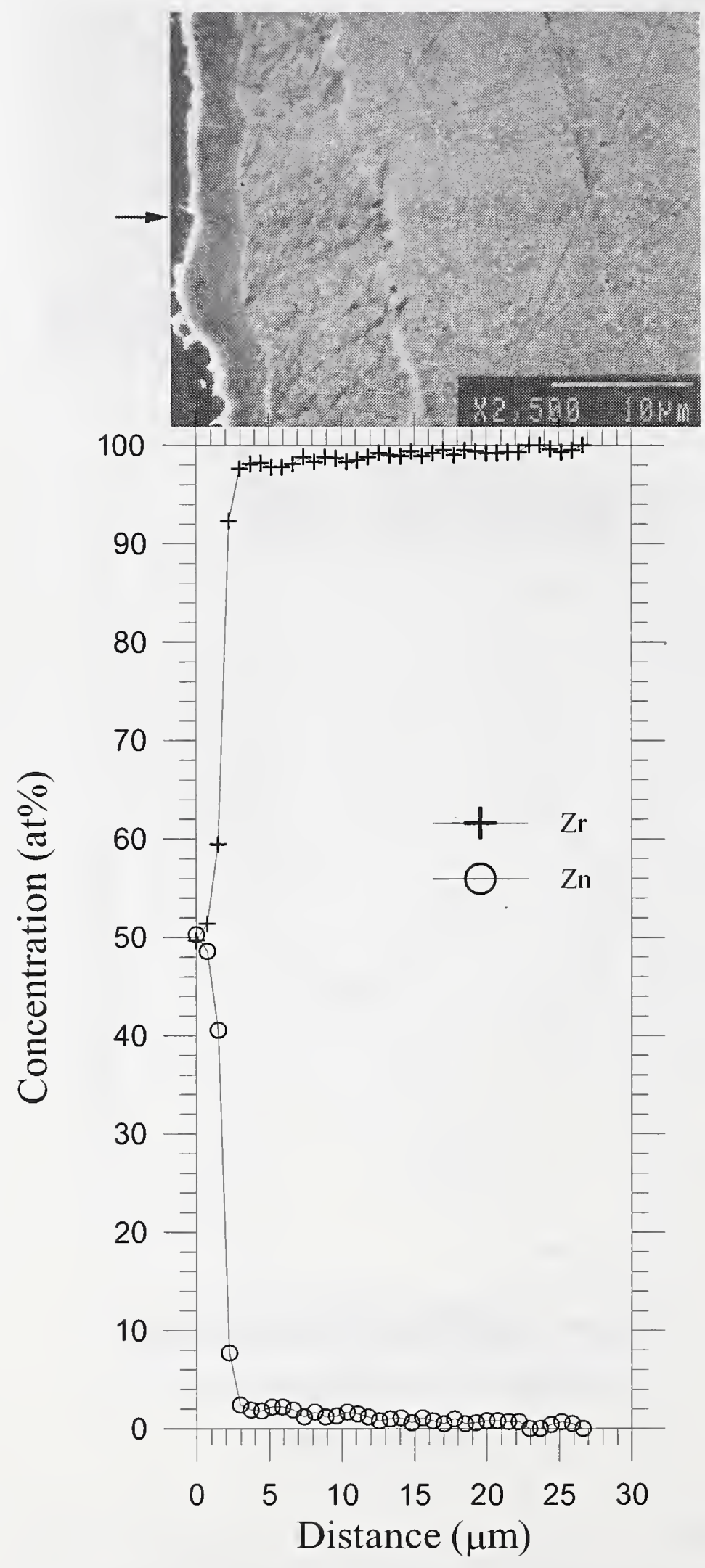

Figure A8. Nuclear grade zirconium heat treated with zinc vapor at $700{ }^{\circ} \mathrm{C}$ for $12 \mathrm{~d}$, water quenched. 


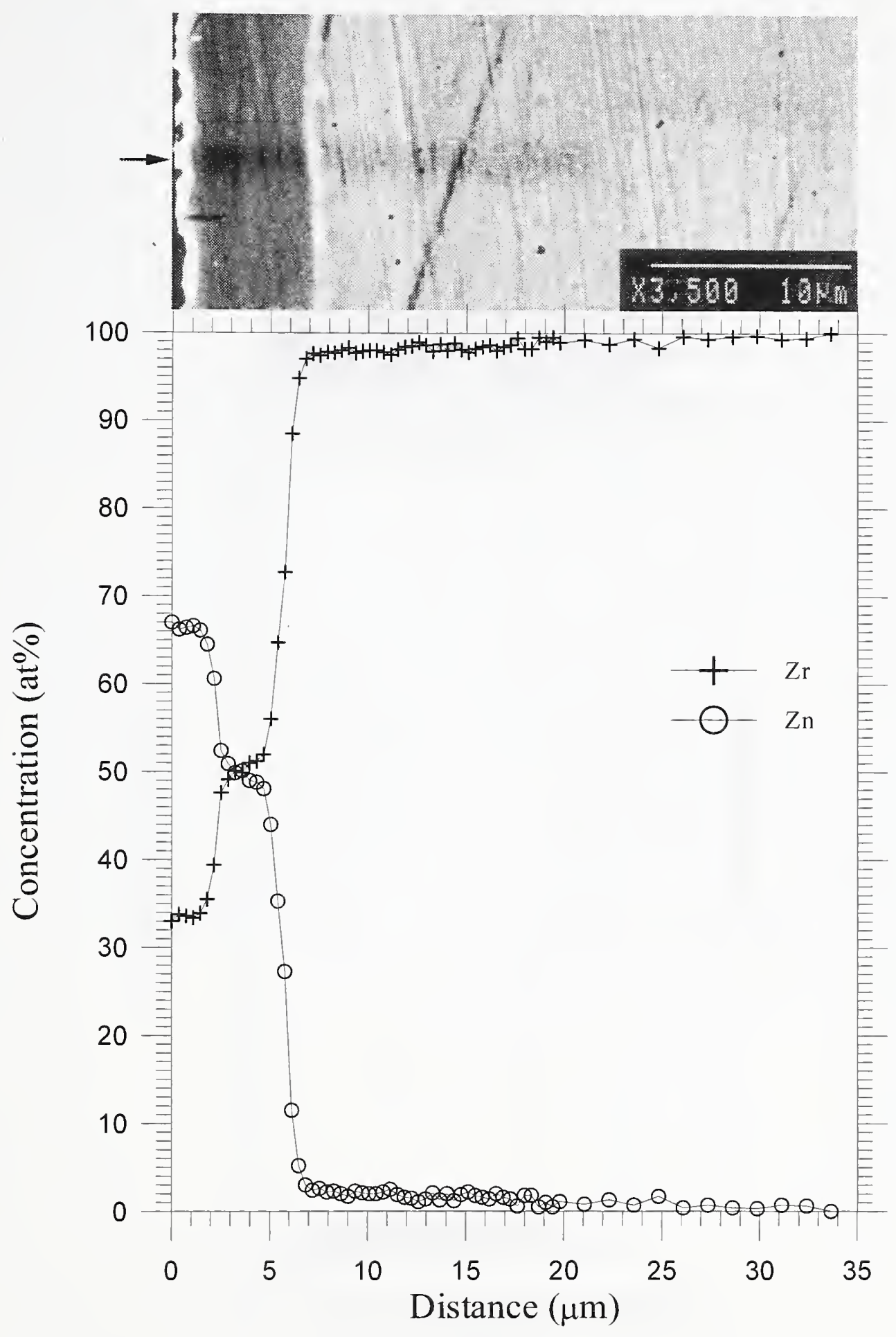

Figure A9. Nuclear grade zirconium heat treated with zinc vapor at $700^{\circ} \mathrm{C}$ for $32 \mathrm{~d}$, water quenched. 


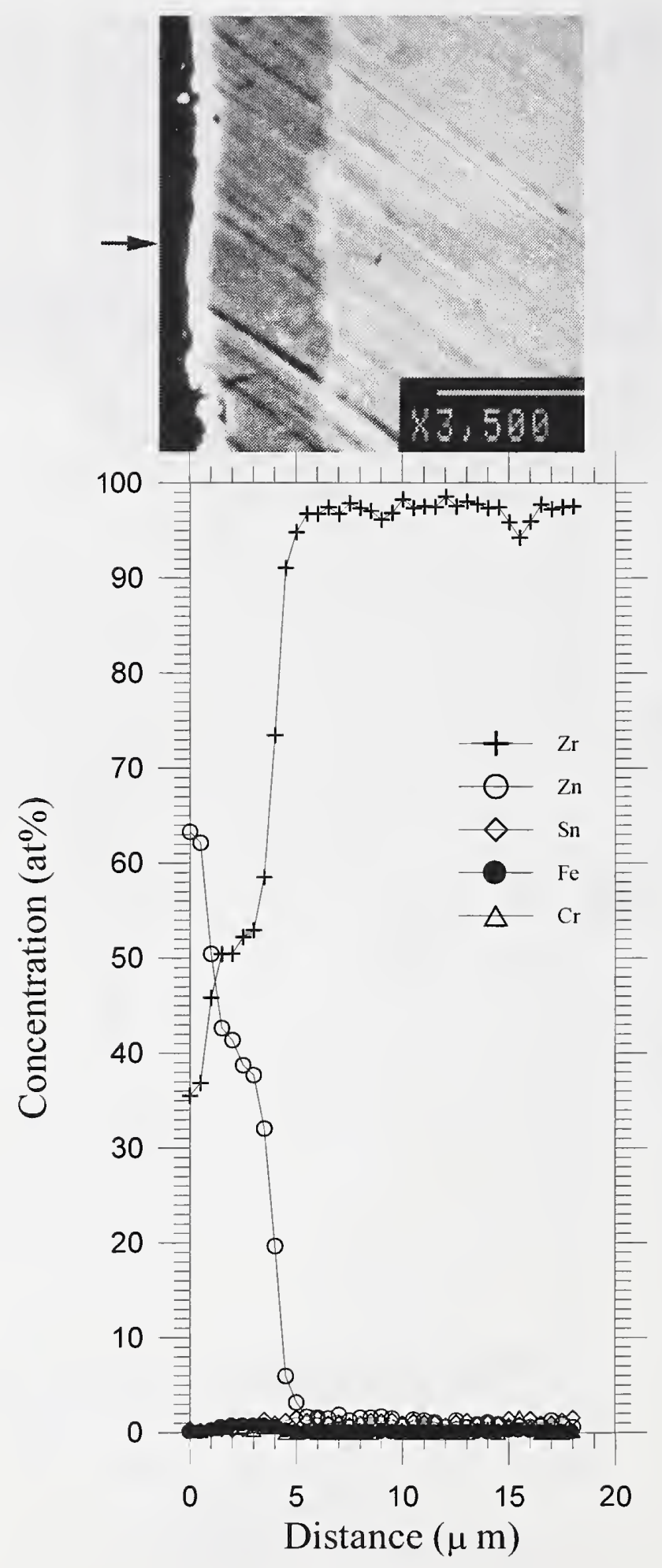

Figure A10. Zircaloy-4 TREX heat treated with zinc vapor at $700{ }^{\circ} \mathrm{C}$ for $4 \mathrm{~d}$, water quenched. 


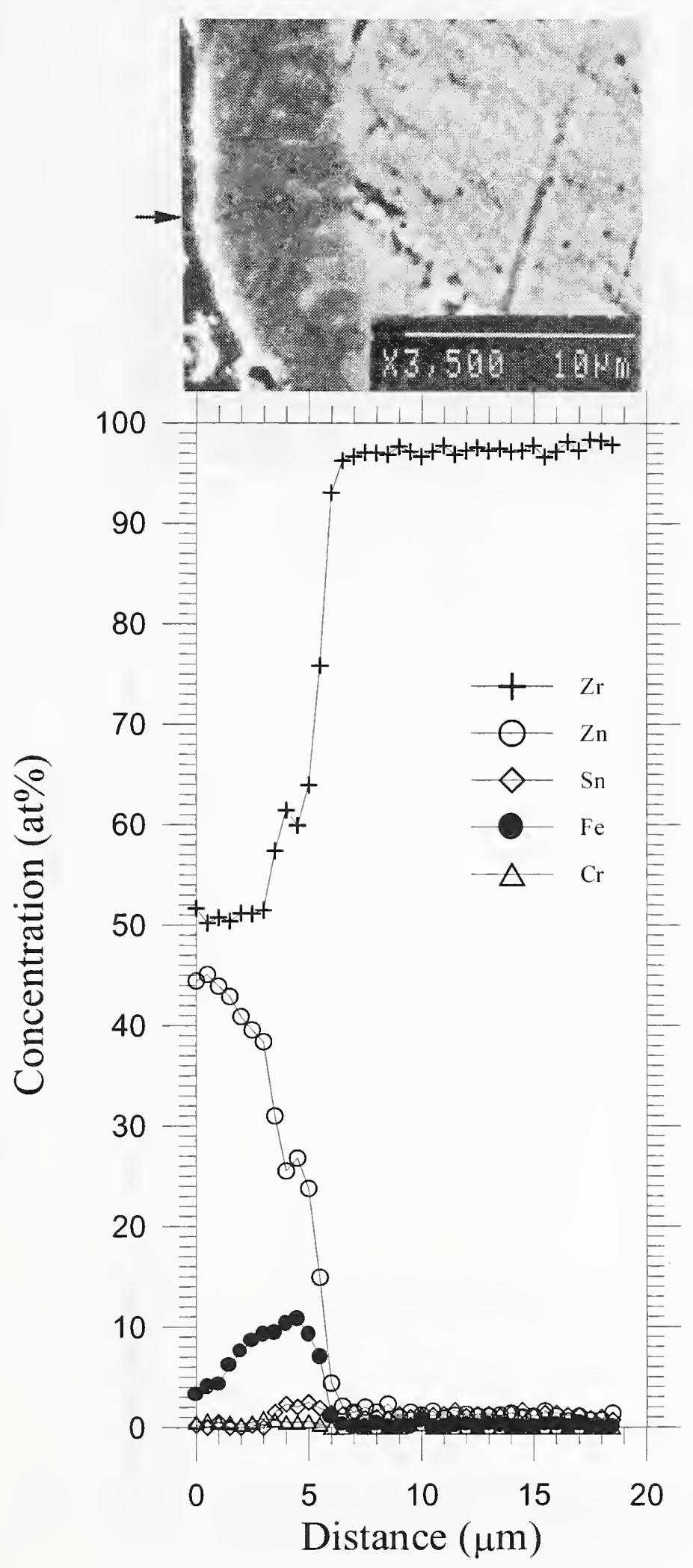

Figure A11. Zircaloy-4 TREX heat treated with zinc vapor at $700{ }^{\circ} \mathrm{C}$ for $10 \mathrm{~d}$, water quenched. 


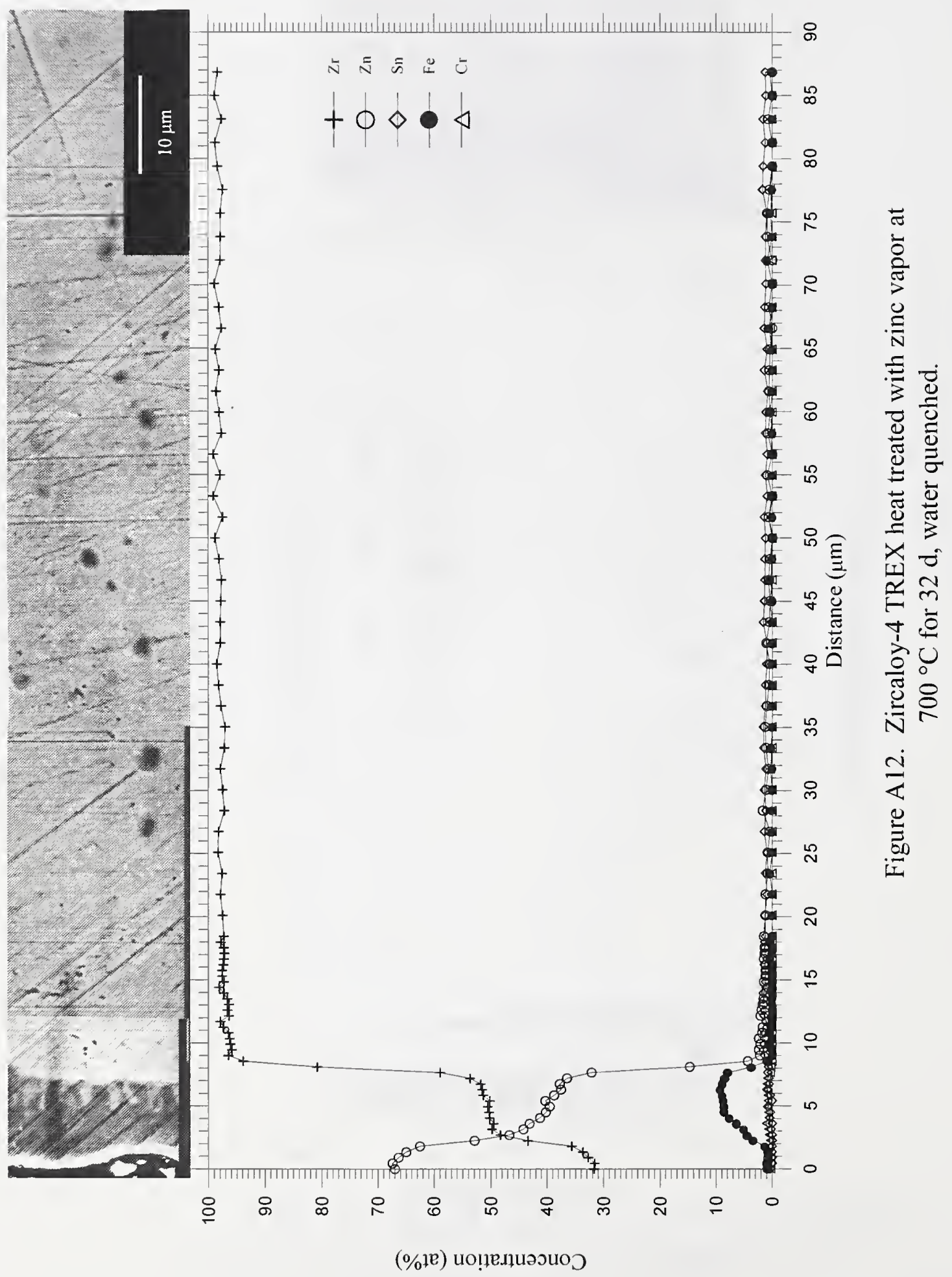




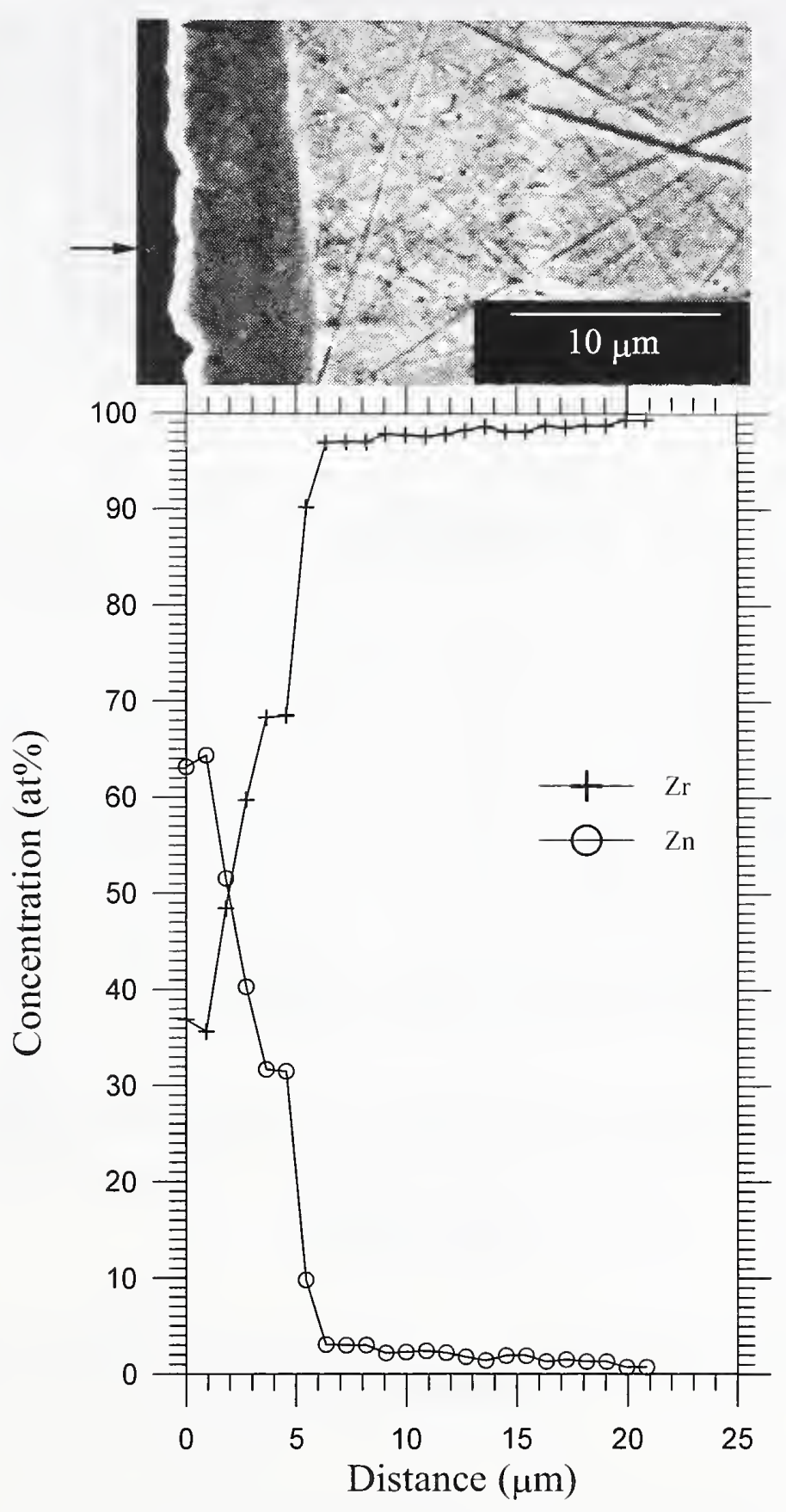

Figure A13. Nuclear grade zirconium heat treated with zinc vapor at $712{ }^{\circ} \mathrm{C}$ for 11.8 days, water quenched. 


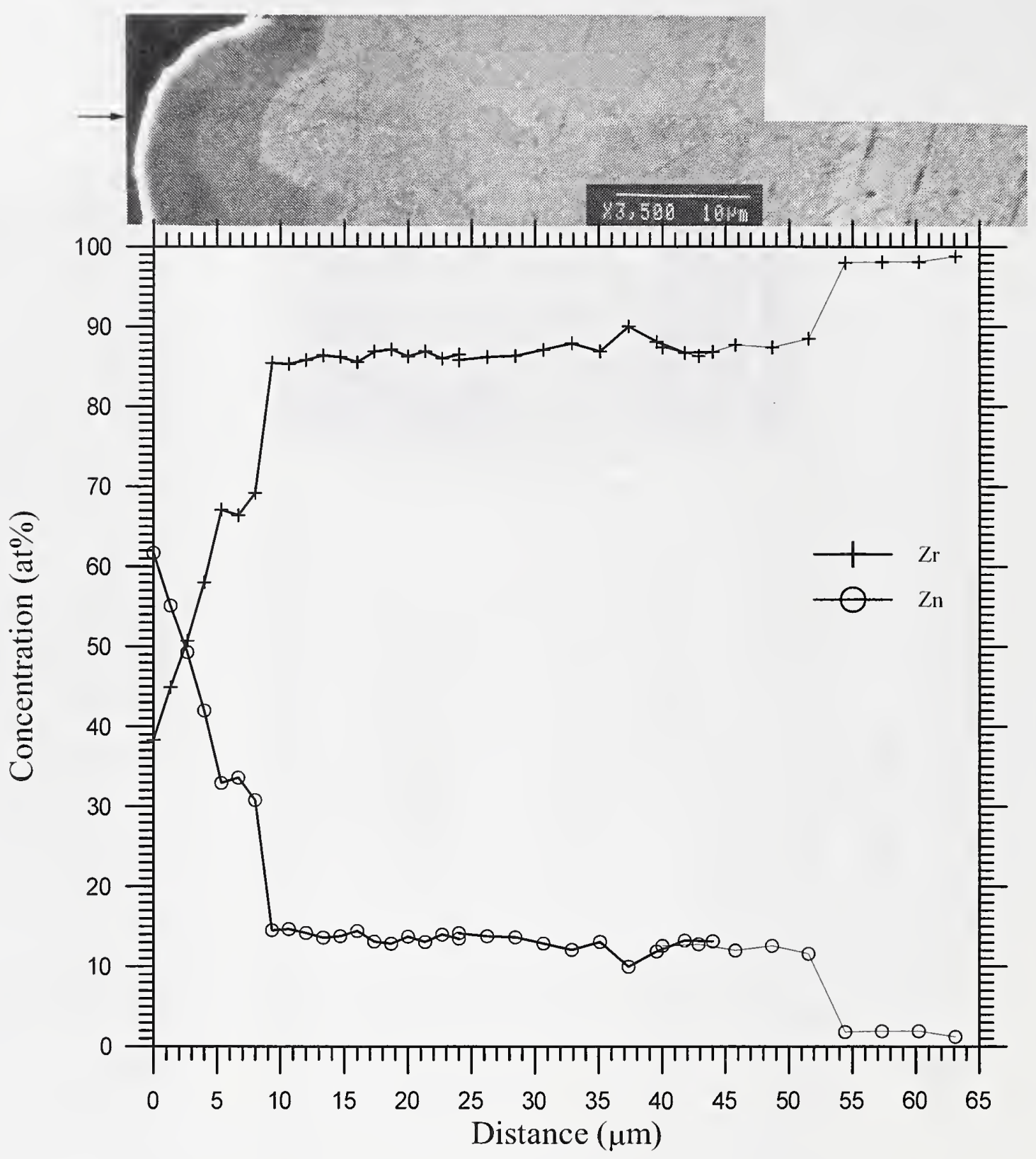

Figure A14. Nuclear grade zirconium heat treated with zinc vapor at $725^{\circ} \mathrm{C}$ for $11.8 \mathrm{~d}$, water quenched. 


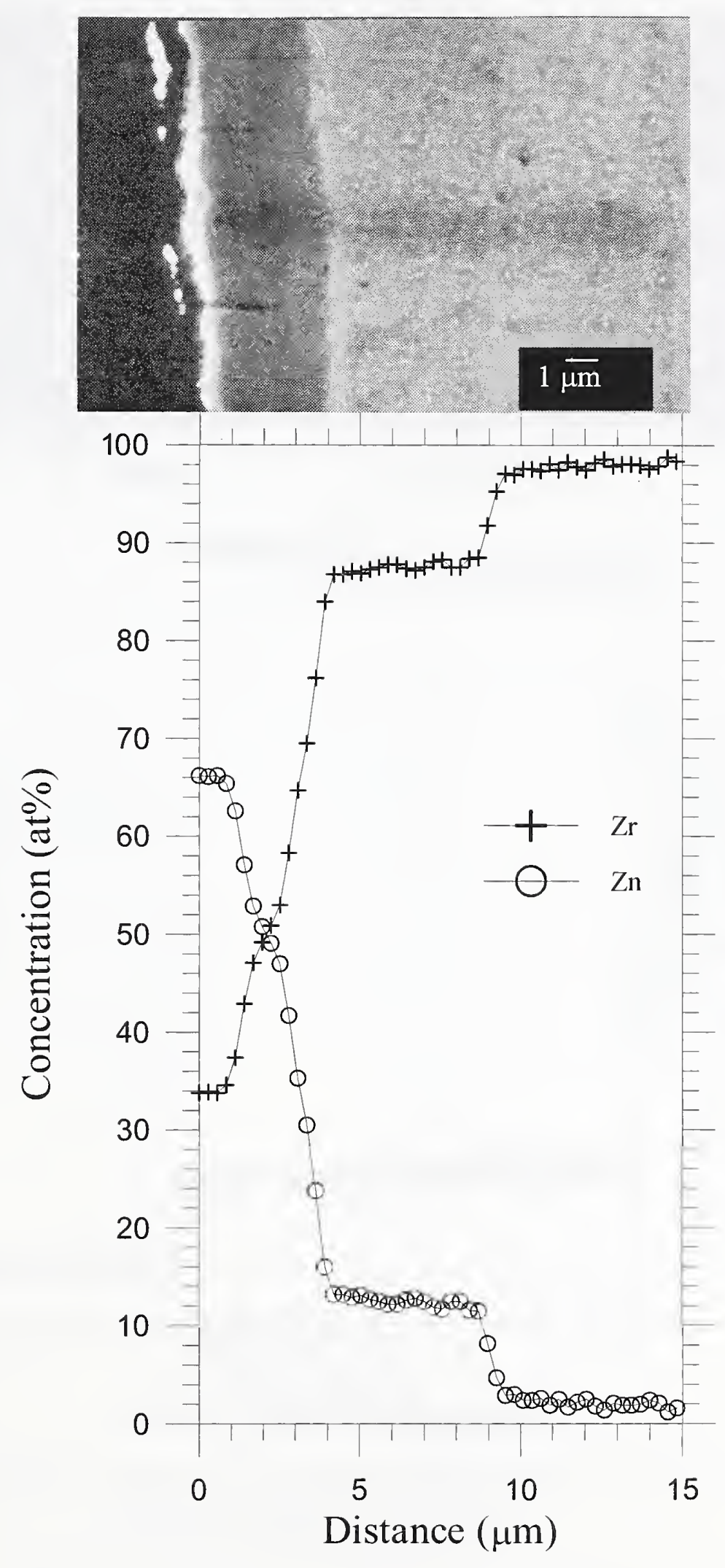

Figure A15. Nuclear grade zirconium heat treated with zinc vapor at $725^{\circ} \mathrm{C}$ for $12 \mathrm{~d}$, water quenched. 




Figure A16. Nuclear grade zirconium heat treated with zinc vapor at $725^{\circ} \mathrm{C}$ for $64 \mathrm{~d}$, water quenched. 


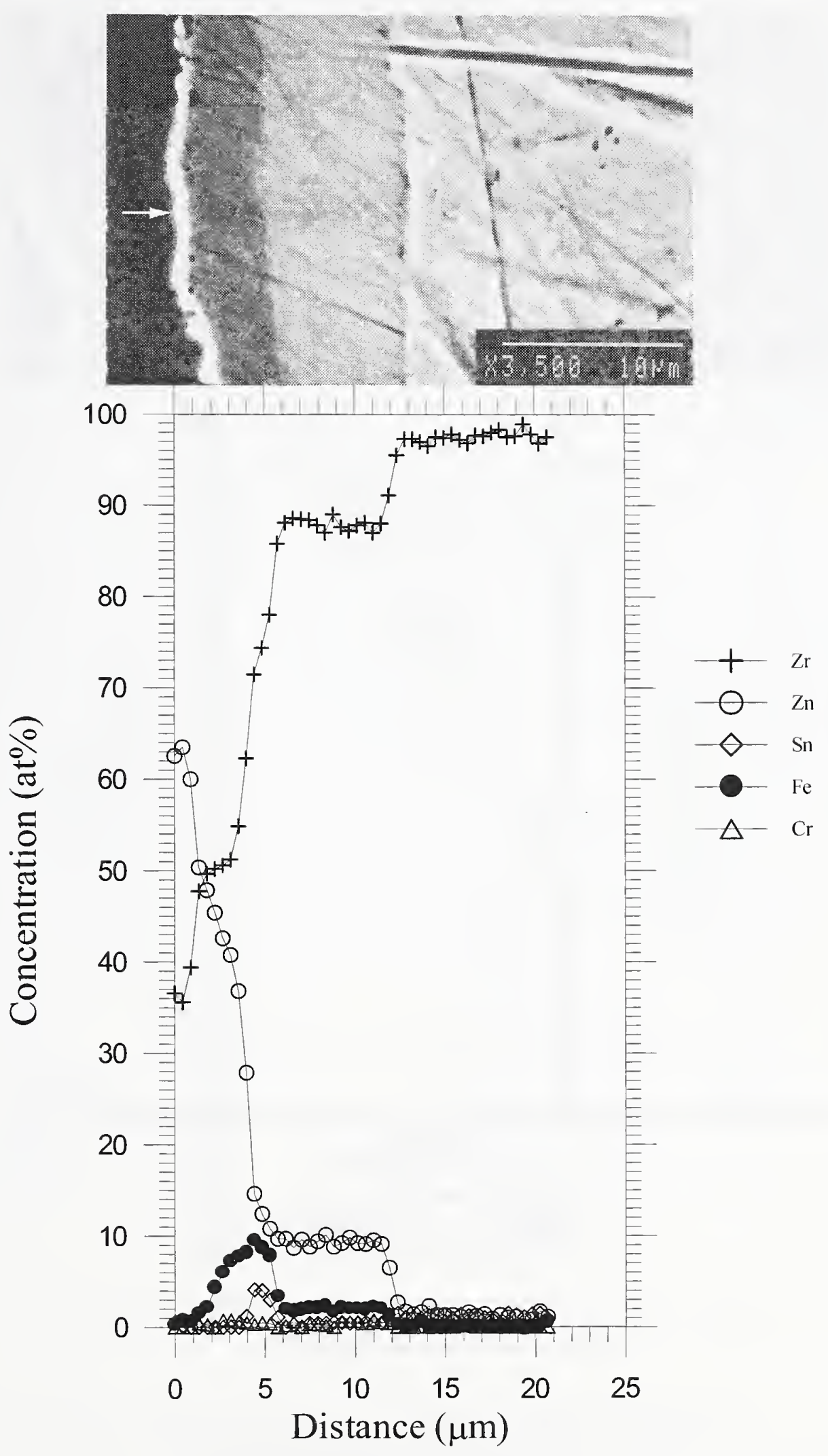

Figure A17. Zircaloy-4 TREX heat treated with zinc vapor at $725^{\circ} \mathrm{C}$ for $2 \mathrm{~d}$, water quenched. 


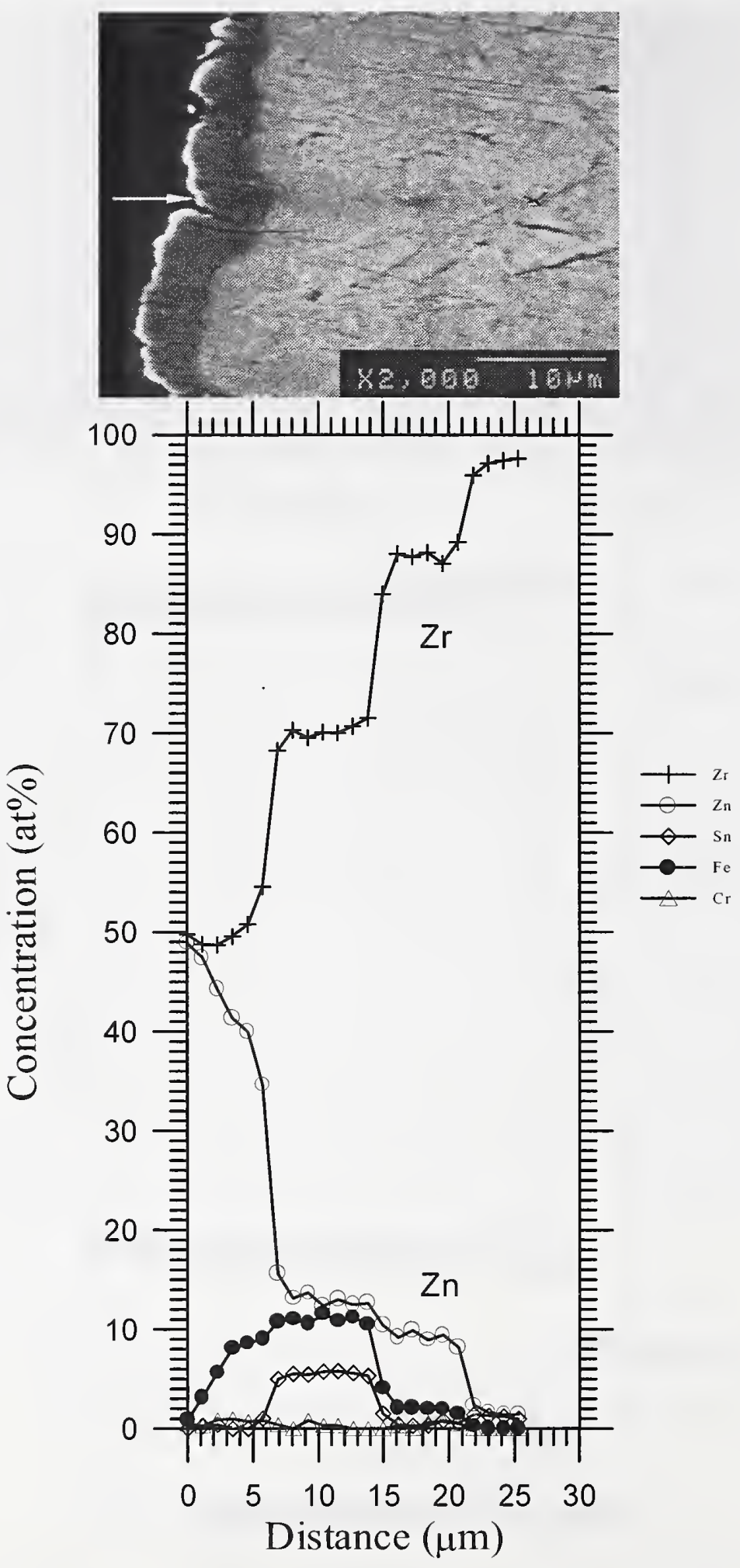

Figure A18. Zircaloy-4 TREX heat treated with zinc vapor at $725^{\circ} \mathrm{C}$ for $11.8 \mathrm{~d}$, water quenched. 


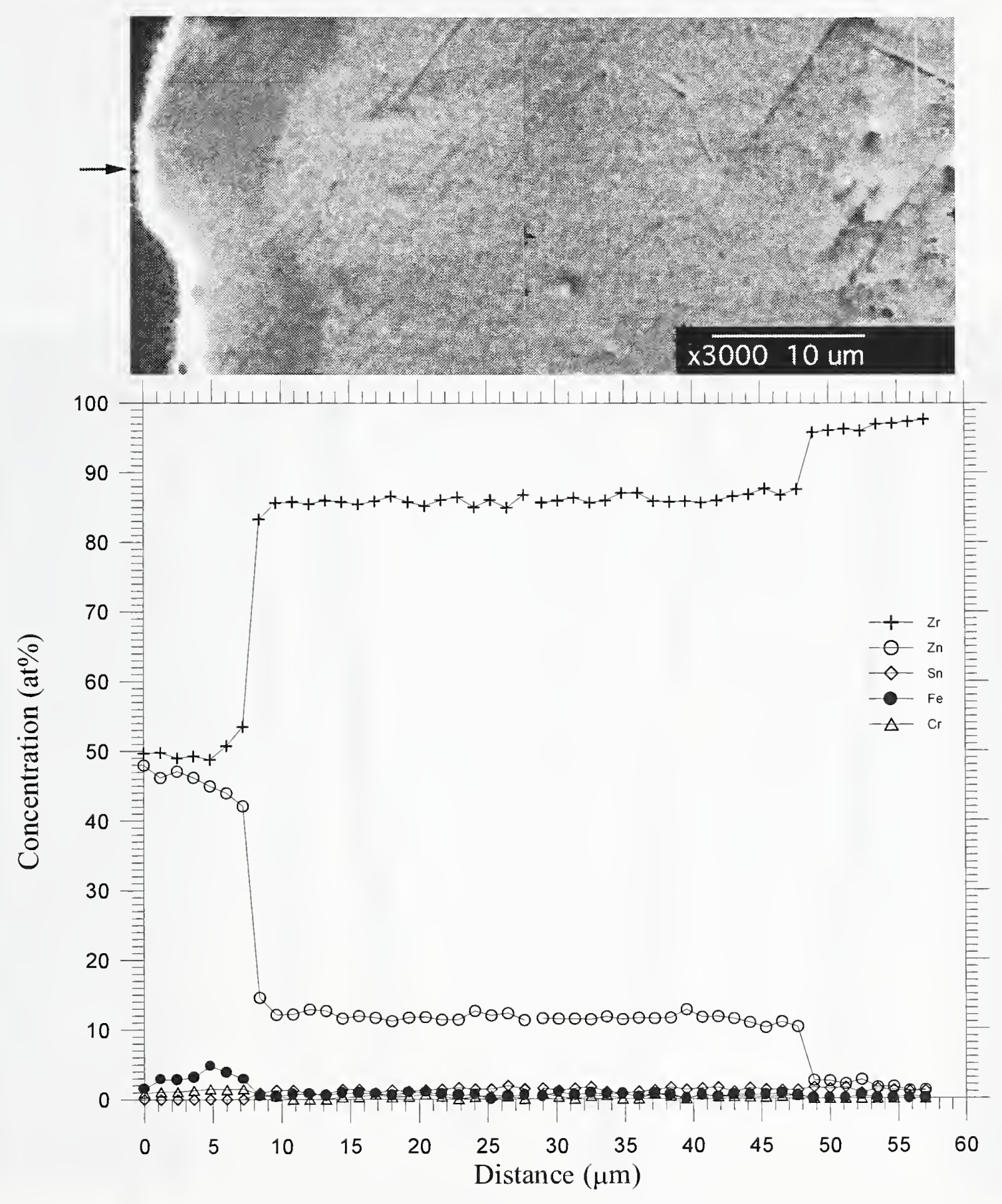

Figure A19. Zircaloy-4 tubing heat treated with zinc vapor at $725^{\circ} \mathrm{C}$ for $39 \mathrm{~d}$, water quenched. 


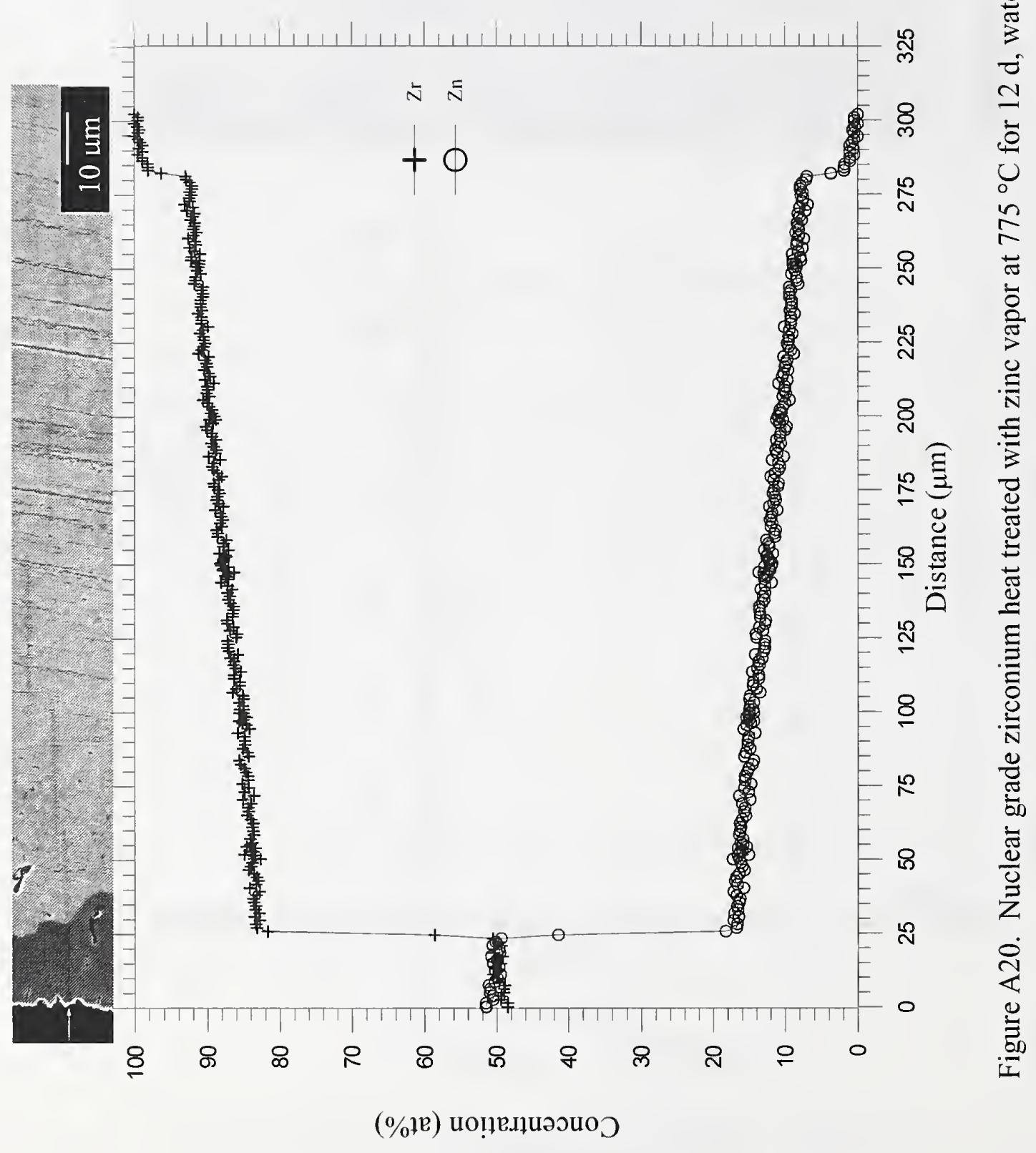




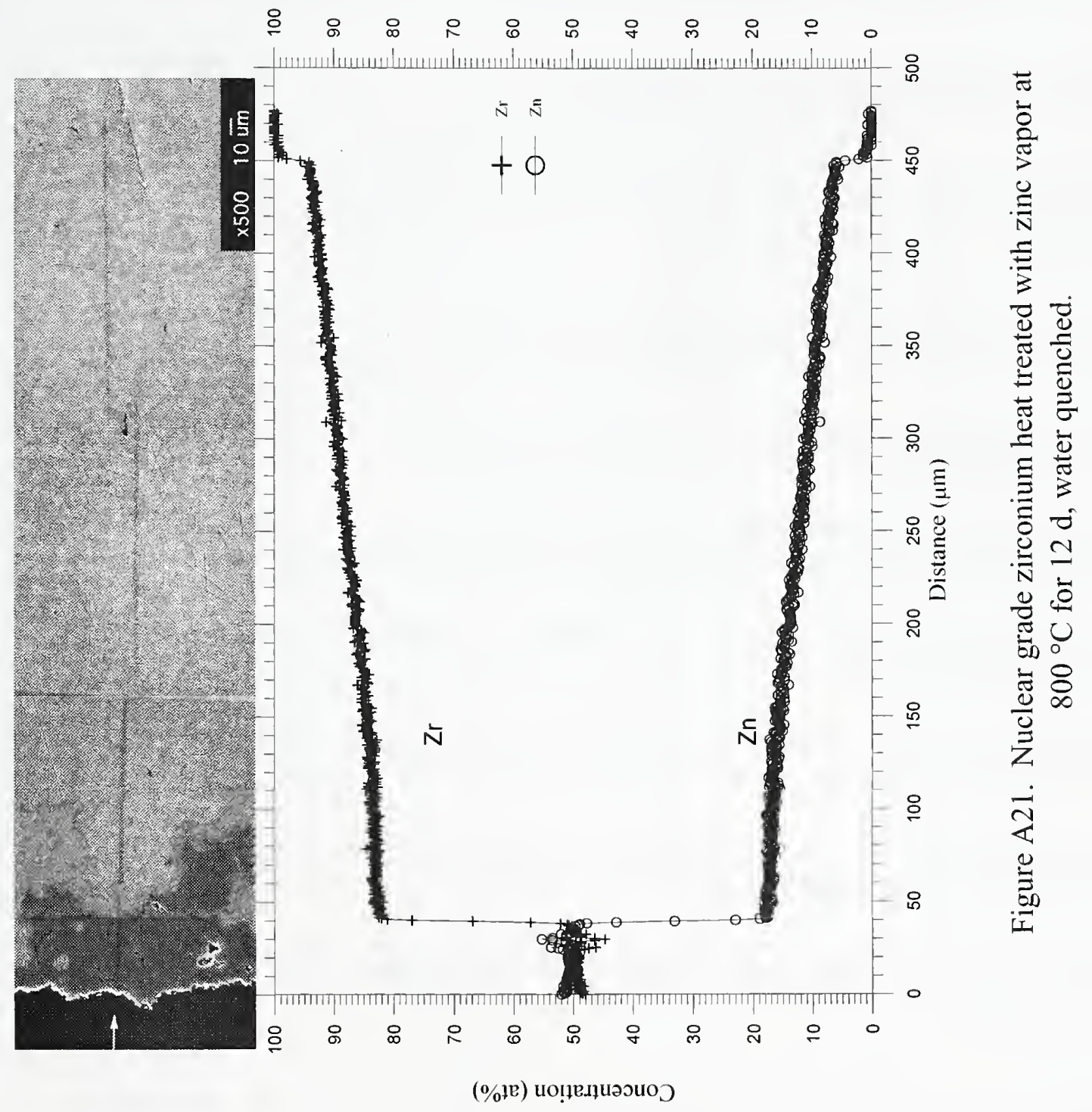




\section{REFERENCES}

1. Viability Assessment of a repository at Yucca Mountain, Yucca Mountain Project website http://www.ymp.gov/timeline/ops.htm, , 2/8/1999, p4.

2. NUREG-1536: Standard Review Plan for Dry Cask Storage Systems

Section 4 - Thermal Evaluation, Nuclear Regulatory Commission website http://www.nrc.gov/NRC/NUREGS/SR1536/part08.html, , 2/9/99, p 3,4.

3. Onsite Storage of Spent Nuclear Fuel, Nuclear Regulatory Commission website, http://www.nrc.gov/OPA/drycask// , , 2/1999, p2.

4. Nonferrous Metal Products Section 2, ASTM Standard B350/B350M - 96, Standard Specification for Zirconium and Zirconium Alloy Ingots for Nuclear Applications, Annual Books of ASTM Standards, 1999

5. NRC bulletin 96-04, Chemical, Galvanic, or other Reactions in Spent Fuel Storage and Transportation Casks, July 1996, p 4.

6. Binary Alloy Phase Diagrams, ASM International, Materials Park, Ohio, Vol.3, 1990, p 3539,3541,3542.

7. Villars, P. and L.D. Calvert, Pearson's Crystallographic Data for Intermetallic Phases, ASM International, Materials Park, Ohio, vol. 3, $3^{\text {rd }}$ ed., 1989, p3256

8. Rossteutscher, W. and K. Schubert, Z. Metallkd, On Several T-Zn and T-Cd Alooy Systems, 56, 1965, p730-734.

9. The Metallurgy of Zirconium, McGraw-Hill, edited by Lustman, Benjamin and Frank Kerze, Jr ,1955, p 5-14.

10. Specific Metals and Alloys Section, Metals Handbook, Ed. Lois A. Abel et al., vol. $2,10^{\text {th }}$ ed., ASM International,1990, p667.

11. Thom, J.R.S., W.M. Walker, T.A. Fallon and G.F.S. Reising, Boiling in Subcooled Water During Flow-up-Heated Tubes or Annuli, Proc. Instn. Mech. Engrs., 180, Pt. C, 1965-66, p226-246.

12. Askeland, D.R., The Science and Engineering of Materials, PWS-Kent Publishing Co, 1984, p95,96,189.

13. Robert E. Reed-Hill and Reza Abbaschian, Physical Metallurgy Principles, PWS Publishing Co Boston, 3 ed , 1994 , p376-377.

14. F.J.J. van Loo, Multiphase Diffusion in Binary and Ternary Solid-State Systems, Great Britain, Prog. Solid St. Chem., Vol.20, 1990 ,pp. 47-99. 
15. Porter, D.A., and K.E. Easterling, Phase Transformations in Metals and Alloys, London: Chapman and Hall, $2^{\text {nd }}$ ed., 1995, p40.

16. Ursula Kattner thermodynamic assessment of zinc in $\alpha$-brass based on $M$.

Kowalski and P.J. Spencer. J Phase Equilibria, 14, 1993, p432-438.

17. Westinghouse Publication, High Quality Zircaloy Tubing for Nuclear Applications, 1984

18. Naylor, T.D. and J.H. Schemel, Zircaloy Cladding Fabrication, Sandvik Special Metals Corporation, American Nuclear Society, June 20, 1978 , p4.

19. Handbook of Chemistry and Physics, Vapor Pressure Variation with Temperature, CRC Press, $65^{\text {th }}$ ed., 1985 , p D-215.

20. Metals Test Methods and Analytical Procedures Section 3, ASTM Standard Test Method E1 12 - 96, Standard Test Methods for Determining Average Grain Size, Annual Books of ASTM Standards, 1999

21. VanderVoort, G.F., Metallography :Principles and Practice, Mc Graw-Hill, 1984 p701. 


